San Jose State University

SJSU ScholarWorks

Master's Theses

Master's Theses and Graduate Research

1994

\title{
Comparison of the effect of oxygen addition methods on the biological degradation rate of diesel fuel contaminated soil in slurry-phase reactors
}

David Adam Cacciatore

San Jose State University

Follow this and additional works at: https://scholarworks.sjsu.edu/etd_theses

\section{Recommended Citation}

Cacciatore, David Adam, "Comparison of the effect of oxygen addition methods on the biological degradation rate of diesel fuel contaminated soil in slurry-phase reactors" (1994). Master's Theses. 897. DOI: https://doi.org/10.31979/etd.5425-gnwq

https://scholarworks.sjsu.edu/etd_theses/897

This Thesis is brought to you for free and open access by the Master's Theses and Graduate Research at SJSU ScholarWorks. It has been accepted for inclusion in Master's Theses by an authorized administrator of SJSU ScholarWorks. For more information, please contact scholarworks@sjsu.edu. 


\section{INFORMATION TO USERS}

This manuscript has been reproduced from the microfilm master. UMI films the text directly from the original or copy submitted. Thus, some thesis and dissertation copies are in typewriter face, while others may be from any type of computer printer.

The quality of this reproduction is dependent upon the quality of the copy submitted. Broken or indistinct print, colored or poor quality illustrations and photographs, print bleedthrough, substandard margins, and improper alignment can adversely affect reproduction.

In the unlikely. event that the author did not send UMI a complete manuscript and there are missing pages, these will be noted. Also, if unauthorized copyright material had to be removed, a note will indicate the deletion.

Oversize materials (e.g., maps, drawings, charts) are reproduced by sectioning the original, beginning at the upper left-hand comer and continuing from left to right in equal sections with small overlaps. Each original is also photographed in one exposure and is included in reduced form at the back of the book

Photographs included in the original manuscript have been reproduced xerographically in this copy. Higher quality $6^{n} \times 9^{n}$ black and white photographic prints are available for any photographs or illustrations appearing in this copy for an additional charge. Contact UMI directly to order.

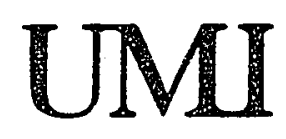

A Beli \& Howell information Company

300 North Zeeb Road. Ann Afbor. MI 48106-1346 USA

$313.761-4700 \quad 800: 521-0600$ 

COMPARISON OF THE EFFECT OF OXYGEN ADDITION METHODS ON THE BIOLOGICAL DEGRADATION RATE OF DIESEL FUEL CONTAMINATED SOIL IN SLURRY-PHASE REACTORS

\author{
A Thesis \\ Presented to \\ The Faculty of the Department of Chemical Engineering \\ San Jose State University
}

In Partial Fulfillment

of the Requirements for the Degree

Master of Science

by

David Adam Cacciatore

December, 1994 
UMI Number: 1361155

Copyright 1994 by

Cacciatore, David Adam

All rights reserved.

UMI Microform Edition 1361155

Copyright 1995, by UMI Company. All rights reserved.

This microform edition is protected against unauthorized copying under Title 17, United States Code.

\section{UMI}

300 North Zeeb Road

Ann Arbor, MI 48103 
(C) 1994

David Adam Cacciatore

ALL RIGHTS RESERVED 


\section{APPROVED FOR THE DEPARTMENT OF CHEMICAL ENGINEERING}

Melami A. Mc p \&

Dr. Melanie A. McNeil, Research Advisor

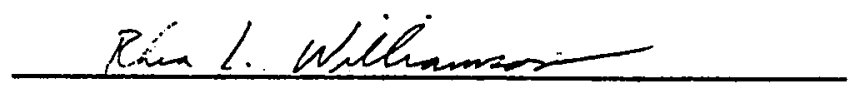

Dr. Rhea L. Williamson, Committee Chairperson

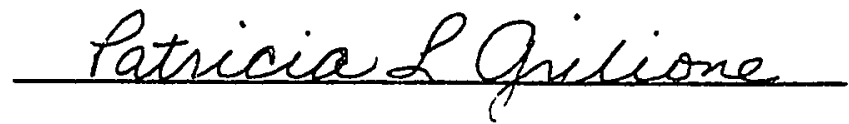

Dr. Patricia L. Grilione, Committee Member

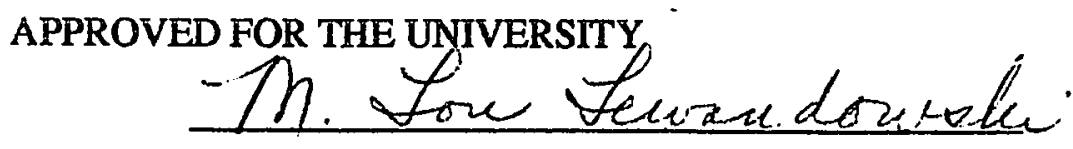




\section{ABSTRACT \\ Comparison of the Effect of Oxygen Addition Methods on the Biological Degradation Rate of Diesel Fuel Contaminated Soil in Slurry-Phase Reactors \\ by \\ David Adam Cacciatore}

The biodegradation rate of diesel fuel contaminated soil in oxygen enhanced, slurry-phase bioreactors was studied. Soil contaminated with a known amount of diesel fuel was mixed to a 10 percent slurry in water, inoculated with a known amount of a microorganism consortium and supplied with nutrients. The oxygen concentration of the slurry mixture was enhanced by three means: mechanical agitation, air sparging with agitation, and hydrogen peroxide $\left(\mathrm{H}_{2} \mathrm{O}_{2}\right)$ addition with agitation.

The concentration of diesel fuel contamination was monitored daily to establish the biodegradation rate. The reactors were also monitored for dissolved oxygen, microbial populations, nutrient levels, $\mathrm{pH}$ and temperature.

The diesel fuel contamination was reduced from an average initial concentration of $3,443 \mathrm{mg} / \mathrm{L}$ to an average final concentration of $92 \mathrm{mg} / \mathrm{L}$ in an 8 day period. First order kinetics were used to describe the diesel fuel degradation for each of the reactors. Average first order rate constants of $0.2438,0.1859$ and 0.1746 in units of days ${ }^{-1}$ were found for the three conditions investigated, air sparging with agitation, $\mathrm{H}_{2} \mathrm{O}_{2}$ addition with agitation, and agitation alone, respectively. 


\section{ACKNOWLEDGMENTS}

The author would like to thank his advising professor, Dr. Melanie A. McNeil, for the introduction to the area of bioremediation and for her valuable guidance, support and encouragement during this research study. The author would like to thank thesis committee chairperson, Dr. Rhea L. Williamson, and thesis committee member, Dr. Patricia L. Grilione, for their guidance and support through this project. Their input to this study and the use of their laboratory facilities proved invaluable during this research.

The author would like to thank the Department of Chemical Engineering, Department of Civil Engineering \& Applied Mechanics and the Department of Biological Sciences for support on this research. The author also acknowledges the San Jose State University Foundation for financial support of this study in the form of research assistantships.

The author recognizes Naresh Channaveerappa, Rashmin Chhokar and Jennifer Evans for their technical support on this project. They each played a pivotal role in establishing experimental procedures and in evaluating system parameters.

Acknowledgments are extended to the Microbiology and Chemistry Stockroom and to the School of Engineering Technical staff. Wafa Niekro, Pat Baty and Linda Goff in the Microbiology Stockroom were of great assistance in the microbiological aspects of this investigation. Paul Wood in the Chemistry Stockroom is recognized for the temporary supply of exhausted chemical reagents. Engineering technicians, Ray Brindos and Erwin Toeffel, are recognized for their aid in investigating and constructing an experimental apparatus. 
The author would like to thank Peter Schruben and John Jess at Solmar Corporation for supplying the microorganisms used in this study.

The author would like to thank long time friend Brian Clarke for his advice regarding the gas chromatograph and extraction procedure. The author would also like to recognize Rolf Jentoft whose advice and ideas helped shape this dissertation.

Finally, the author is grateful to his parents and sister whose patience, assistance and financial support made this dissertation possible. 
ABSTRACT $\quad$ iv

ACKNOWLEDGMENTS $v$

TABLE OF CONTENTS vii

LIST OF TABLES $\mathrm{x}$

LIST OF FIGURES

CHAPTER 1. INTRODUCTION AND BACKGROUND 1

1.1. Definition 1

1.2. Fuel Contamination Focus 1

1.3. Associated Risks 3

1.4. Soil Remediation Methods 3

1.5. Soil Bioremediation Applications 6

1.6. Limiting Factors in Biodegradation 8

1.7. Research Focus 9

CHAPTER 2. LITERATURE REVIEW 10

$\begin{array}{ll}\text { 2.1. Literature Trends } & 10\end{array}$

2.2. Soil Characteristics 11

2.3. Fuel Types 13

2.4. Rate-Limiting Factors 14

2.5. Slurry-Phase Treatment Precedents 15

2.6. Precedents for Fuel Contaminated Soils Treatment 20

2.7. Thesis Study 22 
CHAPTER 3. MATERIALS AND METHODS 23

3.1. Introduction 23

3.2. Hypothesis 23

3.3. Experimental Apparatus ,

3.4. Experimental Procedure 27

3.5. Analytical Methods 32

3.6. Errors Associated with Analytical Methods 36

3.7. Equipment and Materials 41

CHAPTER 4. EXPERIMENTAL RESULTS AND DISCUSSION 44

4.1. Introduction 44

4.2. Diesei Degradation 44

4.3. Degradation Kinetics $\quad 52$

4.4. Dissolved Oxygen $\quad 59$

4.5. Microorganisms 64

4.6. Nutrients 66

4.7. Monitored Conditions $\quad 72$

4.8. Volatile Emissions $\quad 75$

$\begin{array}{ll}\text { CHAPTER 5. CONCLUSIONS } & 78\end{array}$

REFERENCES

$\begin{array}{ll}\text { APPENDICES } & 86\end{array}$

APPENDIX A: Sample Calculations $\quad 87$

APPENDIX B: EPA Method 8015

APPENDIX C: Media Preparation and Spread Plate Technique 101

$\begin{array}{ll}\text { APPENDIX D: Gas Chromatograph Data } & 103\end{array}$

$\begin{array}{ll}\text { APPENDIX E: Calibration Data } & 110\end{array}$ 
$\begin{array}{ll}\text { APPENDIX F: Raw Data } & 115\end{array}$

APPENDIX G: Gas Chromatograph and Integrator Settings 119 


\section{LIST OF TABLES}

Page

Table 1.1 Daily Average Supply of Selected Petroleum Fuels, 1986.

Table 1.2 Advantages and Disadvantages of Bioremediation. 5

$\begin{array}{lll}\text { Table } 1.3 & \text { Treatment Costs. } & 7\end{array}$

$\begin{array}{lll}\text { Table 2.1 Available Oxygen from Different Sources. } & 15\end{array}$

Table 3.1 Experimental Conditions Matrix. 31

Table $3.2 \quad$ Sampling Schedule. 31

Table $3.3 \quad$ Calibration Standards. 33

Table $3.4 \quad$ Injection Error. 38

Table 3.5 Daily Standard Runs on Gas Chromatograph. 39

Table $3.6 \quad$ Extraction Error. $\quad 40$

Table $3.7 \quad$ Experimental Soil Classification. 43

Table $3.8 \quad$ Chemicals List. 43

Table 4.1 Diesel Degradation Data, Experiment \#1. 45

Table 4.2 Diesei Degradation Data, Experiment \#2. 47

Table 4.3 Diesel Degradation Data, Experiment \#3. 48

Table 4.4 Kinetic Parameters. 52

Table 4.5 Dissolved Oxygen Data, Experiment \#1. 59

Table 4.6 Dissolved Oxygen Data, Experiment \#2. 59

Table 4.7 Dissolved Oxygen Data, Experiment \#3. 60

Table 4.8 Microorganism Growth Data. 65

Table 4.9 Nutrient Concentration Data, Experiment \#1. 67

Table 4.10 Nutrient Concentration Data, Experiment \#2 67

Table 4.11 Nutrient Concentration Data, Experiment \#3. 67 
Table 4.12 Slurry pH Data.

Table 4.13 Volatile Emission Data for the Sparge/Stir Reactor. 76

Table 4.14 Volatile Emission Data for the $\mathrm{H}_{2} \mathrm{O}_{2}$ /Stir Reactor. 76 


\section{LIST OF FIGURES}

Page

$\begin{array}{lll}\text { Figure } 1.1 & \text { In-situ Treatment Scheme. } & 7\end{array}$

Figure 1.2 Schematic of a Slurry Treatment Bioreactor. 9

Figure 2.1 Typical Volumetric Composition of Soil. 12

Figure 2.2 Schematic of Slurry-Phase Treatment Operation For 17

Figure 2.3 Schematic of General Slurry-Phase Treatment Jystem. 18

Figure 3.1 Schematic of Individual Reactor Apparatus. 25

Figure 3.2 Schematic of Complete Experimental Apparatus. 26

Figure 4.1 Percentage Diesel Reduction versus Time, Experiment \#1. 45

Figure 4.2 Percentage Diesel Reduction versus Time, Experiment \#2. 47

Figure 4.3 Percentage Diesel Reduction versus Time, Experiment \#3. 49

Figure 4.4 First Order Degradation Kinetics, Experiment \#1. 55

Figure 4.5 First Order Degradation Kinetics, Experiment \#2. 55

Figure 4.6 Dissolved Oxygen Profile, Experiment \#1. 63

Figure 4.7 Dissolved Oxygen Profile, Experiment \#2. 63

Figure 4.8 Dissolved Oxygen Profile, Experiment\#3. 64

Figure $4.9 \quad$ Ammonia-Nitrogen Profile, Experiment \#1. 68

Figure 4.10 Ammonia-Nitrogen Profile, Experiment \#2. 68

Figure 4.11 Ammonia-Nitrogen Profile, Experiment \#3. 69

Figure 4.12 Phosphate-Phosphorus Profile, Experiment \#1. 69

Figure 4.13 Phosphate-Phosphorus Profile, Experiment \#2. 70

Figure 4.14 Phosphate-Phosphorus Profile, Experiment \#3. 70 


\section{CHAPTER 1. INTRODUCTION AND BACKGROUND}

\subsection{Definition}

Bioremediation refers to the process of using microorganisms to decompose organic compounds. Bacteria and other organisms have the ability to consume organic compounds. Carbon dioxide, water and biomass are produced by the aerobic oxidation of hydrocarbons. Thus, biological treatment is an attractive form of hydrocarbon waste treatment since it is a means of converting a potentially hazardous substance to natural by-products.

Bioremediation provides the flexibility of application to various contaminated substances, including water, soil and sludge. Each method of biotreatment involves stimulation of microorganisms to grow in contaminated environments, whereby the growth is accompanied by organic compound degradation. Soil bioremediation is a relatively new process which is receiving increasing attention and will be the focus of this study.

\subsection{Fuel Contamination Focus}

Our society relies heavily on chemical production and usage. Chemicals underlie almost every aspect of day-to-day life. However, along with the conveniences provided by chemical utilization comes the risks of environmental contamination. Focusing particularly on petroleum fuels, the risks involved are manifest in the large quantities consumed for transportation and heating. According to Bauman (1989), the daily average 
fuel consumption in the United States is roughly 500 million gallons, as shown in Table 1.1.

Table 1.1. Daily Average Supply of Selected Petroleum Fuels, 1986 (revised from Bauman, 1989).

\begin{tabular}{cc|cc|c}
\multicolumn{2}{c|}{} & \multicolumn{2}{c|}{ FUEL OIL } & AVIATION \\
\hline Unleaded & Leaded & Distillate & Residual & Jet Fuels \\
$4,656,000$ & $2,096,000$ & $2,796,000$ & 889,000 & $1,186,000$
\end{tabular}

(Units are in barrels; 1 barrel $=42$ gallons)

DAILY TOTAL $=11,623,000$ barrels

This consumption presents a potential threat to the environment and the atmosphere due to emissions of by-product gases of.incomplete combustion. There are also risks due to spills or leaks onto or into the ground.

According to a survey by Westat, Inc. (1986), there are roughly 800,000 underground storage tanks (USTs) in the United States used to store fuels. An estimated 35 percent of these tanks are leaking. As a result, the United States Environmental Protection Agency (USEPA) is enforcing stringent regulations concerning USTs. Many fuel transfer facilities are being required to replace existing tanks. Discovery of contaminated soils often accompanies replacement and requires clean-up to meet USEPA standards. Thus, the demand is large for effective remediation of motor fuel contaminated soils. 


\subsection{Associated Risks}

There are several site-specific health risks associated with sub-surface fuel contamination. Extensive groundwater contamination can occur if heavy fuel components reach aquifer channels. Contamination is likely to occur if the aquifers are shallow and if there is a means by which the fuel can percolate down through the soil. This requires seepage of surface waters through the contaminant zone. Drinking water has been affected at sites with PVC plumbing running through the contaminant plume due to fuel components leaching through the plastic and directly into water supply lines.

The other risks associated with UST fuel spills are related to the volatile components of petroleum fuels, namely benzene, toluene, ethylbenzene and xylene (BTEX). These compounds have low vapor pressures and are essentially present as vapors at ambient conditions. As vapors, they tend to travel upward through the soil. They can pose an explosion threat at the ground surface or in sub-surface structures if they accumulate. These vapors also may contaminate low-lying and surface soils which could impact crops and animals.

\subsection{Soil Remediation Methods}

The methods available for treatment of fuel contaminated soils are vacuum extraction, mechanical aeration, thermal treatment, landfilling and bioremediation. Vacuum extraction, or soil venting, involves aerating the contaminated soil to drive off volatile organics. This can be done in place by constructing a matrix of sink holes throughout the contaminant site or by excavating and piling the soil at the surface. Mechanical aeration is an enhancement of soil venting whereby excavated piles are turned frequently to expedite the volatilization. These methods are simple to implement but only result in partial treatment. The volatile contaminants have not been eliminated 
but merely transferred from the soil to the air. Further treatment is required to remove the volatiles from the air and to remove any hazardous contaminants adsorbed to the soil.

Thermal treatment or incineration involves combustion of all the organic compounds in the soil through high temperature exposure. Incineration has the advantage of complete destruction of the contaminants. However incineration is very expensive. The high cost is reflective of the time and money required of the incinerator facility in obtaining the necessary operating permits. The cost of incineration is further increased for the producer due to the transportation required, either for the incinerator in the case of a mobile unit, or for the soil.

Landfilling refers to relocating the contaminated soil to a specially-designed, subsurface enclosure. As such, landfilling does not represent treatment at all, but rather a change of contaminated sites. Producer liability for potential contamination caused by the soil has not been reduced. Landfilling was the first and the simplest solution for dealing with contaminated soils. However new regulations are limiting its usage and making costs prohibitive.

Bioremediation is defined by the USEPA (1991) as the manipulation of living systems to bring about desired chemical and physical changes in a confined and regulated environment. In most cases the living organisms used are bacteria and the process is carried out aerobically. The result of complete aerobic bioremediation is the conversion to carbon dioxide and water. Bioremediation can be carried out on-site so transportation is not required. In-situ or in-place treatment of contaminated soil is possible, which eliminates the need for excavation and makes this method of remediation the most cost effective. 
Bioremediation is not applicable to all contaminant sites. Some contaminants will not degrade and others degrade so slowly that biological treatment is not a viable alternative. Treatability studies are required to determine the minimum contaminant levels achievable. Careful process control is needed to sustain microbial populations. Most bioremediation processes require additional steps for soil preparation and for volatile organic emissions. Table 1.2 summarizes the advantages and disadvantages associated with biological treatment.

Table 1.2. Advantages and Disadvantages of Bioremediation (USEPA, 1991).

\section{ADVANTAGES OF BIOREMEDIATION}

1. Many organic compounds removed quickly and effectively

2. Terminal destruction of organic contaminants possible

3. Most cost-effective treatment technology

4. On-site treatment

\section{DISADVANTAGES OF BIOREMEDIATION}

1. Inorganics and some organics not biodegradable

2. Aerated processes liberate volatile organics which require additional treatment

3. Additional processes are required to remove dissolved solids and heavy metals

4. Treatability studies are required to determine the minimum contaminant levels achievable

5. Treatment slows considerably at low contaminant concentration

6. Process must be carefully monitored for oxygen, $\mathrm{pH}$, nutrients and moisture 


\subsection{Soil Bioremediation Applications}

Application of bioremediation to soil contamination is a relatively new technology. Laboratory studies have only recently been performed to characterize the process. Bioremediation applications are generally classified as in-situ or $e x$-situ. In-situ applications involve treating the soil without excavating. This treatment is well suited for sites with deeply contaminated soils where extraction costs would be excessive or for sites with restricted access. The in-situ treatment method involves setting up an artificial hydrostatic gradient through the suspect area. Water enriched with nutrients, oxygen and/or microorganisms is placed on the site so that it will flow through the contaminated area. The water that has passed through the contamination is continually pumped to the surface. Continuous recirculation is carried on until the contaminants have been reduced to acceptable levels.

In-situ bioremediation is the most cost effective soil treatment method as shown in Table 1.3. However in-situ treatment does have limitations. This treatment is only effective if the subsurface soils are highly permeable. The in-situ bioremediation process is generally applied to sites with relatively shallow and already contaminated ground water. In-situ treatment can be applied to sites in which the groundwater is not contaminated, as long as the site contains a natural clay or rock barrier. This barrier collects the percolated water for recycle to the surface and prevents further contamination of groundwater. Treatment times range from one to two years depending upon contamination levels and depths of contamination. This method only offers limited assurance that the site has been treated to acceptable levels due to the difficulty in obtaining a representative sample. Figure 1.1 depicts one example of an in-situ treatment scheme. 
Table 1.3. Treatment Costs (Adapted from Molnaa and Grubbs, 1989; * Brox and Hanify, 1991).

\begin{tabular}{|c|c|}
\hline TREATMENT PROCESS & COST (\$/ton) \\
\hline Landfill (disposal fee) & $120-140$ \\
\hline Mobile Incineration & $150-400$ \\
\hline General Above-Ground Treatment & $100-200$ \\
\hline Bioremediation Slurry-Phase & $75-180^{*}$ \\
\hline In-situ & $15-70$ \\
\hline
\end{tabular}

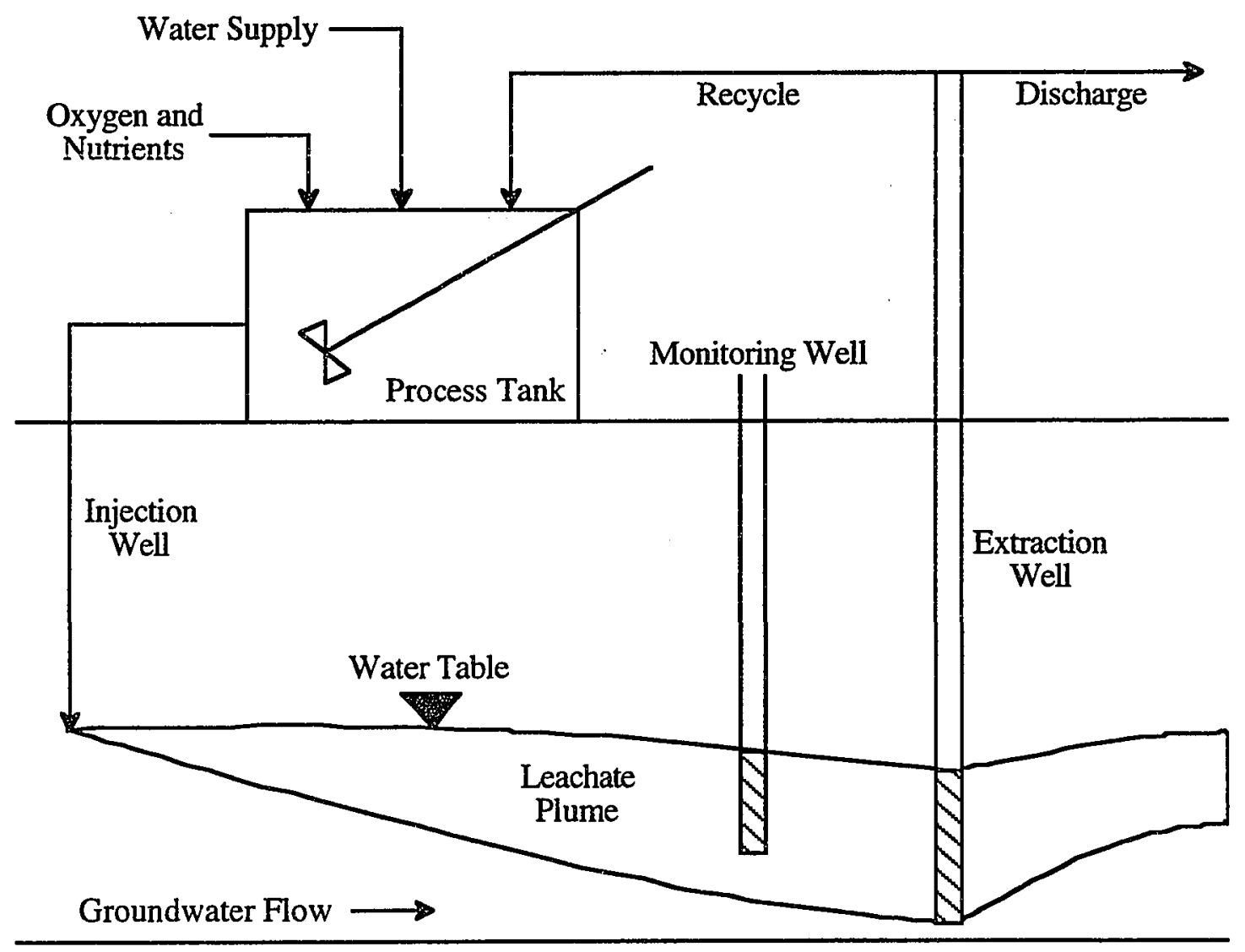

Figure 1.1. In-situ Treatment Scheme (Adapted from Bradford and Krishnamoorthy, 1991). 
$E x$-situ methods involve excavation of the contaminated site followed by treatment above ground. As with the in-situ method, nutrients, oxygen and often microorganisms are added to the soil to implement the degradation. The remediation takes place above the surface where adequate mixing of the constituents can be assured. The biodegradation can be easily monitored above the surface and additional changes can be made as needed. The ease of process control means shorter treatment times.

Bioreactor treatment is an extension of the general ex-situ method. Figure 1.2 is a process schematic of a slurry treatment bioreactor. Excavated soil is slurried in water and is treated in a well-mixed reactor. An impeller is used to maintain the well-mixed suspension which maximizes the mass transfer of the contaminants to the aqueous phase and provides maximum contact between the contaminated material and the microorganisms. This application represents the most effective means of mixing the microorganisms with the contaminated soil, nutrients and oxygen. Efficient mixing fosters rapid bacterial growth and reduces the treatment time. This reactor can be operated in batch or continuous mode.

\subsection{Limiting Factors in Biodegradation}

Several factors limit the rate of biodegradation, including temperature, $\mathrm{pH}$, oxygen content and availability, soil nutrient content and availability, soil moisture content and the suitability of the bacteria utilized to the enhanced conditions (Autry and Shearon, 1991). Bioreactor treatment is an effective means of optimizing these factors. This potential for optimization and the possibility for continuous-mode operation can minimize treatment times and make the bioreactor an attractive alternative. 


\subsection{Research Focus}

This research will focus on the bioremediation of diesel fuel contaminated soils in a slurry-phase bioreactor. In particular, the oxygen addition of air sparging, hydrogen peroxide addition and stirring will be investigated. A constant microorganism source will be used.

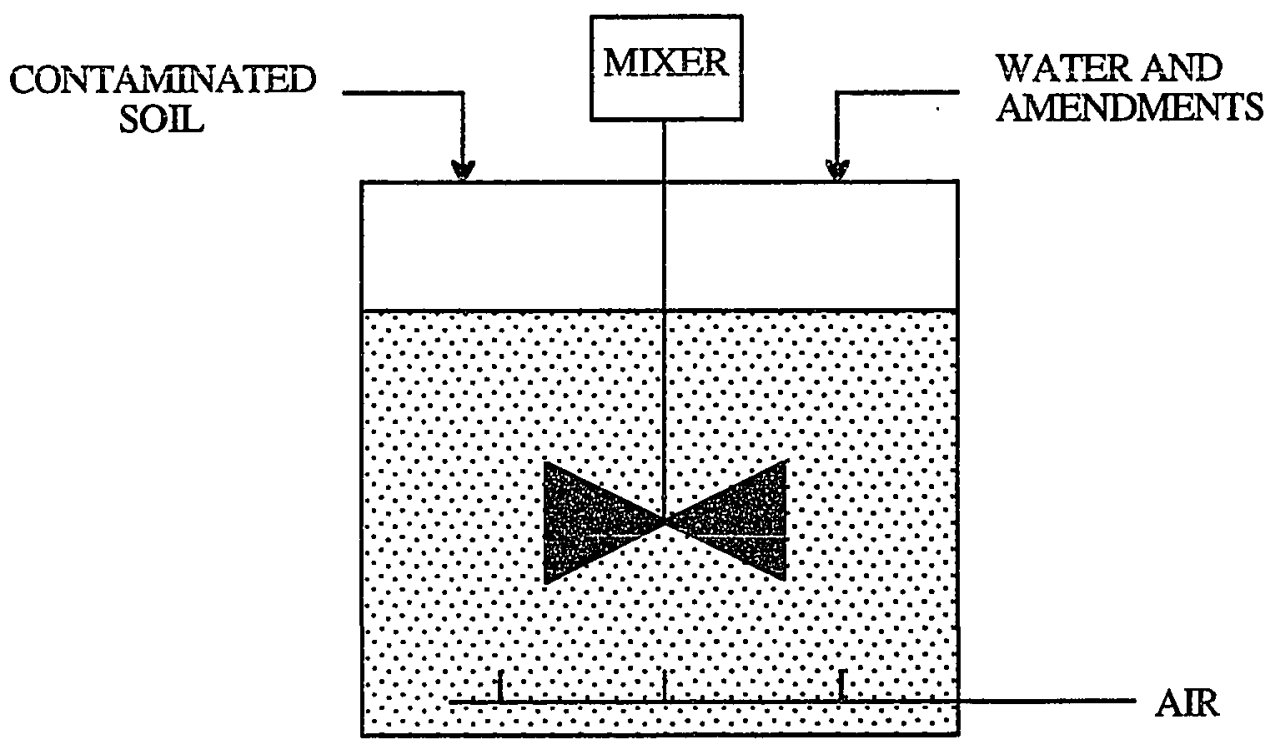

Figure 1.2. Schematic of a Slurry Treatment Bioreactor (Adapted from Emcon Associates). 


\section{CHAPTER 2. LITERATURE REVIEW}

\subsection{Literature Trends}

Most of the literature on bioremediation of fuel contaminated soils is associated with in-situ or in-place treatment. There are several advantages of in-situ treatment. Treatment in this fashion is the most inexpensive of any of the remediation processes. Insitu bioremediation costs $\$ 15$ to $\$ 70 /$ ton. This compares favorably to the most expensive option, incineration, at $\$ 150$ to $\$ 400 /$ ton (Molnaa and Grubbs). Also, in-situ treatment reduces the possible exposure of operators to contaminants that would be associated with excavation. In-situ treatment is an established technology. The first application occurred in 1972 by Sun Pipeline Company to treat a gasoline spill (Raymond et al., 1976). An estimated 1,000 barrels of gasoline were removed from 2.5 million gallons of water in the 12 month treatment program whereby the indigenous microbes were stimulated through nutrient addition and aeration.

Slurry-phase treatment (SPT) of contaminated soils is a recent innovation in bioremediation. In this form of remediation, the excavated soil is treated as a water-based slurry in a bioreactor. There is limited coverage on this method in the literature. Most of the sources discuss preliminary research stages, pilot scale studies and vendor application case studies (Castaldi and Ford, 1992, Compeau et al., 1991, Dosani et al., 1993, Morgan et al., 1991, Ryan et al., 1991 USEPA, 1989 and USEPA, 1990). Reports of these initial studies, some of which are discussed in Section 2.5, are promising, with results of reduced treatment times and continuous operations. These benefits are the direct result of the effective process control that can be utilized in SPT. Another advantage reported is 
successful treatment of soils contaminated with high concentrations of organics (Compeau et al., 1991). This is a result of the aqueous phase in SPT which dilutes the contaminant and effectively protects the microorganisms. Indigenous and cultured microbial populations have proved successful in SPT (Castaldi and Ford, 1992, Compeau et al., 1991 and Dosani et al., 1993). The disadvantages reported with SPT include treatability studies required to assess the biological treatment potentials, extensive pretreatment of soils and slurry required to protect the microorganisms and high operating costs (Compeau et al., 1991, Dosani et al., 1993, USEPA, 1989 and USEPA, 1990).

\subsection{Soil Characteristics}

Soil bioremediation is very site specific. Work by McFarland et al. (1991) emphasized the need for site specific treatability studies to determine the optimal bioremediation method. Treatability studies are laboratory or field tests designed to provide data for the evaluation and implementation of a given remediation technology. These studies are required to prevent investment in a full-scale treatment technology that cannot achieve the desired goal. Study of the soil and contaminant characteristics and their interaction is very important in determining the best bioremediation method.

Soil is a complex system consisting of four phases: soil gas, soil water, inorganic solids and organic solids (Figure 2.1). Gases and water comprise roughly 50 percent of the soil volume. An organic contaminant will distribute among the four soil phases in relation to its solubility, volatility and ionic charge. The soil phases may make the organic compound more or less susceptible to biological treatment. 


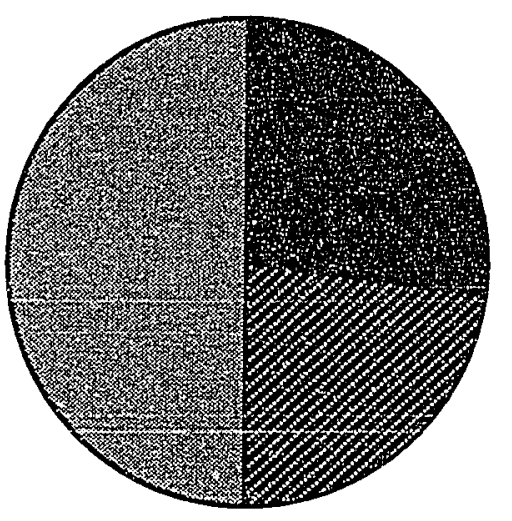
GAS (15-35\%)
$\checkmark$ WATER (15-35\%)
SOLIDS (38-55\%) Inorganic 38-45\% Organic 5-12\%

Figure 2.1. Typical Volumetric Composition of Soil (Adapted from McFarland et al., 1991).

Successful remediation of contaminated soil requires complete characterization and evaluation of the contaminant mobility and the potential removal mechanisms. For each chemical or representative compound type the following properties are important for evaluating bioremediation potential:

1. Leaching characteristics - water solubility and partition coefficient

2. Volatility - vapor pressure and Henry's Law Constant

3. Biodegradation potential - half-life and transformation by-products

4. Chemical reactivity - hydrolysis possibility and redox potential

The rate of overall depletion or transformation can be calculated either by measuring the loss of the parent compound (material balances) or the production of carbon dioxide with time of treatment (mineralization). If material balances are used to assess the degradation rate, the concentrations of the parent compound and the possible transformation products need to be measured over time in the air, the soil water and the extractions from the soil solid. If the mineralization approach is to be used, carbon 
dioxide and/or methane need to be measured in the air over time. Also any substituent groups that might be released due to transformation need to be tested for in the air, soil water and soil solids. Either method of degradation assessment requires knowledge of contaminant mobility and transformation potential.

\subsection{Fuel Types}

Studies on fuel contamination of soils are well reported in the literature. Contamination by gasoline, diesel fuel and fuel oils has been studied. These fuels are produced by different degrees of crude petroleum distillation. Due to the largely different properties of these fuels, each type of contamination poses a different remediation challenge.

Gasoline is a complex mixture of low boiling-point hydrocarbons in the range of $50-200^{\circ} \mathrm{C}$. The major components are organic compounds containing 4 to 12 carbons $\left(\mathrm{C}_{4}\right.$ to $\left.\mathrm{C}_{12}\right)$. Gasoline contains a large number of volatile aromatic compounds, including BTEX. Solubility of gasoline in water is in the range of $50-150 \mathrm{mg} /$ (Bauman 1989). Due to these properties, remediation of gasoline contaminated soils involves gas and water treatment along with soil treatment.

Diesel fuel contains distillates that are slightly heavier than gasoline. The compounds in diesel range in boiling point from $50-340^{\circ} \mathrm{C}$. This boiling point range varies depending upon the diesel fuel grade and the type of application. Diesel fuel consists primarily of straight-chain hydrocarbons (alkanes and alkenes) varying in length from $\mathrm{C}_{10}$ to $\mathrm{C}_{23}$ (State of California, 1989). Diesel fuel has a low volatility and water solubility between 0.4 and $8.0 \mathrm{mg} / 1$. Diesel fuel is concentrated in the soil phase at contamination sites. 
Other fuel contaminants of soil addressed in the literature include JP-4 (jet fuel) and Bunker C fuel (No. 6 fuel oil) used by merchant vessels (Wang and Bartha 1990). JP-4 is a wide-cut jet fuel developed by the U.S. Air Force in order to ensure the availability of a maximum volume of fuel in the event of a war. The boiling point composition ranges from $60-300^{\circ} \mathrm{C}$. Bunker $\mathrm{C}$ fuel is a residual product from petroleum distillation. Other bottom products include asphalt, petroleum coke and heavy industrial fuel. The boiling point range is not reported as the only properties limiting the use of these products are viscosity and metals content.

\subsection{Rate-Limiting Factors}

As stated previously, several factors linit the rate of biodegradation, including temperature, $\mathrm{pH}$, oxygen content and availability, soil nutrient content and availability, soil moisture content and the suitability of the bacteria utilized to the enhanced conditions. The oxygen supply is typically the rate-limiting factor in biological treatment. As such, oxygen is the most common limitation addressed in the literature.

In order to initiate hydrocarbon oxidation, aerobic microorganisms require oxygen for sustenance. An electron acceptor is required for hydrocarbon oxidation and oxygen serves this purpose. Hydrocarbon subsurface contamination results in decreased oxygen concentrations in areas that are essentially anaerobic already. Thus, oxygen has to be supplied to implement biodegradation. Sources of oxygen include air, pure oxygen and hydrogen peroxide $\left(\mathrm{H}_{2} \mathrm{O}_{2}\right)$. Air and pure oxygen can be supplied in the gaseous form or can be introduced dissolved in water. $\mathrm{H}_{2} \mathrm{O}_{2}$ is added as a dilute solution in water. Subsequent oxidation can also be sustained by alternative electron acceptors such as the nitrate ion, which is usually supplied in a dilute salt solution. 
In an EPA evaluation by Staps (1989), oxygen supply and sources are addressed relative to in-situ application. According to Staps, although the simplest method of supplying oxygen is by aeration with saturated water, this method is limited. Because the treatment is in-situ, the amount of water in contact with the contaminated soil is limited by the soil porosity. Therefore the amount of water required to remediate a given contamination level increases as the available oxygen concentration decreases. Table 2.1 shows the quantities of oxygen available to subsurface soils from the sources mentioned.

Table 2.1. Available Oxygen from Different Sources (Adapted from Staps, 1989).

\begin{tabular}{c|c} 
Oxygen Source & $\begin{array}{c}\text { Available Oxygen } \\
\text { (mg/L at 10 } \mathrm{C})\end{array}$ \\
\hline aerated water & 10 \\
$\mathrm{O}_{2}$ saturated water & 40 \\
$\mathrm{H}_{2} \mathrm{O}_{2}(200 \mathrm{mg} / \mathrm{L})$ & 94
\end{tabular}

These limits are based on in-situ treatments where oxygen is added to the soil through enriched water. The aerated water and oxygenated water are limited by their respective saturation limits. Oxygen addition by $\mathrm{H}_{2} \mathrm{O}_{2}$ is limited by the toxicity of $\mathrm{H}_{2} \mathrm{O}_{2}$ to microorganisms and the instability of $\mathrm{H}_{2} \mathrm{O}_{2}$ in the subsurface (Morgan et al., 1992, Pardieck et al., 1992 and Staps 1990).

\subsection{Slurry-Phase Treatment Precedents}

Slurry-phase treatment offers a means of reducing the effect of the rate-limiting factors including oxygen addition. Complete mixing of the nutrients, oxygen source, water and microorganisms can be achieved. The rate-limiting factors can be monitored and optimized for the most efficient environment for biodegradation. Oxygen or air can 
be sparged through the reactor without the limitations associated with liquid addition, greatly reducing treatment times. However, slurry-phase treatment is more costly than insitu treatment (Table 1.3).

Successful slurry-phase bioremediation has been documented for soils contaminated with halogenated organic compounds and explosives. Compeau et al. (1991) have demonstrated successful slurry-phase treatment of soils contaminated with pentachlorophenol (PCP), a wood treating chemical. Indigenous microorganisms were not effective in degrading PCP. A site-specific microbial consortium was developed and used in a slurry-phase bioreactor. In an automated, continuous bench-scale unit, operating for 23 days, 95 percent PCP biodegradation was achieved on soils contaminated with as much as $9000 \mathrm{mg} / \mathrm{kg}$. A full-scale remediation process using $2 \mathrm{x}$ 25,000-gallon, slurry bioreactors in batch mode resulted in a PCP reduction from 370 ppm in slurry solids to below the detection limit of $0.55 \mathrm{ppm}$ by weight (or $0.55 \mathrm{mg} / \mathrm{kg}$ ). Figure 2.2 is a schematic of the full-scale operation described by Compeau et al. (1991).

An USEPA document on slurry-phase biodegradation (USEPA, 1989) reports the successful application of SPT claimed by Detox Industries, Incorporated. Detox applied pilot-scale, slurry-phase bioremediation to soils contaminated with polychlorinated biphenyls (PCBs) at a hazardous waste site in Herne, Texas. Roughly 1,500 pounds of sludge containing 2,000 ppm PCBs were treated to less than $4 \mathrm{ppm}$, or 99.8 percent removal, in 4 months. 


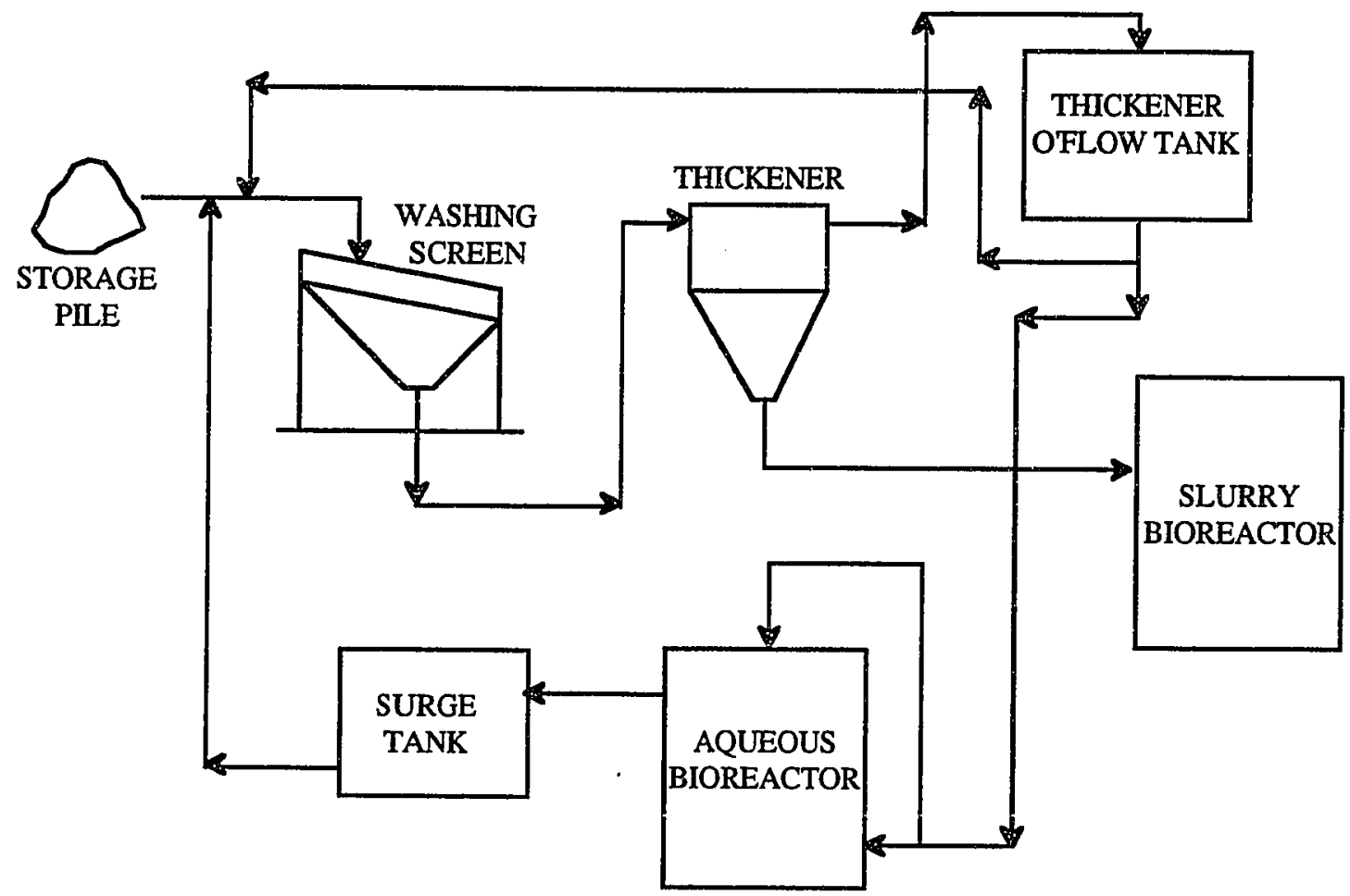

Figure 2.2. Schematic of Slurry-Phase Treatment Operation For Remediation of PCP Contaminated Soils (Adapted from Compeau et al., 1991).

Dosani et al. (1993) performed a pilot-scale study on the slurry-phase treatment of creosote-contaminated soil. Creosote is a wood preserving agent derived from coal tar distillation and contains 17 different polynuclear aromatic hydrocarbons (PAHs). Five bioreactors were operated in parallel, each containing 66 liters of a 30 percent solids by weight slurry. Each of the reactors was aerated and supplemented with nutrients and an inoculum of indigenous PAH-utilizing microorganisms. Initial soil bound PAHs ranged from 5.5 to $840 \mathrm{mg} / \mathrm{kg}$ and initial liquid phase PAHs ranged from $0.006 \mathrm{mg} / \mathrm{L}$ to 18 $\mathrm{mg} / \mathrm{L}$. After the twelve week testing period, soil bound $\mathrm{PAH}$ reductions of greater than 67 percent to greater than 93 percent were observed. Aqueous phase PAHs were reduced by greater than 99 percent. Figure 2.3 is a schematic of a general slurry-phase treatment system. 


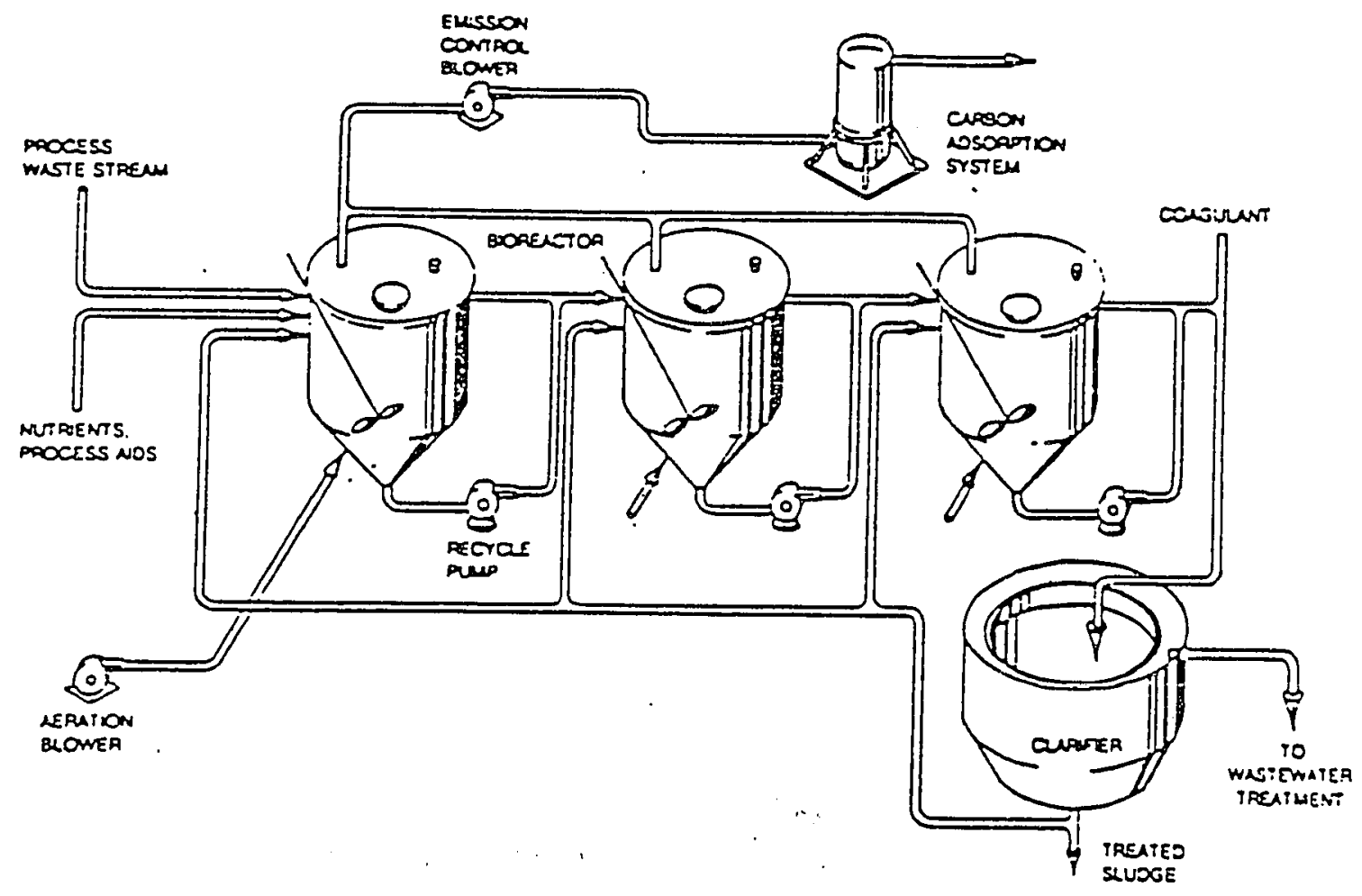

Figure 2.3. Schematic of General Slurry-Phase Treatment System (Ryan et al., 1991).

Morgan et al. (1991) studied the biodegradation rate of polynuclear aromatic hydrocarbon (PAH) contaminated soil from manufactured gas plant sites. Degradation rates were compared between slurry-phase treatment and treatment as a moist cake in a soil pan reactor. Four different contaminated soil types were studied with initial concentrations ranging from $150 \mathrm{ppm}$ to about $30,000 \mathrm{ppm}$ total PAHs. Morgan et al. (1991) showed that the slurry reactors were able to achieve biodegradation rates that were equivalent to or greater than those obtained in pan reactors. 
Morgan et al. (1991) fit the experimental data for each reactor to the following empirical relationship:

$$
\mathrm{C}(\mathrm{t})=\mathrm{C}_{\mathrm{R}}+\left(\mathrm{C}_{\mathrm{O}}-\mathrm{C}_{\mathrm{R}}\right)^{*} \exp (-\mathrm{kt})
$$

where:

$$
\begin{aligned}
& \text { C(t) } \begin{array}{l}
\text { represents the } P A H \text { concentration at time } t \text { after the beginning } \\
\text { of the biotreatment; [=] } \mathrm{mg} / \mathrm{kg}
\end{array} \\
& \begin{array}{l}
\text { represents the residual or final } \mathrm{PAH} \text { concentration at the end } \\
\text { of the treatment period; }[=] \mathrm{mg} / \mathrm{kg}
\end{array} \\
& \mathrm{C}_{\mathrm{R}} \quad \begin{array}{l}
\text { represents the initial } \mathrm{PAH} \text { concentration prior to treatment; } \\
{[=] \mathrm{mg} / \mathrm{kg}}
\end{array} \\
& \mathrm{k} \quad \text { represents a first-order rate coefficient; }[=] \text { weeks }-1 \\
& t \quad \text { represents time; }[=] \text { weeks }
\end{aligned}
$$

The data were presented in a series of plots of concentration versus time for the individual PAH components, 2- through 6-member rings, and for the overall PAH concentration. Smooth curves determined by the best non-linear regression fit of the data to the empirical expression were drawn through the experimental data points. The estimated values of the first-order rate constant for the slurry reactors were greater than the soil pan reactors for virtually all PAHs in all of the tested soils. According to Morgan et al. (1991), this difference in rate constants reflects the higher ratio of water to soil, the greater population of bacteria, the enhanced aerobic conditions and the enhanced mass transfer of the PAHs from the soil to solution that occurs in the slurry reactor. 


\subsection{Precedents for Fuel Contaminated Soils Treatment}

No examples of slurry-phase treatment of hydrocarbon or diesel fuel contaminated soils have been found in the literature thus far. However, several sources report successful ex-situ treatments of fuel contaminated soils.

Galaska et al. (1990) presented results that show the effectiveness of indigenous bacterial degradation of hydrocarbon contaminated soils. In this study, bioremediation of $4,000 \mathrm{mg} / \mathrm{kg}$ petroleum contamination was examined in moist piles of soil. Degradation was compared in a control sample, a poison sample, an aeration only sample, and an aeration plus nutrient addition sample. The control sample was left undisturbed throughout the project duration. The poison sample served as a negative biological control and was sprayed with mercuric chloride solution during the first few weeks of the study. The poison sample received no further treatment. The aeration only sample was aerated daily by simple hand mixing of the soil pile. The aeration and nutrient sample was aerated daily and sprayed with an nutrient solution containing nitrogen and phosphorus.

The aeration plus nutrient addition pile showed a 300 percent reduction in petroleum concentration over 14 weeks of treatment. The aeration only, control and poison samples showed decreases of 53,41 and 30 percent, respectively. The degradation rates were determined from the measurement of total organic carbon in the soils over time following USEPA Method 418.1. The aerobic treatability study by Galaska et al. (1990) shows the positive effect aeration and nutrient addition has on degradation rates. 
Hinchee and Arthur (1991) demonstrated that forced aeration together with nutrient and moisture addition stimulates fuel degradation by indigenous microorganisms. In this study, contaminated soil was prepared by mixing unsaturated soil with JP-4 jet fuel to an approximate concentration of $5,000 \mathrm{mg} / \mathrm{kg}$. The soil was then treated in $30 \mathrm{x}$ $3.8 \mathrm{~cm}$ columns. Air, which was scrubbed to remove any background carbon dioxide, was passed through the columns to create the aerobic conditions. The air was humidified with a 2 percent aqueous nutrient mixture containing 50 percent ammonium chloride, 20 percent sodium phosphate, 17.5 percent sodium tripolyphosphate and 12.5 percent monosodium phosphate. The off-gases from each column were passed through individual traps of $1 \mathrm{NNaOH}$. Degradation rates were measured from $\mathrm{CO}_{2}$ evolved as milligrams of carbon. The results show a 3-fold increase in degradation rate over 48 days relative to non-nutrient-supplied and non-moisture-supplied control columns.

Arthur et al. (1990) studied jet fuel contaminated soils in laboratory soil columns ( $39 \times 12$ in.) as an in-situ treatability study. The objective of the experimentation was the evaluation of aeration methods, hydrogen peroxide treatment and forced aeration, relative to a non-aerated control. The soil was adjusted to roughly neutral $\mathrm{pH}$ and the carbon:nitrogen and carbon:phosphorus ( $\mathrm{C}: \mathrm{N}$ and $\mathrm{C}: \mathrm{P}$ ) ratios were augmented to 60:1 and $800: 1$, respectively, prior to loading in the columns. As in the work by Hinchee and Arthur (1991), moistened air was passed through the columns for aeration of the soil. Control columns received the moisture and nutrient addition but were not aerated. The degradation rates were determined from total organic carbon analyses on air-dried soil samples. The carbon content was determined gravimetrically on an oven-dry weight basis.

Arthur et al. (1990) found that hydrogen peroxide treatment resulted in a rapid increase in the number of aerobic organisms in the soil. The rate of increase was 
significant in comparison to the forced aeration method. After the initial growth phase, both methods showed comparable enhanced microbial populations that persisted for the first two months of the study. Despite the initial difference in microbial population, the rates of fuel reduction during the first two-month period and throughout the six-month study were roughly the same between the methods.

Hydrogen peroxide treatment has been shown to result in a rapid increase in aerobic microbial populations. The beneficial effect of this increase is not realized in a column treatment scheme. This would be true of most in-situ treatment methods where the transfer of the contaminant from the soil to the aqueous phase is rate-limiting. In a slurry reactor format, transfer limitations between the phases is minimized. The treatment times are shorter and are comparable to the time period in which the increase in microorganisms was observed. Therefore the rapid increase in microbial population due to $\mathrm{H}_{2} \mathrm{O}_{2}$ enhancement is predicted to result in an increased slurry reactor degradation rate relative to forced aeration.

\subsection{Thesis Study}

Castaldi and Ford (1992), Compeau et al. (1991), Dosani et al. (1993), Morgan et al. (1991), Ryan et al. (1991), USEPA (1989) and USEPA (1990) have shown the effectiveness of slurry-phase bioreactors in treating organic contaminants in the soil. Galaska et al. (1990), Hinchee and Arthur (1991), and Arthur et al. (1990) have demonstrated the positive effect aeration has on $e x$-situ treatment schemes for fuel contaminated soils. This experimentation was designed to combine these two approaches. Slurry-phase bioreactors were used to treat diesel fuel contaminated soils. The effects of different oxygen sources and distributions on the fuel degradation rates were analyzed. 


\section{CHAPTER 3. MATERIALS AND METHODS}

\subsection{Introduction}

The purpose of this study was to determine the biodegradation rates of diesel fuel contaminated soil in oxygen enhanced, slurry-phase bioreactors. Soil contaminated with a known amount of diesel fuel was mixed to a 10 percent slurry concentration with water, inoculated with a set amount of a microorganism consortium and supplied with nutrients. The oxygen concentration of the slurry mixture was enhanced by three means: mechanical agitation, air sparging with agitation and hydrogen peroxide addition with agitation. Under constant environmental conditions of temperature, pressure and humidity, the concentration of diesel fuel contamination was monitored daily to establish the biodegradation rate.

\subsection{Hypothesis}

Oxygen enhancement by air sparging and hydrogen peroxide addition in connection with agitation in slurry-phase treatment of diesel fuel contaminated soils will result in higher biodegradation rates than oxygen enhancement by agitation alone. Oxygen addition using hydrogen peroxide with agitation is predicted to result in the highest biodegradation rate.

\subsection{Experimental Apparatus}

Each bioreactor used in this study consisted of an $800 \mathrm{~mL}$ glass vessel and a magnetic stir bar. A solid rubber stopper was used to seal off the reactor contents and provide protection against random contamination during the experiment. Figure 3.1 is a detailed schematic diagram of an individual reactor. Three bioreactors, one for each 
method of oxygen addition, were mounted on air-driven magnetic stir plates located in a large water bath. The complete experimental apparatus is shown in Figure 3.2. The water bath was maintained at the constant temperature of $25^{\circ} \mathrm{C}$ with a water circulating, immersion heater.

A port in the stopper lid was used to make additions, remove samples and monitor the reactor conditions. The compressed air supplied to the sparged reactor was delivered at a controlled rate through a rotameter. The air was filtered to remove oil and dirt and prevent contamination of the systems. The vent gases from the sparged reactor were passed through a soil-packed column to capture any volatilized organic compounds. At the end of the experimentation, the soil from this trap was extracted with freon to determine the volatile emission losses from the sparged reactor. 


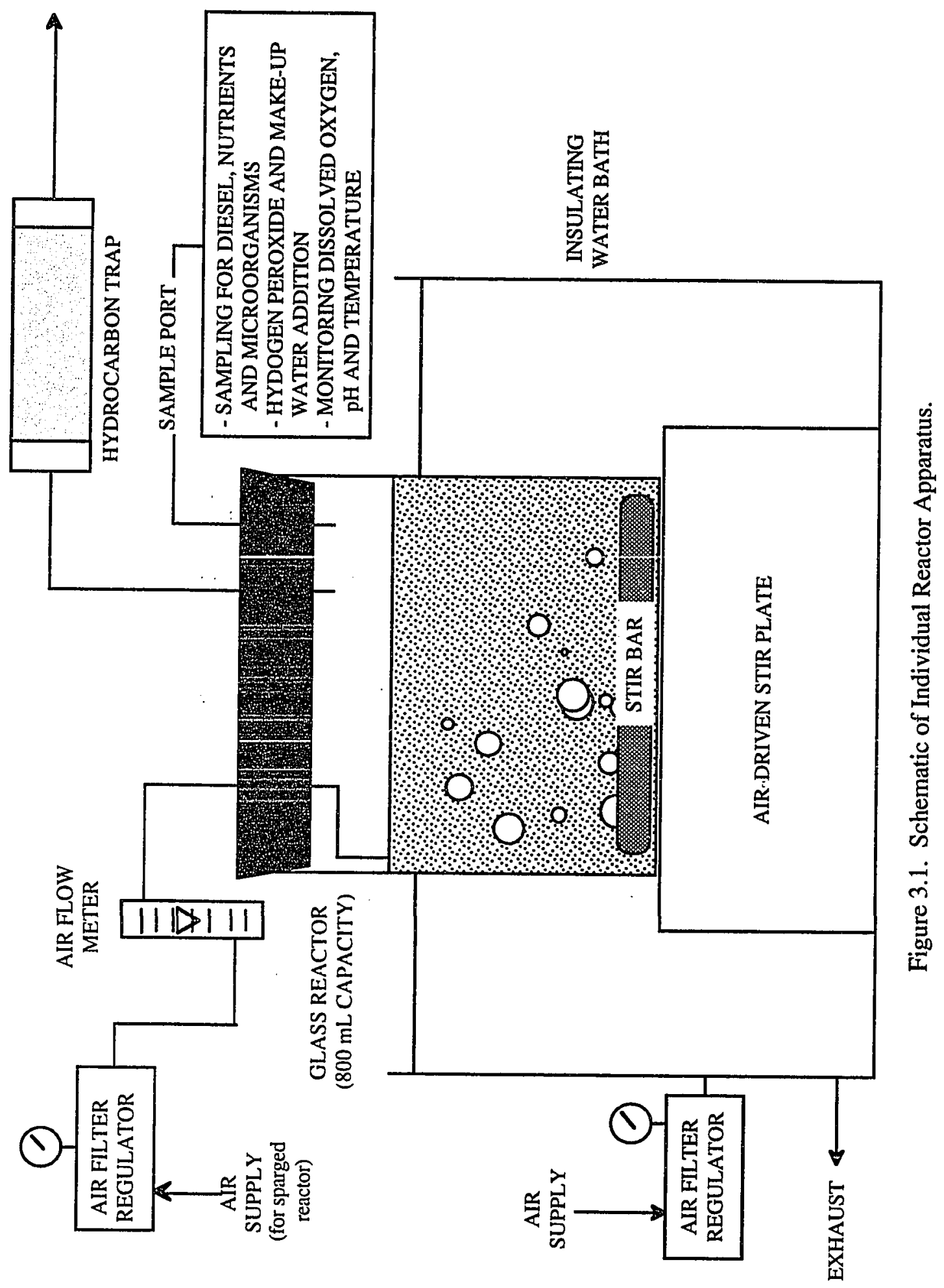




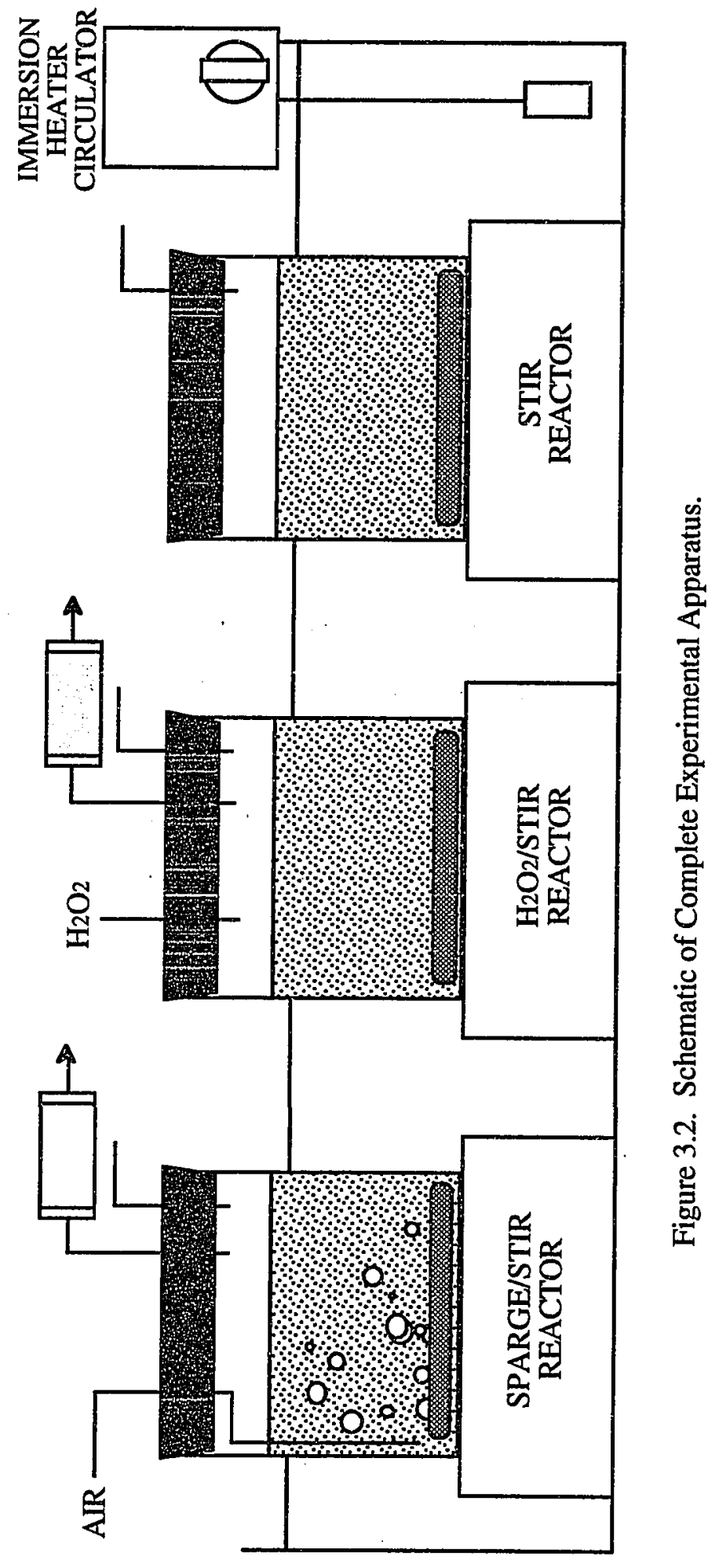




\subsection{Experimental Procedure}

The effectiveness of slurry-phase treatment of contaminated soil was examined under three different methods of supplying oxygen. The three types of oxygen enhancement were mechanical agitation, air sparging with agitation and hydrogen peroxide addition with agitation. The mechanical agitation was constant and equal for each of these three oxygen enhancement types. The reactor that was aerated by agitation alone served as the aeration control.

The sparged reactor received a compressed air flow of 1 liter per hour $(\mathrm{L} / \mathrm{hr})$. The air flow rate was measured using a standard gas rotameter which was calibrated using a bubble flow meter. The flow rate of $1 \mathrm{~L} / \mathrm{hr}$ was chosen based on reports by Arthur et al. (1990). This air flowrate represents the upper limit of the experimental set-up. Any higher air flow caused the seal between the bioreactor and stopper to break and thus, would not permit volatile emissions trapping. The hydrogen peroxide treatment reactor received either one $10 \mathrm{~mL}$ portion of a $5,000 \mathrm{mg} / \mathrm{L} \mathrm{H}_{2} \mathrm{O}_{2}$ solution (Experimental Series \#1) or four-10 mL aliquots of a 2,500 $\mathrm{mg} / \mathrm{L}$ solution of $\mathrm{H}_{2} \mathrm{O}_{2}$ (Experimental Series \#2 and \#3). The total amount of hydrogen peroxide added to the reactor was $50 \mathrm{mg}$ and 100 $\mathrm{mg}$, respectively. This amount of $\mathrm{H}_{2} \mathrm{O}_{2}$ results in maximum reactor concentrations of $100 \mathrm{mg} / \mathrm{L}$ and $200 \mathrm{mg} / \mathrm{L}$, respectively. Use of the 100 to $200 \mathrm{mg} / \mathrm{L}$ solution is based upon reports by Arthur et al. (1990) and Staps (1990).

A slurry ratio of 10 percent solids by weight was investigated. Optimal slurry ranges of $10-40,25$ - 50 and 5 - 40 percent solids have been suggested by USEPA (1990), Brox and Hanify (1991), and Compeau et al. (1991), respectively. Each reactor was maintained in the range of $\mathrm{pH} 6.5$ to 8.5 . The $\mathrm{pH}$ range of 4.8 and 8.5 was suggested by the USEPA (1989) as optimal for biological activity. Dalyan et al. (1990) have 
classified a more the restrictive $\mathrm{pH}$ range of 6.5 to 8 as optimal for hydrocarbon biodegradation.

Contaminated soil was prepared in the laboratory from uncontaminated soil and retail diesel fuel. The uncontaminated soil was sieved to remove particles larger than 2 $\mathrm{mm}$ in diameter, slurried in deionized water to break up aggregates, dried in an oven at $80^{\circ} \mathrm{C}$ and autoclaved at $121^{\circ} \mathrm{C}$ and 2 atmospheres for 30 minutes to reduce the population of any host microorganisms. The diesel fuel was dissolved in trichlorotrifluoroethane (frecn). The resulting solution was added to the uncontaminated soil to create a completely saturated slurry. The slurry was mixed by hand using a wooden paint stirring rod for 10 minutes. The freon was removed by heating the mixture in a water bath at $50^{\circ} \mathrm{C}$. The volatilized freon was collected by cold water condensation and disposed of properly. The contaminated soil was stored at $4^{\circ} \mathrm{C}$ in a stoppered glass jar until used.

The soil was contaminated with roughly $30,000 \mathrm{mg}$ diesel per kilogram of soil $(\mathrm{mg} / \mathrm{kg}$ ). At this concentration, a 10 percent by weight slurry of the soil in water yielded a concentration of approximately $3,000 \mathrm{mg}$ diesel per liter of slurry $(\mathrm{mg} / \mathrm{L})$. Sample calculations are provided in Appendix A.

Contaminated soil samples, 50 grams dry weight, were slurried in $450 \mathrm{~mL}$ of deionized water. The slurry $\mathrm{pH}$ was adjusted to $\mathrm{pH} 7.0$ as necessary using dilute solutions of sodium hydroxide or hydrochloric acid. The soil nutrients were amended by the addition of nitrogen in the form of a $141.3 \mathrm{~g} / \mathrm{L}$ ammonium sulfate $\left(\left(\mathrm{NH}_{4}\right)_{2} \mathrm{SO}_{4}\right)$ solution and phosphorous in the form of a $16.84 \mathrm{~g} / \mathrm{L}$ potassium phosphate $\left(\mathrm{K}_{2} \mathrm{HPO}_{4}\right)$ solution. The ammonium sulfate solution has an ammonia-nitrogen $\left(\mathrm{NH}_{3}-\mathrm{N}\right)$ concentration of $30,000 \mathrm{mg} / \mathrm{L}$ and the potassium phosphate solution has a phosphatephosphorus $\left(\mathrm{PO}_{4}^{3--P}\right)$ concentration of $3,000 \mathrm{mg} / \mathrm{L}$. 
Several different carbon:nitrogen:phosphorous ( $\mathrm{C}: \mathrm{N}: \mathrm{P})$ ratios have been suggested in the literature on bioremediation: Arthur et al. (1990) - 800:60:1, Compeau et al. (1991) - 300:25:1, Grundmann and Rehm (1991) - 60:10:1, Harder et al. (1991) 100:10:1 and Staps (1990) - 250:10:3 or 100:10:2. The initial C:N:P ratio used in this study was 100:10:1 based upon the work by Harder et al. (1991) and Grundmann and Rehm (1991) which was applied specifically to biodegradation of diesel fuel. To achieve a C:N:P ratio of 100:10:1 based on an initial diesel fuel concentration of $3,000 \mathrm{mg} / \mathrm{L}, 5$ $\mathrm{mL}$ of the $\left(\mathrm{NH}_{4}\right)_{2} \mathrm{SO}_{4}$ solution and $5 \mathrm{~mL}$ of the $\mathrm{K}_{2} \mathrm{HPO}_{4}$ solution were added to the experimental reactors. The theoretical $\mathrm{NH}_{3}-\mathrm{N}$ and $\mathrm{PO}_{4}{ }^{3-}-\mathrm{P}$ concentrations in the reactor were $300 \mathrm{mg} / \mathrm{L}$ and $30 \mathrm{mg} / \mathrm{L}$ initially. The nitrogen and phosphorus concentrations were monitored from these initial levels throughout the experiments. However, the concentrations of nitrogen and phosphorus were not further amended during the experiments.

The microorganisms used in this study were provided by Solmar Corporation. Formulation L-104 is a proprietary consortium of 10 different mesophilic, spore-forming bacteria. This formulation is designed to degrade coal tars, diesel fuel, bunker oil, crude oil, creosote and pentachlorophenol in waste water and soil. The Solmar L-104 formulation is provided as a dry powder. Prior to use, the culture was hydrated at one gram of culture per 10 milliliters of deionized water. The formulation was soaked for 4 hours at room temperature without aeration or stirring. Once reconstituted the microbial population of the culture was measured in triplicate and found to contain $61,000,000$ colony forming units per milliliter (CFU/mL). The Solmar product specifications suggested that the culture be applied to the contaminated soil at a ratio of 10 milliliters of soaked solution to one kilogram of soil. Thus, each of the experimental reactors in this 
study received $0.5 \mathrm{~mL}$ of well-mixed, acclimated culture via a modified, open-tipped pipette.

Table 3.1 outlines the set of three experimental conditions designed to determine the oxygen enhancement method that most significantly affects the rate of diesel fuel degradation. The set of 3 experiments was performed 3 times in order to obtain a statistically significant amount of data and determine the reproducibility of the data. Repeatability data were generated from duplicate runs of each experimental condition.

Each bioreactor was monitored for $\mathrm{pH}$, temperature, microbial population and concentrations of diesel fuel, dissolved oxygen and nutrients over the course of the experiment. Table 3.2 was the sampling schedule for the experimentation. The soil was treated for eight days, which generally yielded a residual diesel concentration of less than $100 \mathrm{mg} / \mathrm{L}$. According to Bell et al. (1989), a residual diesel concentration of $100 \mathrm{ppm}$ has been set as a remediation goal for some contaminated soil sites in California. 
Table 3.1. Experimental Conditions Matrix.

\begin{tabular}{|c|c|c|c|c|c|c|}
\hline & & Experimental Factors & & & \\
\hline $\begin{array}{c}\text { Experimental } \\
\text { Condition }\end{array}$ & $\mathrm{H}_{2} \mathrm{O}_{2}$, mg total & Sparge, L/hr & Mixing & Slurry \% & pH Range & $\mathrm{T}$, ${ }^{\circ} \mathrm{C}$ \\
\hline Sparge/Stir & - & 1 & Moderate* & 10 & $6.5-8.5$ & 25 \\
\hline $\mathrm{H}_{2} \mathrm{O}_{2} /$ Stir & 50 and $100^{\dagger}$ & - & Moderate* & 10 & $6.5-8.5$ & 25 \\
\hline Stir & - & - & Moderate* & 10 & $6.5-8.5$ & 25 \\
\hline
\end{tabular}

* Moderate refers to the constant stirring rate achieved with air-driven magnetic stirrers using air regulated to $45 \mathrm{psig}$.

$\dagger$ A total of $50 \mathrm{mg} \mathrm{H} \mathrm{H}_{2} \mathrm{O}_{2}$ (10 mL of $5,000 \mathrm{mg} / \mathrm{L} \mathrm{H}_{2} \mathrm{O}_{2}$ solution) was added during the first experimental run; A total of $100 \mathrm{mg} \mathrm{H}_{2} \mathrm{O}_{2}\left(40 \mathrm{~mL}\right.$ of $2,500 \mathrm{mg} / \mathrm{L} \mathrm{H}_{2} \mathrm{O}_{2}$ solution) was added during the second and third experimental runs.

Table 3.2. Sampling Schedule.

\begin{tabular}{|c|c|c|c|c|c|c|c|}
\hline Day \#[ & Diesel], mg/L & {$[\mathrm{D} .0],. \mathrm{mg} / \mathrm{L}$} & Microbes, CFU/mL* & $\mathrm{T},{ }^{\circ} \mathrm{C}$ & $\mathrm{pH}$ & {$[\mathrm{N}], \mathrm{mg} / \mathrm{L}$} & {$[\mathrm{P}], \mathrm{mg} / \mathrm{L}$} \\
\hline 0 & $\mathrm{X}$ & $\mathrm{X}$ & $\mathrm{X}$ & $\mathrm{X}$ & $\mathrm{X}$ & $\mathrm{X}$ & $\mathrm{X}$ \\
\hline 1 & $\mathrm{X} \dagger$ & $\mathrm{X}$ & & $\mathrm{X}$ & $\mathrm{X}$ & & \\
\hline 2 & $\mathrm{X}$ & $\mathrm{X}$ & & $\mathrm{X}$ & $\mathrm{X}$ & $\mathrm{X}$ & $\mathrm{X}$ \\
\hline 3 & $\mathrm{X} \dagger$ & $\mathrm{X}$ & $\mathrm{X}$ & $\mathrm{X}$ & $\mathrm{X}$ & & \\
\hline 4 & $\mathrm{X}$ & $\mathrm{X}$ & & $\mathrm{X}$ & $\mathrm{X}$ & $\mathrm{X}$ & $\mathrm{X}$ \\
\hline 5 & $\mathrm{X} \dagger$ & $\mathrm{X}$ & & $\mathrm{X}$ & $\mathrm{X}$ & & \\
\hline 6 & $\mathrm{X}$ & $\mathrm{X}$ & & $\mathrm{X}$ & $\mathrm{X}$ & $\mathrm{X}$ & $\mathrm{X}$ \\
\hline 7 & $\mathrm{X} \dagger$ & $\mathrm{X}$ & & $\mathrm{X}$ & $\mathrm{X}$ & & \\
\hline 8 & $\mathrm{X}$ & $\mathrm{X}$ & $\mathrm{X}$ & $\mathrm{X}$ & $\mathrm{X}$ & $\mathrm{X}$ & $\mathrm{X}$ \\
\hline
\end{tabular}

* $\mathrm{CFU}=$ colony forming units and $\mathrm{CFU} / \mathrm{mL}$ refers to the number of colony forming units per milliliter of reactor volume.

$\dagger$ During the first experimental series, diesel samples were taken every other day as opposed to everyday as was done for the second and third experimental series. 


\subsection{Analytical Methods}

The soil used was characterized by the measurement of the bulk density, particle size distribution and soil $\mathrm{pH}$. The bulk density was determined by measuring the settled volume of a known weight soil sample slurried in water. The particle size distribution was determined by sieving the soil over six screens ranging from 10 to 80 U.S. Standard mesh. The soil $\mathrm{pH}$ was measured from a 10 percent solids slurry in deionized water.

The level of diesel fuel contamination of the soil slurries was determined by a modified version of EPA Method 8015. EPA Method 8015 is a testing protocol for nonhalogenated volatile organic compounds. For soils and slurries, this method involves gas chromatographic analysis of a solvent extract with a flame ionization detector (FID). EPA Method 8015 was modified in the use of a capillary column, which required reduced flow rates and the use of a make-up gas. A copy of EPA Method 8015 is provided in Appendix B (USEPA, 1986).

The solvent used for the soil and slurry extractions was 1,1,2trichlorotrifluoroethane (freon). A calibration curve was prepared for diesel fuel/freon standards in the range of 10 to $3,000 \mathrm{mg} / \mathrm{L}$. Table 3.3 is a list of the standards used in the gas chromatograph calibration.

The samples were quantified by total area determined from peak-to-peak integration of the main diesel fuel peaks. The standard samples were stored at $4^{\circ} \mathrm{C}$ in septum-sealed vials with minimal headspace. The standard samples were taken from the refrigerator just prior to injection and were returned to the refrigerator promptly after injection in order to minimize the chance of any volatile losses. A $2 \mu \mathrm{L}$ syringe was used 
for sample injection to the gas chromatograph. The syringe was purged with freon a minimum of 10 times prior to and after each diesel sample injection.

Table 3.3. Calibration Standards.

\begin{tabular}{|c|c|c|}
\hline Sample & Preparation & [Diesel], mg/L \\
\hline PD.1* & $5.0350 \mathrm{~g}$ diesel in $100 \mathrm{~mL}$ freon & 50,350 \\
\hline PD.2 & $0.6330 \mathrm{~g}$ diesel in $50 \mathrm{~mL}$ freon & 12,660 \\
\hline $\mathrm{A}$ & $3 \mathrm{~mL}$ PD. 1 in $50 \mathrm{~mL}$ freon & 3,021 \\
\hline B & $2 \mathrm{~mL}$ PD. 1 in $50 \mathrm{~mL}$ freon & 2,014 \\
\hline $\bar{C}$ & $1 \mathrm{~mL}$ PD. 1 in $50 \mathrm{~mL}$ freon & 1,007 \\
\hline$\overline{\mathrm{D}}$ & $700 \mu \mathrm{L}$ PD. 1 in $50 \mathrm{~mL}$ freon & 705 \\
\hline $\bar{E}$ & $400 \mu \mathrm{L}$ PD. 1 in $50 \mathrm{~mL}$ freon & 403 \\
\hline $\bar{F}$ & $100 \mu \mathrm{L}$ PD. 1 in $50 \mathrm{~mL}$ freon & 101 \\
\hline $\bar{G}$ & $200 \mu \mathrm{L}$ PD .2 in $50 \mathrm{~mL}$ freon & 51 \\
\hline$\overline{\mathrm{H}}$ & $40 \mu \mathrm{L}$ PD. 2 in $50 \mathrm{~mL}$ freon & 10 \\
\hline
\end{tabular}

* PD stands for primary dilution.

During the course of the experiment, $5 \mathrm{~mL}$ samples were taken from the reactors for diesel fuel quantification. The samples were extracted with $10 \mathrm{~mL}$ of freon, refrigerated at $4^{\circ} \mathrm{C}$ for a minimum of 30 minutes, then injected as a $1 \mu \mathrm{L}$ freon-phase sample into the gas chromatograph. The extraction was carried out in a stoppered, 500 $\mathrm{mL}$ Erlenmeyer flask by 30 minutes of rigorous mixing at $175 \mathrm{RPM}$ in a reciprocating shaker bath maintained between $18-20^{\circ} \mathrm{C}$.

The gas chromatograph analysis procedure previously described was used to determine the initial level of contamination in the prepared soil. Three separate samples of the prepared soil were extracted with freon and analyzed on the GC to establish the average initial diesel fuel contamination. A ratio of one gram of soil to $10 \mathrm{~mL}$ of freon was used in the first extraction procedure and a ratio of one gram of soil to $20 \mathrm{~mL}$ of freon was used in the other two extraction procedures. The amount of freon used in the extraction procedure was doubled to test for increased diesel extraction efficiency. No enhanced diesel extraction was observed with the use of the larger amount of freon. 
The results of the gas chromatograph analysis were converted from mg diesel per liter of freon as calibrated from the standards to mg diesel per liter of reactor slurry for the slurry samples and $\mathrm{mg}$ diesel per $\mathrm{kg}$ soil for the prepared soil samples. An example of these sample calculations is provided in Appendix A.

Microbial enumeration was carried out in triplicate using a standard plate count format. The total microbial population was determined on a yeast extract/dextrose/calcium carbonate (YDC) agar medium using a spread-plate technique (APHA and AWWA, 1985, and Methods of Soil Analysis, 1982). The standard glass plates were incubated at $28^{\circ} \mathrm{C}$ for 3 days. One milliliter reactor samples were taken using separate sterile pipettes and transferred to $9.0 \mathrm{~mL}$ of a sterile, buffered dilution blank.

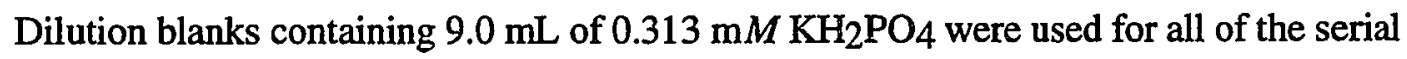
dilutions. Only plates with colony forming units between 30 and 300 were counted. A description of the media preparation and the spread plate technique are provided in Appendix C.

The dissolved oxygen (DO) concentration in the slurry reactors was determined using a YSI Model 57 Dissolved Oxygen Meter and a YSI Model 5739 probe. The DO probe was calibrated for temperature and salinity according to the manufacturer's instructions. At the time of monitoring, the DO probe was introduced through a large port in the reactor lid. The temperature of the slurry mixture was measured using a thermocouple integrated in the DO probe. A five minute equilibration time was allowed prior to recording the DO concentration and slurry temperature.

Aqueous nitrogen was measured as ammonia and aqueous phosphorous was measured as orthophosphate using color disk analysis kits available from Hach Company. For the nitrogen determination, $1.0 \mathrm{~mL}$ was pipetted from the reactor and diluted with 9.0 
$\mathrm{mL}$ of deionized water. For the phosphorus determination, $2.0 \mathrm{~mL}$ was pipetted from the reactor and diluted with $2.0 \mathrm{~mL}$ of deionized water. The nitrogen and the phosphorus samples were taken from the stirred reactors using modified $1.0 \mathrm{~mL}$ and $5.0 \mathrm{~mL}$ pipettes, respectively. The pipettes were modified with the tips cut off so that a representative siurry sample could be taken. Samples were stored in the refrigerator at $4^{\circ} \mathrm{C}$ in sealed test tubes until analysis.

The analysis of the water samples for $\mathrm{NH}_{3}-\mathrm{N}$ and $\mathrm{PO}_{4}^{3-}-\mathrm{P}$ was performed within 4 days of sampling, in accordance with USEPA standard of analysis within 28 days (Kopp and McKee, 1983). The proper preservation for these samples is cold storage at $4^{\circ} \mathrm{C}$ and acidification to $\mathrm{pH}<2$ (Kopp and McKee, 1983). The nitrogen and phosphorus samples from this experimentation were not acidified. However, by keeping the samples cool until analysis, biological changes were minimized; which is the main source of loss for the species in question.

For the nitrogen analysis, a $200 \mu \mathrm{L}$ sample of the above dilution was tested according to the procedures in the Hach kit. For the phosphorus analysis, a $500 \mu \mathrm{L}$ sample of the above dilution was tested according to the Hach procedure. The large dilution factors used in these analyses were required for use of the Hach kits which had testing limitations for $\mathrm{NH}_{3}-\mathrm{N}$ and $\mathrm{PO}_{4}{ }^{3-}$ of $0-3 \mathrm{mg} / \mathrm{L}$ and $0-50 \mathrm{mg} / \mathrm{L}$, respectively.

During the second and third experimental runs, due to the increased frequency of sampling, deionized water was added back to the reactors after samples were taken and measurements were made. By adding water back to the reactors, the reactor volumes were held constant, which is important since the residual diesel concentration data and the microbial population data were reported on a reactor volume basis. 


\subsection{Errors Associated with Analytical Methods}

The data detailing the errors associated with the gas chromatograph analysis are discussed in this section. The specific errors addressed in this section are: same sample/repeated injection error, day-to-day/same standard error and slurry reactor sampling error.

Table 3.4 presents the error associated with repeated injections of the same calibration standard on the same day. This table is a collection of data over the course of this study where a calibration standard was run at least 3 times in a row. The relative standard deviation ranges from 2.3 to 12 percent with an average of 7.2 percent. These data establish the error in the injection technique and gas chromatograph. This error was expected to be inversely proportionai to the standard concentration. Thus the error was expected to be high for the low concentration standards and low for the high concentration standards. However, the repeated injection error measured does not follow any trend relative to standard sample concentration.

Table 3.5 presents the data for the daily calibration standard runs on the gas chromatograph over the duration of each experimental run. The same calibration standard sample (C) containing $1,007 \mathrm{mg} / \mathrm{L}$ diesel fuel in freon was used to test day-today error and measure the consistency of the GC. This sample was injected daily prior to testing any other samples. The column labeled "\% error" represents the error percentage of an individual area relative to the average of all daily standard runs within a given experimental series. The ranges of error for Experimental Series \#1, \#2 and \#3 were: -17 to 26 percent, -8.8 to 24 percent and -8.7 to 8.2 percent, respectively. This daily standard error is a measure of fluctuations in the gas chromatograph from day to day. The averages of these day-to-day errors were $8.9,5.8$ and 4.6 percent, respectively, for 
Experimental Series \#1, \#2 and \#3. These errors are roughly equivalent to the injection error. The decreasing trend in this day-to-day error is probably an indication that this error is GC user related. As the user becomes more familiar with the GC operation and controls, the day-to-day error is likely to decrease. These errors associated with daily standard sample analyses are comparable to those reported by Peters et al. (1991) in the analysis of slurry-phase diesel fuel concentrations.

The results of external standard GC analysis can be normalized with respect to the daily standard runs. By dividing each of the sample analyses on a given day by the standard run on that day, the need to report this day-to-day error can be eliminated and deviations in the data can be eliminated. The results of this study were not normalized with respect to the daily standard runs. The data required to perform such a normalization is included in Appendix D. 
Table 3.4. Injection Error.

\begin{tabular}{|c|c|c|c|c|c|}
\hline Run & Date & Sample & [Diesel], mg/L & Total Area & Average \pm S.D. $*$ (R.S.D. $) \dagger$ \\
\hline 200 & $2 / 9$ & $\mathrm{C}$ & 1,007 & 334,720 & \\
\hline 201 & $2 / 9$ & $\mathrm{C}$ & 1,007 & 408,610 & $386,140 \pm 44,649(11.6 \%)$ \\
\hline 202 & $2 / 9$ & $\mathrm{C}$ & 1,007 & 415,090 & \\
\hline 203 & $2 / 9$ & $\bar{B}$ & 2,014 & 744,240 & \\
\hline 204 & $2 / 9$ & $\mathrm{~B}$ & 2,014 & 719,820 & $695,717 \pm 64,070(9.2 \%)$ \\
\hline 205 & $2 / 9$ & $\mathrm{~B}$ & 2,014 & 623,090 & \\
\hline 208 & $2 / 10$ & $\mathrm{~F}$ & 101 & 24,145 & \\
\hline 209 & $2 / 10$ & $\mathrm{~F}$ & 101 & 29,246 & $27,300 \pm 2,757(10.1 \%)$ \\
\hline 210 & $2 / 10$ & $\bar{F}$ & 101 & 28,509 & \\
\hline 224 & $2 / 11$ & $\overline{\mathrm{D}}$ & 705 & 328,580 & \\
\hline 225 & $2 / 11$ & $\mathrm{D}$ & 705 & 375,180 & $358,930 \pm 26,306(7.3 \%)$ \\
\hline 226 & $2 / 11$ & $\mathrm{D}$ & 705 & 373,030 & \\
\hline 227 & $2 / 12$ & $\mathrm{~A}$ & 3,021 & $1,061,000$ & \\
\hline 228 & $2 / 12$ & $\bar{A}$ & 3,021 & $1,154,800$ & $1,142,967 \pm 76,737(6.7 \%)$ \\
\hline 229 & $2 / 12$ & $\mathrm{~A}$ & 3,021 & $1,213,100$ & \\
\hline 393 & $4 / 13$ & $\mathrm{C}$ & 1,007 & 264,780 & \\
\hline 394 & $4 / 13$ & $\bar{C}$ & 1,007 & 249,230 & $257,753 \pm 7,882(3.1 \%)$ \\
\hline 395 & $4 / 13$ & $\mathrm{C}$ & 1,007 & 259,250 & \\
\hline 483 & $5 / 6$ & $\bar{A}$ & 3,021 & 622,590 & \\
\hline 484 & $5 / 6$ & $\bar{A}$ & 3,021 & 732,830 & $716,825 \pm 64,779(9.0 \%)$ \\
\hline 485 & $5 / 6$ & A & 3,021 & 769,950 & \\
\hline 486 & $5 / 6$ & A & 3,021 & 741,930 & \\
\hline 551 & $5 / 20$ & $\bar{C}$ & 1,007 & 223,040 & \\
\hline 552 & $5 / 20$ & $\bar{C}$ & 1,007 & 228,480 & $221,805 \pm 5,088(2.3 \%)$ \\
\hline 553 & $5 / 20$ & $\mathrm{C}$ & 1,007 & 218,240 & \\
\hline 554 & $5 / 20$ & $\mathrm{C}$ & 1,007 & 217,460 & \\
\hline 560 & $5 / 22$ & $\mathrm{C}$ & 1,007 & 302,420 & \\
\hline 561 & $5 / 22$ & $\mathrm{C}$ & 1,007 & 306,230 & $310,313 \pm 20,033(6.4 \%)$ \\
\hline 562 & $5 / 22$ & $\mathrm{C}$ & 1,007 & 339,250 & \\
\hline 563 & $5 / 22$ & $\mathrm{C}$ & 1,007 & 293,350 & \\
\hline 655 & $6 / 24$ & $\mathrm{C}$ & 1,007 & 323,610 & \\
\hline 656 & $6 / 24$ & $\mathrm{C}$ & 1,007 & 322,190 & $334,740 \pm 20,520(6.1 \%)$ \\
\hline 657 & $6 / 24$ & $\mathrm{C}$ & 1,007 & 358,420 & \\
\hline
\end{tabular}

* S.D. refers to standard deviation.

$\dagger$ R.S.D. refers to the relative standard deviation percentage, the ratio of the standard deviation to the average as a percentage. 
Table 3.5. Daily Standard Runs on Gas Chromatograph.

Experiment \#1

\begin{tabular}{|c|c|r|r|}
\hline Date & GC Run\# & Total Area & \% Error \\
\hline $4 / 21$ & 419 & 266,470 & 14.0 \\
\hline $4 / 22$ & 423 & 294,650 & 26.0 \\
\hline $4 / 23$ & 428 & 222,000 & -5.1 \\
\hline $4 / 24$ & 432 & 207,670 & -11.2 \\
\hline $4 / 24$ & 433 & 228,920 & -2.1 \\
\hline $4 / 26$ & 434 & 244,260 & 4.5 \\
\hline $4 / 28$ & 446 & 193,060 & -17.4 \\
\hline $4 / 28$ & 447 & 231,180 & -1.1 \\
\hline $5 / 2$ & 463 & 222,220 & -5.0 \\
\hline $5 / 3$ & 465 & 227,840 & -2.6 \\
\hline
\end{tabular}

Experiment \#2

\begin{tabular}{|c|c|r|r|}
\hline Date & GC Run\# & Total Area & \% Error \\
\hline $5 / 8$ & 493 & 268,680 & 1.5 \\
\hline $5 / 9$ & 497 & 328,830 & 24.2 \\
\hline $5 / 9$ & 498 & 249,860 & -5.6 \\
\hline $5 / 10$ & 501 & 259,890 & -1.8 \\
\hline $5 / 11$ & 518 & 241,460 & -8.8 \\
\hline $5 / 12$ & 520 & 259,120 & -2.1 \\
\hline $5 / 13$ & 526 & 267,880 & 1.2 \\
\hline $5 / 15$ & 534 & 248,820 & -6.0 \\
\hline $5 / 17$ & 538 & 270,410 & 2.1 \\
\hline $5 / 18$ & 543 & 252,720 & -4.6 \\
\hline
\end{tabular}

Experiment \#3

\begin{tabular}{|c|c|r|r|}
\hline Date & GC Run\# & Total Area & \% Error \\
\hline $5 / 25$ & 575 & 317,090 & -8.7 \\
\hline $5 / 26$ & 582 & 319,070 & -8.2 \\
\hline $5 / 27$ & 589 & 333,130 & -4.1 \\
\hline $5 / 27$ & 590 & 335,280 & -3.5 \\
\hline $5 / 28$ & 596 & 344,810 & -0.8 \\
\hline $5 / 29$ & 601 & 340,420 & -2.0 \\
\hline $5 / 30$ & 605 & 365,500 & 5.2 \\
\hline $6 / 1$ & 608 & 374,940 & 7.9 \\
\hline $6 / 1$ & 609 & 370,100 & 6.5 \\
\hline $6 / 2$ & 614 & 348,850 & 0.4 \\
\hline $6 / 3$ & 619 & 352,930 & 1.6 \\
\hline $6 / 4$ & 626 & 375,810 & 8.2 \\
\hline $6 / 6$ & 632 & 338,770 & -2.5 \\
\hline
\end{tabular}


Table 3.6 presents data addressing the error involved in taking slurry samples from the experimental reactors and the error involved in the freon extraction process. In each of the two studies presented, five separate samples were taken from a single stirred reactor one after another. Each sample was extracted with freon individually as described in the experimental procedure section of Chapter 3. The averages, standard deviation and relative standard deviation of each five sample series are listed. The data suggest that the relative standard deviation of the sampling/extraction process error is 5.3 percent.

Table 3.6. Extraction Error.

\begin{tabular}{|c|c|c|c|}
\hline Run \# & Sample & Total Area & Average \pm S.D. (R.S.D.) \\
\hline $646 / 651$ & $33-6$ & 228,525 & \\
\hline 647 & $33-7$ & 247,300 & \\
\hline 648 & 33-8 & 251,690 & $235,177 \pm 14,784(6.3 \%)$ \\
\hline 649 & $33-9$ & 233,370 & \\
\hline 650 & $33-10$ & 215,000 & \\
\hline Run \# & Sample & Total Area & Average \pm S.D. (R.S.D.) \\
\hline 658 & $33-11$ & 197,250 & \\
\hline 659 & $33-12$ & 198,570 & \\
\hline 661 & $33-13$ & 185,440 & $198,306 \pm 8,515(4.3 \%)$ \\
\hline$\overline{662}$ & 33-14 & 209,010 & \\
\hline 663 & $33-15$ & 201,260 & \\
\hline
\end{tabular}

The average sampling/extraction error was expected to be greater than 5.3 percent. The reactors were not perfectly stirred. Difficulties were expected in obtaining a representative sample from the heterogeneous mixture. Errors associated with sampling of experimental systems have been noted in the literature. Dasappa et al. (1988) and Namkoong et al. (1988) have reported the use of sacrificial experimental designs as opposed to sampling single systems due to large sampling errors related to slurry-phase studies. However the resulting error of 5.3 percent is low. This indicates the validity of 
the single system sampling method, especially in relation to the other errors involved in this experimentation.

The calibration data for each experimental series is given in Appendix $\mathrm{E}$.

\subsection{Equipment and Materials}

Gas chromatograph analysis was performed on a Hewlett-Packard (HP) Model 5890A gas chromatograph equipped with an FID. The capillary column used was a J\&W Scientific DB5 phase with a film thickness of $0.25 \mu \mathrm{m}$ and a length of $30 \mathrm{~m}$. A $5 \mathrm{~m}$ silanized, fused silica guard column was used. Integration was performed using a HP 3392A integrator. Calibration was based on total area integrated valley-to-valley over the major diesel fuel components. Manual injections were made using a Hamilton \#7102 positive displacement syringe.

Separations were obtained by splitless injections of a $1-\mu \mathrm{L}$ sample with the following temperature program: begin at $40^{\circ} \mathrm{C}$, hold for 1 minute, raise to $240^{\circ} \mathrm{C}$ at $4^{\circ} \mathrm{C} / \mathrm{min}$, no hold, raise to $310^{\circ} \mathrm{C}$ at $50^{\circ} \mathrm{C} / \mathrm{min}$ and hold for 10 minutes. The injector temperature was held at $310^{\circ} \mathrm{C}$ and the detector at $340^{\circ} \mathrm{C}$. The inlet purge was off at 0.01 minutes and on at 1 minute. The carrier gas was helium $(\mathrm{He})$ metered to a linear flow rate of $26 \mathrm{~cm} / \mathrm{s}$ and a volumetric flow rate of $1 \mathrm{~mL} / \mathrm{min}$. The He flow was regulated to 40 psig and a column head pressure of $15 \mathrm{psig}$. The make-up gas, nitrogen, was regulated to $40 \mathrm{psig}$ and held at a flowrate of $30 \mathrm{~mL} / \mathrm{min}$. The hydrogen flow rate was also 30 $\mathrm{mL} / \mathrm{min}$ and the tank regulated to $17 \mathrm{psig}$. The air flowrate was set to $300 \mathrm{~mL} / \mathrm{min}$ with the supply regulated to 35 psig.

The slurry pH was measured using a Corning Scientific Instruments Model 7 temperature compensating pH meter with a Corning General Purpose Combination electrode. The $\mathrm{pH}$ electrode was calibrated using two standard buffers, either the 
combination of $\mathrm{pH} 4.00$ and 7.00 or the combination of $\mathrm{pH} 7.00$ and 10.00 . The reactor $\mathrm{pH}$ was adjusted only if the $\mathrm{pH}$ drifted outside the range of 6.5 to 8.5 .

A Precision Scientific Reciprocal Shaking Bath Model 50 was used in the diesel fuel extractions. Fisher Scientific air-driven, turbine, magnetic stirrers and large (1/2 inch in diameter by 3 inches in length), Teflon-coated, magnetic stir bars were used to agitate the soil/water mixtures. The air supplied to the stir plates was regulated to $45 \mathrm{psig}$. A Precision Thelco Model 4 Incubator was used to incubate the microorganisms.

The glass reactors were 32 ounce, straight-walled jars with the screw tops cut off, supplied by Quorpak. The reactor covers were size 15 rubber stopper. The main sample port was plugged with a size 7 stopper when not in use. Air was fed into the sparged reactor through a piece of $1 / 16$ inch stainless steel tubing. The tubing was modified with a crimped end and two- 0.0175 inch diameter, drilled holes to provide fine bubbles to the slurry mixture.

The soil used in this study was supplied by San Carlos Nursery Supply Company, San Carlos, California, under the classification of "top soil." Table 3.7 lists the range of particle sizes in the soil. According to standard size range limits given by Friedman and Sanders (1978), the soil used in this experimentation is 68 percent sand and 32 percent silt and clay. According to the U.S. Bureau of Soils triangular chart for textural classification, Truitt (1983), the experimental soil is termed a sandy loam. The $\mathrm{pH}$ of a 10 percent slurry of the soil in water was 7.78 . The bulk density of the soil was 1.07 $\mathrm{g} / \mathrm{mL}$.

The diesel fuel used was Grade \#2 obtained from the Exxon Service Station at the intersection of Senter and Tully in San Jose, California. The specifics, supplier, grade 
and lot number, on the various chemicals used in this experimentation are given in Table 3.8 .

Table 3.7. Experimental Soil Classification.

\begin{tabular}{|c|c|c|}
\hline U.S. Standard Sieve No. Range & Particle Size Range $(\mathrm{mm})$ & Weight \% in Range \\
\hline$>10$ & $>2.000$ & 0.00 \\
\hline $10-20$ & $2.000-0.841$ & 0.61 \\
\hline $20-40$ & $0.841-0.420$ & 13.52 \\
\hline $40-60$ & $0.420-0.250$ & 15.02 \\
\hline $60-80$ & $0.250-0.177$ & 11.50 \\
\hline $80-100$ & $0.177-0.149$ & 7.66 \\
\hline $100-200$ & $0.149-0.074$ & 19.39 \\
\hline $200-400$ & $0.074-0.037$ & 16.94 \\
\hline$<400$ & $<0.037$ & 14.90 \\
\hline
\end{tabular}

Table 3.8. Chemicals List.

\begin{tabular}{|c|c|c|c|c|}
\hline Chemical & Formula & Supplier & Grade & Lot \# \\
\hline Dipotassium Hydrogen Phosphate & $\mathrm{K}_{2} \mathrm{HPO}_{4}$ & Spectrum & Reagent ACS & $57162 \mathrm{A4}$ \\
\hline Ammomium Sulfate & $\left(\mathrm{NH}_{4}\right)_{2} \mathrm{SO}_{4}$ & Baker & Reagent & 25167 \\
\hline Hydrogen Peroxide, $3 \%$ & $\mathrm{H}_{2} \mathrm{O}_{2}$ & Fisher & Certified & 920117 \\
\hline Calcium Carbonate & $\mathrm{CaCO}_{3}$ & Baker & Reagent & 23657,28081 \\
\hline Dextrose & $\mathrm{C}_{6} \mathrm{H}_{12} \mathrm{O}_{6}$ & Fisher & Certified & 926468 \\
\hline Sulfuric Acid & $\mathrm{H}_{2} \mathrm{SO}_{4}$ & Fisher & Reagent & FL-O5-1290 \\
\hline Hydrochloric Acid & $\mathrm{HCl}$ & Fisher & Reagent ACS & 905856 \\
\hline Agar & & Difco & Certified & $0140-01$ \\
\hline Freon & $\mathrm{Cl}_{2} \mathrm{CF} \cdot \mathrm{CClF}_{2}$ & Du Pont & Precision & $237 \mathrm{~A}$ \\
\hline Freon & $\mathrm{Cl}_{2} \mathrm{CF} \cdot \mathrm{CClF}_{2}$ & Fisher & Optima & 916275 \\
\hline Diesel Fuel & & Exxon & $\# 2$ & 122392 \\
\hline Yeast Extract & & Difco & Certified & 773434 \\
\hline Acetone & $\mathrm{C}_{3} \mathrm{H}_{6} \mathrm{O}$ & Fisher & Certified & 920338 \\
\hline
\end{tabular}

All of the glassware used in this experimentation was cleaned by hand by the following procedure: (1) washed with soap and warm water, (2) rinsed with deionized water, (3) acetone rinsed and (4) dried with filtered, compressed air. The gas chromatograph syringe was flushed with freon before and after each injection. 


\section{CHAPTER 4. EXPERIMENTAL RESULTS AND DISCUSSION}

\subsection{Introduction}

Experimental Run \#1 took place between 20 April and 28 April 1993, Experimental Run \#2 between 7 May and 15 May 1993 and Experimental Run \#3 between 22 May and 30 May 1993. The data observed in these three experimental runs are presented and discussed in this chapter. In each experimental run, the system parameters of the three reactor conditions were monitored for 8 days. The system parameters studied were diesel fuel concentration, dissolved oxygen concentration, microbial populations, nutrient concentrations, $\mathrm{pH}$, temperature and volatile emissions. The results are grouped by experimental run. The results are discussed individually and in relation to other parameters of the investigation.

\subsection{Diesel Degradation}

The diesel fuel degradation data are reported and discussed in this section. All three experimental systems, Sparge/Stir, $\mathrm{H}_{2} \mathrm{O}_{2} /$ Stir and Stir, result in greater than 90 percent reduction in diesel fuel concentration in 8 days. Initial diesel fuel levels in the reactors ranged from $4,563 \mathrm{mg}$ of diesel per liter of slurry $(\mathrm{mg} / \mathrm{L})$ to $2,621 \mathrm{mg} / \mathrm{L}$ and final levels ranged from $225 \mathrm{mg} / \mathrm{L}$ to nondetectable. In most cases, half of the initial diesel fuel concentration present was degraded in less than 2 days. The average diesel reductions at 2, 4, 6 and 8 days for all three conditions and the three experimental series were $65,82,88$ and 97 percent, respectively. The degradation rate falls off as the diesel fuel concentration declines.

Table 4.1 lists the diesel concentration versus time for Experimental Series \#1. During this experimental run, slurry samples for diesel extraction were taken every other 
day. Figure 4.1 is a presentation of the data in Table 4.1 as percentage diesel reduction over time.

Table 4.1. Diesel Degradation Data, Experiment \#1.

\begin{tabular}{|r|r|r|r|}
\hline & \multicolumn{3}{|c|}{ Diesel Concentration, mg/L* } \\
\hline Time, days & Sparge/Stir & $\mathrm{H}_{2} \mathrm{O}_{2} /$ Stir & \multicolumn{1}{c|}{ Stir } \\
\hline 0 & 4,526 & 4,563 & 4,184 \\
\hline 2 & 788 & 1,241 & 981 \\
\hline 4 & 193 & 401 & 477 \\
\hline 6 & 154 & 78 & 251 \\
\hline 8 & 45 & 95 & 61 \\
\hline Fefers to diesel concentration in the slurry, as milligrams \\
diesel per liter of slurry
\end{tabular}

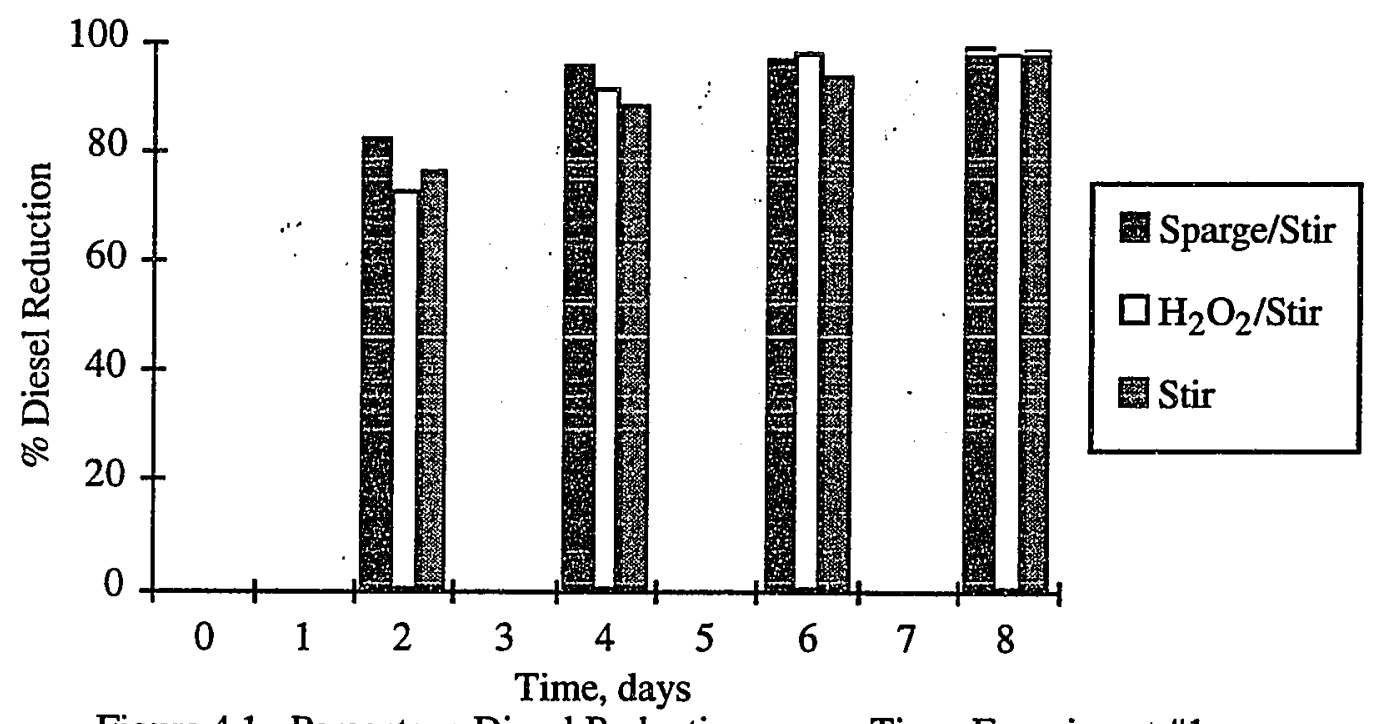

Figure 4.1. Percentage Diesel Reduction versus Time, Experiment \#1.

After two days of treatment, the diesel fuel concentration was reduced by more than 70 percent in each of the experimental conditions tested. The reductions in diesel fuel concentration between Day 4 and Day 6 and between Day 6 and Day 8 are small relative to the total initial diesel fuel concentration. However, as can be seen in the data provided in Table 4.1, these reductions represent between 20 and 80 percent declines 
relative to the preceding day's level. By Day 8, each of the reactors in Experimental Series \#1 achieved better than 98 percent diesel fuel reduction.

The Sparge/Stir experimental condition resulted in the greatest initial degradation. This increased initial degradation may have been due to the readily available form of the oxygen amendment or enhanced mixing as a result of the sparging.

However the difference between the experimental conditions declines by Day 6 . By Day 8, each of the experimental conditions had effected equivalent diesel degradation. Although the differences are small, the trend in the data for Experimental Series \#1 suggests the following order for degradation effectiveness: Sparge/Stir $>\mathrm{H}_{2} \mathrm{O}_{2} / \mathrm{Stir}>$ Stir.

For the $\mathrm{H}_{2} \mathrm{O}_{2} /$ Stir reactor; between Day 6 and Day 8 , the measured diesel fuel concentration rose by 22 percent. This erroneous datum is an indication of the errors involved in the sampling and analysis procedure.

Similarly rapid degradation was observed for the three reactors in Experimental Series \#2. The diesel degradation data for Experiment \#2 are provided in Table 4.2 and Figure 4.2. More data are available for analysis in Experimental Series \#2 due to the daily sampling. 
Table 4.2. Diesel Degradation Data, Experiment \#2.

\begin{tabular}{|r|r|r|r|}
\hline & \multicolumn{3}{|c|}{ Diesel Concentration, $\mathrm{mg} / \mathrm{L}$} \\
\hline Time, days & Sparge/Stir & $\mathrm{H}_{2} \mathrm{O}_{2} /$ Stir & \multicolumn{1}{c|}{ Stir } \\
\hline 0 & 3,166 & 3,538 & 2,644 \\
\hline 1 & 980 & 2,129 & 2,899 \\
\hline 2 & 1,114 & 1,170 & 1,556 \\
\hline 3 & 259 & 711 & 704 \\
\hline 4 & 250 & 704 & 611 \\
\hline 5 & 93 & 341 & 224 \\
\hline 6 & 58 & 217 & 190 \\
\hline 7 & 2 & 159 & 86 \\
\hline 8 & 0 & 121 & 65 \\
\hline
\end{tabular}

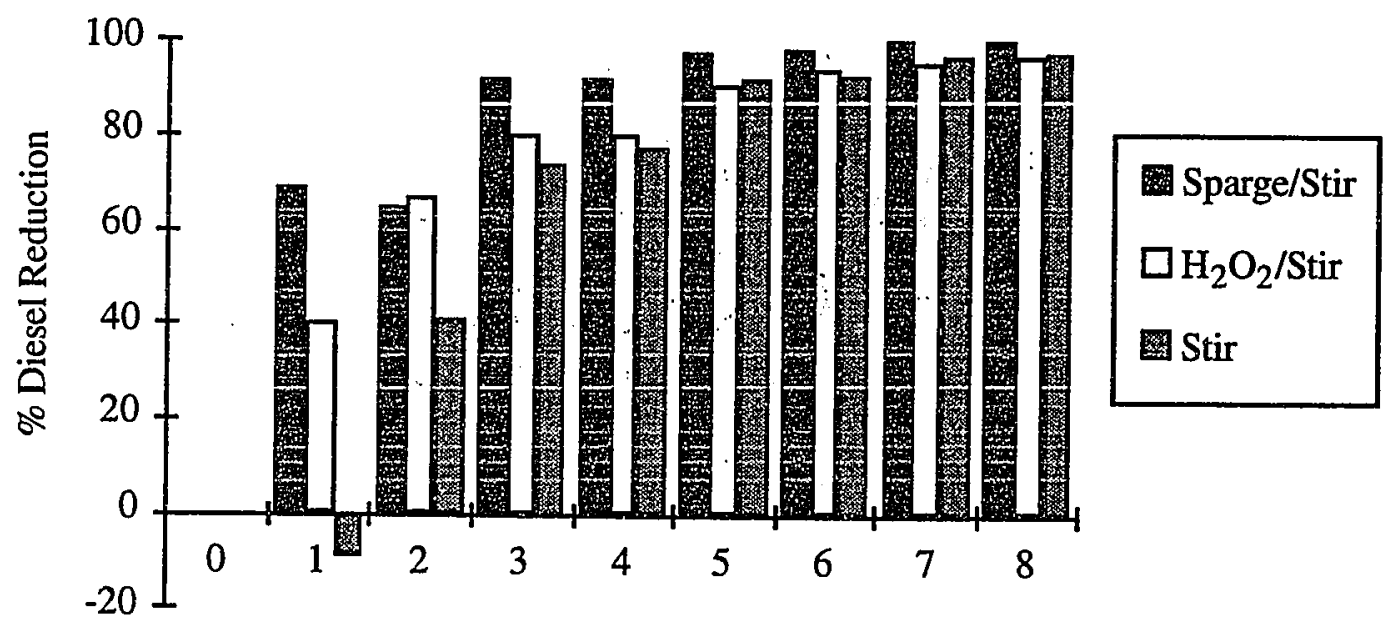

Time, days

Figure 4.2. Percent Diesel Reduction versus Time, Experiment \#2.

As in Experimental Series \#1, the Sparge/Stir reactor of Experimental Series \#2 showed the most effective initial diesel fuel degradation. The Sparge/Stir reactor achieved the largest reduction at most of the time points. However the differences between the experimental conditions declined over the 8-day period. The general trend of 
the data points to the following diesel degradation hierarchy for Experimental Series \#2: Sparge/Stir $>\mathrm{H}_{2} \mathrm{O}_{2} /$ Stir $>$ Stir.

More variation was observed in the data from Experimental Series \#2 than with the data from Experimental Series \#1. The Sparge/Stir reactor showed an increase in diesel concentration going from Day 1 sampling to Day 2 sampling. Between Day 3 and Day 4, negligible changes in diesel fuel concentration were observed in all three reactors. Errors in sampling, extraction and/or external standard GC analysis are possible explanations for these discrepancies.

In Experimental Series \#3, as in the previous experimental series, nearly all of the diesel fuel was degraded over the 8-day period. The diesel reduction data for Experiment $\# 3$ are provided in Table 4.3 and Figure 4.3. Although the degradation was as complete as in the previous series, the degradation was slower in Experimental Series \#3.

Table 4.3. Diesel Degradation Data, Experiment \#3.

\begin{tabular}{|r|r|r|r|}
\hline & \multicolumn{3}{|c|}{ Diesel Concentration, mg/L } \\
\hline Time, days & Sparge/Stir & $\mathrm{H}_{2} \mathrm{O}_{2}$ /Stir & \multicolumn{1}{c|}{ Stir } \\
\hline 0 & 2,987 & 2,621 & 2,760 \\
\hline 1 & 1,788 & 1,885 & 1,510 \\
\hline 2 & 1,416 & 913 & 1,181 \\
\hline 3 & 684 & 878 & 759 \\
\hline 4 & 264 & 793 & 1,319 \\
\hline 5 & 82 & 2,058 & 1,242 \\
\hline 6 & 132 & 715 & 1,380 \\
\hline 7 & 0 & 137 & 565 \\
\hline 8 & 103 & 112 & 225 \\
\hline
\end{tabular}




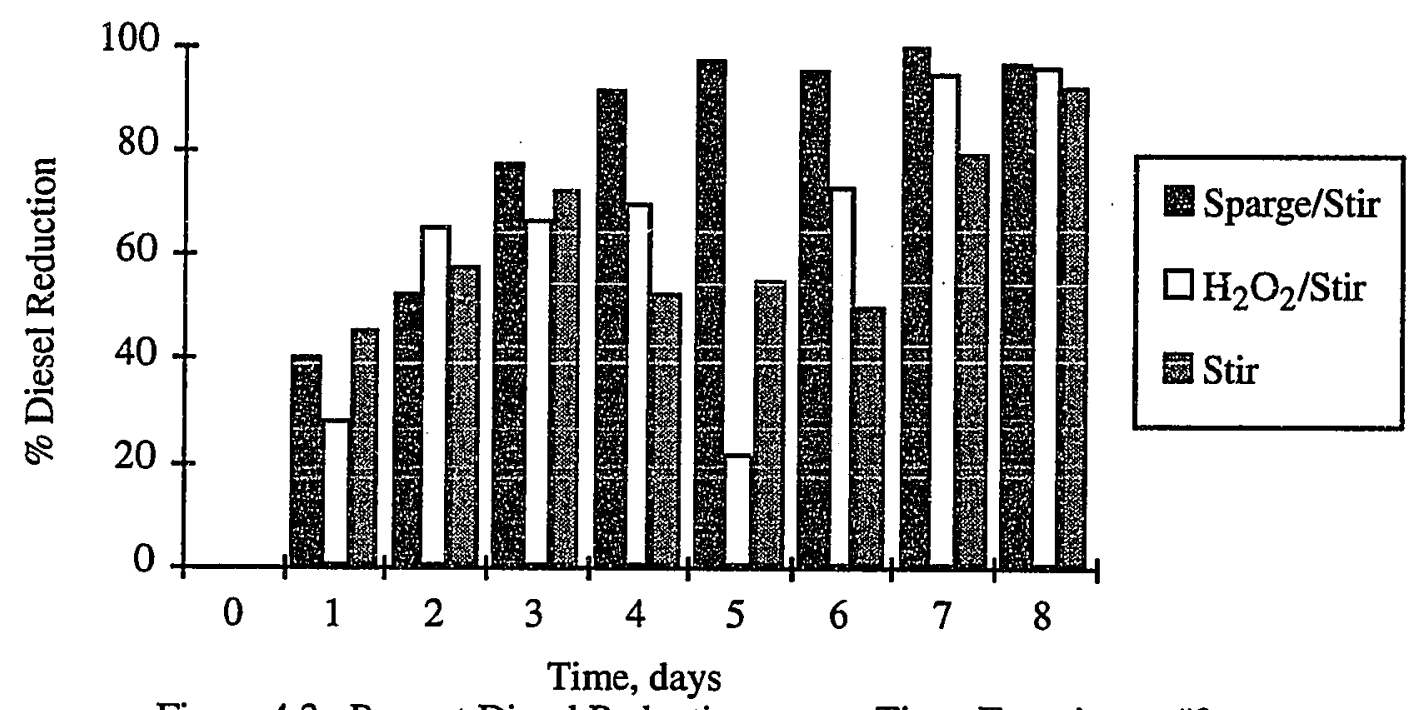

Figure 4.3. Percent Diesel Reduction versus Time, Experiment \#3.

The general trend in the diesel degradation data for Experimental Series \#3 was Sparge/Stir $>\mathrm{H}_{2} \mathrm{O}_{2} /$ Stir $>$ Stir. The Sparge/Stir reactor was more effective than the other conditions. The small difference in reduction trends between the $\mathrm{H}_{2} \mathrm{O}_{2} / \mathrm{Stir}$ and Stir reactors was probably negligible.

The most experimental variance occurred with Experimental Series \#3. The reason for the additional variance is uncertain. Experimental Series \#3 was an exact repeat of Experimental Series \#2. The $\mathrm{H}_{2} \mathrm{O}_{2} /$ Stir reactor in Experimental Series \#3 showed a steady diesel fuel reduction through most of the 8-day period. However, on Day 5, the diesel fuel measured was 160 percent higher than the Day 4 measurement and only 21 percent less than the initial concentration measured on Day 0 . There is no single source of error that could be attributed to this large variance. The high level of diesel measured for the $\mathrm{H}_{2} \mathrm{O}_{2} / \mathrm{Stir}$ condition does not accurately reflect the diesel concentration in the reactor on Day 5. 
Between Day 4 and Day 6, sampling of the Stir reactor showed a constant diesel fuel concentration that was increased from the Day 3 measurement. On Day 4 the diesel fuel concentration was measured as $1,319 \mathrm{mg} / \mathrm{L}$, which is an increase of 74 percent from the Day 3 sampling. The measured diesel fuel concentration within the Stir reactor was constant at an average increased level of $1,311 \mathrm{mg} / \mathrm{L}$ for Day 5 and Day 6 sampling. On Day 7 , the measured concentration fell by 59 percent to $565 \mathrm{mg} / \mathrm{L}$. The level on Day 7 is consistent with the trend occurring on Day 0 through Day 3. The increased, constant diesel fuel levels measured on Day 4, 5 and 6 cannot be explained by any single source of experimental error.

The Sparge/Stir reactor sampling also showed some variability in Experimental Series \#3. Steady degradation was observed through Day 5 of the experiment. On Day 6 , 7 and 8 , the measured diesel concentration fluctuated. The measured diesel concentration on Day 6 was 61 percent greater than on Day 7. On Day 7, no diesel was detected in the sample. Finally on Day 8, the measured level was up 100 percent from Day 7 sampling. The fluctuating data are most likely due to a combination of errors.

The diesel fuel degradation data were analyzed to see if the results for each oxygen addition method were significantly different. The measured errors involved with this investigation are the injection error (average of 7.2 percent), the daily standard error (averages range from 4.6 to 8.9 percent) and the extraction error (average of 5.2 percent). The \pm 7.2 percent corresponding to the same sample, repeated injection error was applied to the degradation data for each experimental condition in each experimental series. Each data point and its respective error range were compared to the data and error range for the other two reactors on a given day. The 7.2 percent error results in common error ranges (overlap) on 1 of 5 data points in Experimental Series \#1, 5 of 9 data points in Experimental Series \#2 and 4 of 9 data points in Experimental Series \#3. Overall, the 
application of the 7.2 percent error results in overlapping on 43 percent of the diesel degradation data points taken.

Upon application of the 7.2 percent error, the Sparge/Stir reactor shows overlapping on 7 of the 23 total data points, or 30 percent of the data recorded. The $\mathrm{H}_{2} \mathrm{O}_{2}$ /Stir shows overlapping on 9 of the 23 total data points, or 39 percent of the data. The Stir reactors show overlapping data on 6 of the 23 data points, or 26 percent of the data. More than 50 percent of the data for each experimental condition show that the differences in the diesel degradation is more significant than the 7.2 percent error.

Despite being prepared from the same batch of bulk contaminated soil, the measured initial diesel fuel concentrations showed variation. The initial concentrations of diesel fuel ranged from 4,184 to $4,526 \mathrm{mg} / \mathrm{L}$ with an average of $4,424 \mathrm{mg} / \mathrm{L}$ for Experimental Series \#1, 2,644 to $3,538 \mathrm{mg} / \mathrm{L}$ with an average of $3,116 \mathrm{mg} / \mathrm{L}$ for Experimental Series \#2 and 2,621 to 3,202 mg/L with an average of 2,789 $\mathrm{mg} / \mathrm{L}$ for Experimental Series \#3. This variation represents 4.7, 14 and 6.6 percent from the average for Experimental Series \#1, \#2 and \#3, respectively. Bulk soil heterogeneity is largely responsible for the variance. Bulk soil sample testing showed concentration differences as great as 50 percent despite thorough mixing in the preparation and sampling of the soil.

The average initial diesel fuel concentration showed a decreasing trend going from Experimental Series \#1 to Experimental Series \#3. Bulk soil heterogeneity could explain some of the variation in the average initial diesel fuel concentrations.

Volatilization and indigenous microbial degradation could also explain some changes in diesel fuel levels within the bulk soil. However volatilization and biodegradation were minimized by the sealed, cold storage of the bulk soil. 


\subsection{Degradation Kinetics}

The results from the first order kinetics regressions are provided in this section. The kinetic parameters describing the diesel fuel degradation under the experimental conditions examined were estimated based on a first order kinetic model. The diesel concentration versus time data for the three experiments were fit using the Exponential Model in Cricket Graph version 1.3, which is of the form:

$$
[\text { Diesel }]=[\text { Diesel }]_{0} 10^{-k t}
$$

where [Diesel] is Diesel Concentration in $\mathrm{mg} / \mathrm{L}$

[Diesel] $]_{0}$ is the initial Diesel Concentration in $\mathrm{mg} / \mathrm{L}$

$t$ is Time in days

$k$ is the first order rate constant in time $e^{-1}$.

The results of the first order kinetic model regression are given in Table 4.4.

Table 4.4. Kinetic Parameters.

\begin{tabular}{|c|c|c|c|c|c|}
\hline Experiment\#1 & {$[\text { Diesel }]_{\mathrm{m}}, \mathrm{mg} / \mathrm{L}^{*}$} & {$[\text { Diesel }]_{\mathrm{o}}, \mathrm{mg} / \mathrm{L}^{* *}$} & $\mathrm{k}$, days $^{-1}$ & $\mathrm{t}_{1 / 2}$, days & $\mathrm{R}^{2}$ \\
\hline Sparge/Stir & 4,526 & 3009.6 & 0.23570 & 1.27717 & 0.947 \\
\hline $\mathrm{H}_{2} \mathrm{O}_{2} /$ Stir & 4,563 & 3615.3 & 0.22824 & 1.31892 & 0.929 \\
\hline Stir & 4,184 & 3533.9 & 0.21323 & 1.41176 & 0.977 \\
\hline Experiment\#2 & {$[\text { Diesel }]_{m}, \mathrm{mg} / \mathrm{L}^{*}$} & {$[\text { Diesel }]_{0}, \mathrm{mg} / \mathrm{L}^{* *}$} & $\mathrm{k}$, days ${ }^{-1}$ & $t_{1} 12$, days & $R^{2}$ \\
\hline Sparge/Stirt & 3,166 & 2692.4 & 0.28235 & 106616 & $\frac{\Lambda^{2}}{0.956}$ \\
\hline $\mathrm{H}_{2} \mathrm{O}_{2} / \mathrm{Stir}$ & 3,538 & 3093.5 & 0.18378 & 1.63799 & 0.985 \\
\hline Stir & 2,644 & 3680.6 & 0.22241 & 1.35349 & 0.976 \\
\hline Experiment\#3 & {$[\text { Diesel }]_{\mathrm{m}} \mathrm{mg} / \mathrm{L}^{*}$} & Diesell $l_{0} \mathrm{mg} / \mathrm{L}^{* *}$ & $\mathrm{k}$, days ${ }^{-1}$ & $t_{10}$, davs & $R^{2}$ \\
\hline Sparge/Stir $\dagger$ & 2.987 & 26397 & 0.21344 & 141037 & $\frac{\Lambda^{2}}{0.871}$ \\
\hline $\mathrm{H}_{2} \mathrm{O}_{2} /$ Stir & 2,621 & 2848.7 & 0.14559 & 2.06766 & 0.674 \\
\hline Stir & 2,760 & 2269.2 & 0.08811 & 3.41656 & 0.605 \\
\hline
\end{tabular}

* measured, initial Diesel fuel concentration.

** initial Diesel fuel concentration determined by first order kinetic model.

$\dagger$ the data regression for the Sparge/Stir reactor of Experiment \#2 was obtained without the Day 7 or Day 8 data and the regression for Experiment \#3 was obtained without the Day 7 data; this is due to very low diesel concentrations on these later days that distorts the exponential curve. 
The data from Experimental Series \#1 and \#2 fit the first order kinetics model well. The correlation coefficients, $\mathrm{R}^{2}$, range from 0.929 to 0.985 . There is more scatter in the data of Run \#3 which is reflected in the considerably lower correlation coefficients, 0.605 to 0.871 .

Experimental Series \#3 does not adequately fit the first order kinetics model. The data for Day 5 in the $\mathrm{H}_{2} \mathrm{O}_{2} /$ Stir reactor and Day 4,5 and 6 in the Stir reactor appear to be in error, yielding diesel concentration values higher than several previous days. These large variations appear to be the result of a combination of error sources within the experimental study, including sampling error, extraction error and external standard GC analysis error. However it is uncertain why this scattering occurred more significantly in Experimental Series \#3. This experimental series will need to be run 3 to 5 times to analyze the data scattering and be certain of the kinetic parameters.

In each experimental series, the Sparge/Stir reactor yields the best degradation results. The Sparge/Stir condition results in the lowest diesel fuel half-life and the largest first order rate constant.

A comparison of the best first order curve fits for the three experimental conditions in Experimental Series \#1 and \#2 is provided in Figures 4.4 and 4.5, respectively. The diesel degradation results from Experimental Series \#3 were not plotted. The data of Experimental Series \#3 were not predicted by a first order kinetic model.

Figure 4.4 shows that the first order kinetics describes the $\mathrm{H}_{2} \mathrm{O}_{2} / \mathrm{Stir}$ and the Stir reactors by almost the same curve. The first order kinetics model describes the Sparge/Stir reactor by a distinctly different curve. Although the curve fit of the Sparge/Stir reactor is similar in curvature to the other fits, and the initial degradation rates 
are similar, the curve predicts a lower diesel fuel concentration in the Sparge/Stir reactor for 8 days of the 9 days monitored.

Figure 4.5 provides the curve fits for the reactors in Experimental Series \#2. The similarity between the first order model of the $\mathrm{H}_{2} \mathrm{O}_{2}$ /Stir and Stir reactors is not as great as in Experimental Series \#1. However after Day 2 , the curves are fairly similar. The curve fit of the Sparge/Stir experimental condition predicts the lowest diesel fuel concentration throughout the study. The initial slope of the curve for the Sparge/Stir reactor is roughly the same as that for the Stir reactor.

Two general trends are apparent from Figures 4.4 and 4.5: (1) the first order model predicts similar diesel degradation kinetics for the $\mathrm{H}_{2} \mathrm{O}_{2}$ /Stir and the Stir experimental conditions and (2) the first order kinetics modeling of the Sparge/Stir reactor consistently predicts the lowest daily diesel fuel concentrations.

Error analysis was applied to the exponential model representing the first order kinetics. The error analysis was based on a 7.2 percent error in diesel fuel concentrations and an error of 0.17 days and 0.094 days for time in Experimental Series \#1 and \#2, respectively. The errors in time were approximated from the standard deviation of the average time that the diesel fuel samples were taken from reactors during the experimentation. Sample calculations for the error analysis are provided in Appendix A.

The results of the error analysis show that the average individual determinations of the error in the first order rate constant $(\mathrm{k})$ range from 9.8 to 10 percent for Experimental Series \#1 and from 11 to 14 percent for Experimental Series \#2. Application of the errors in the $\mathrm{k}$ values to the first order rate constants determined from the Exponential Model for Experimental Series \#1 showed that the error ranges overlap 


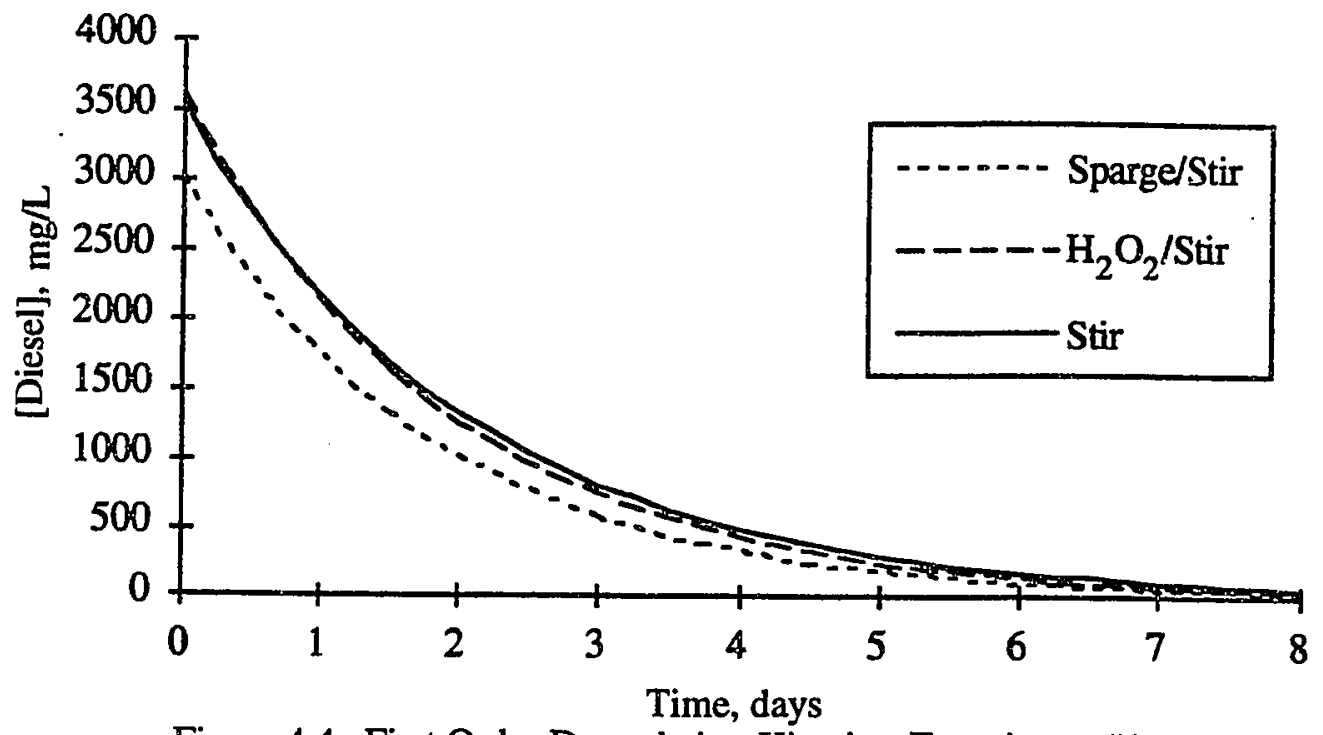

Figure 4.4. First Order Degradation Kinetics, Experiment \#1.

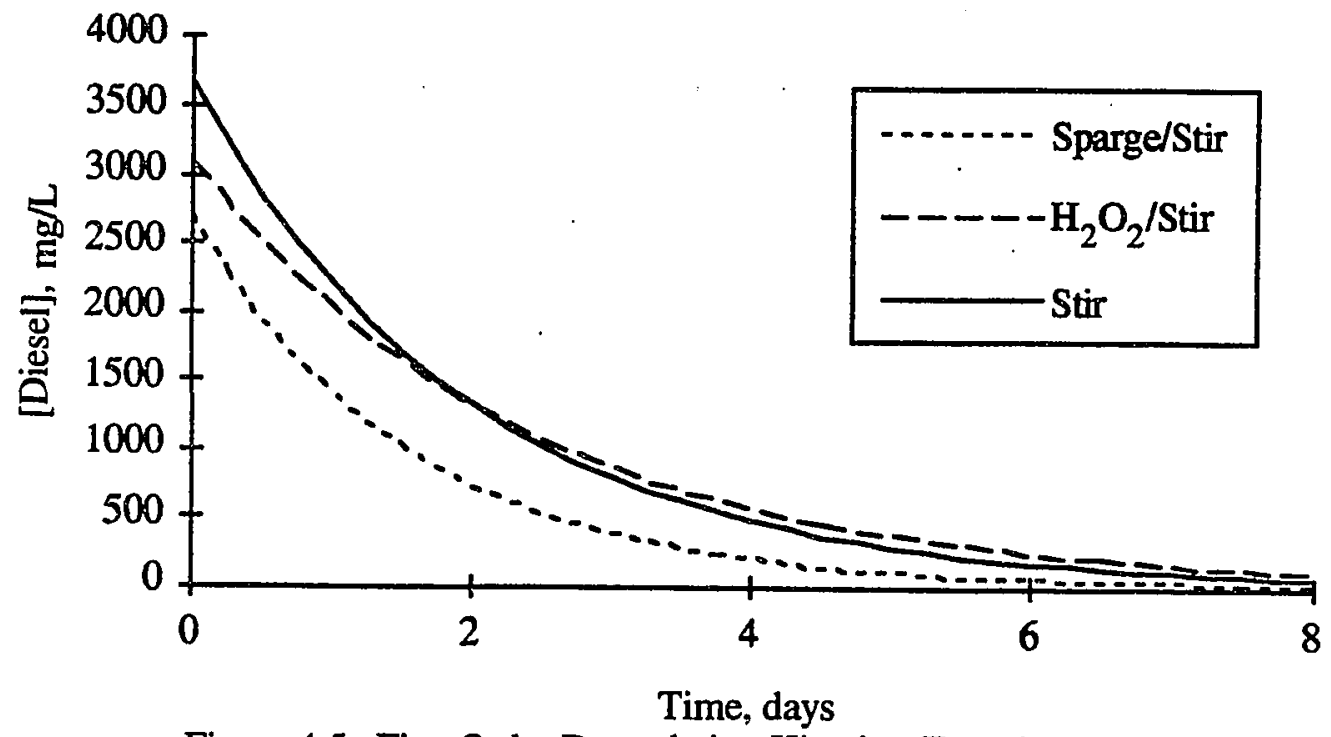

Figure 4.5. First Order Degradation Kinetics, Experiment \#2. 
for all three experimental conditions. None of the $\mathrm{k}$ values in Experimental Series \#1 was significantly different from the other conditions.

The errors in the $\mathrm{k}$ values applied to the data of Experimental Series \#2 showed that the Sparge/Stir condition was significantly different than the $\mathrm{H}_{2} \mathrm{O}_{2}$ /Stir and the Stir experimental conditions. The error range for the Sparge/Stir reactor did not overlap with the other experimental conditions. However the $\mathrm{H}_{2} \mathrm{O}_{2} /$ Stir and the Stir experimental conditions in Experimental Series \#2 showed error range overlap and thus were not significantly different from one another.

Analysis of the data from Experimental Series \#1 showed that the three conditions investigated were not significantly different. Analysis of the data from Experimental Series \#2 showed that the Sparge/Stir condition was significantly different from the $\mathrm{H}_{2} \mathrm{O}_{2}$ /Stir and the Stir experimental conditions. The data from Experimental Series \#3 were not adequately fit by the first order kinetics model. The error analysis and the application of the first order kinetics model to the data of this study suggest that further experimentation is necessary to make a comparison of the effectiveness of the oxygen addition methods investigated.

The results of the first order kinetic model fit of the data were compared between Experimental Series \#1 and \#2. The differences in the first order rate constant and diesel fuel half life for the experimental conditions between Experimental Series \#1 and \#2 were not more significant than the associated error ranges determined by the error analysis. However trends in the variation of the kinetic parameters for the three different experimental conditions are apparent. For the Sparge/Stir and Stir reactors, the first order rate constant, increased from Series \#1 to Series \#2. For the $\mathrm{H}_{2} \mathrm{O}_{2} /$ Stir reactor, $\mathrm{k}$ decreased from Series \#1 to Series \#2. The diesel fuel half life, $t_{1 / 2}$, decreased from 
Series \#1 to Series \#2 for the Sparge/Stir and Stir reactors and increased from \#1 to \#2 for the $\mathrm{H}_{2} \mathrm{O}_{2} /$ Stir reactor.

Although changes were observed in the $\mathrm{k}$ and $\mathrm{t}_{1 / 2}$ values for the Sparge/Stir and Stir reactors between Experimental Series \#1 and Experimental Series \#2, no changes in experimental conditions occurred. The changes observed in the kinetic data were not expected and no conclusions can be made regarding the trends for these reactor conditions.

The trend in the results for the $\mathrm{H}_{2} \mathrm{O}_{2}$ /Stir reactor suggest that adding the $\mathrm{H}_{2} \mathrm{O}_{2}$ all at once in the beginning of the experiment is better than incremental addition over the course of the experiment. This result was not expected based on the well-documented toxicity of $\mathrm{H}_{2} \mathrm{O}_{2}$ to microorganisms (Miorgan et ai., 1992, Pardieck et al., 1992 and Staps 1990). These authors agree that application of $\mathrm{H}_{2} \mathrm{O}_{2}$ at concentrations of 50 to $100 \mathrm{mg} / \mathrm{L}$ has been found to inhibit the growth of non-acclimated bacteria. Therefore, one would expect that the incremental addition of $\mathrm{H}_{2} \mathrm{O}_{2}$, allowing microbial acclimation, would be better for the bacteria and result in increased degradation over one large $\mathrm{H}_{2} \mathrm{O}_{2}$ dose.

One explanation for the trend in the results that suggests a single addition of $\mathrm{H}_{2} \mathrm{O}_{2}$ is better than incremental addition over the study duration is backed by Pardieck $e$ al. (1992). They suggest that the intermittent addition of $\mathrm{H}_{2} \mathrm{O}_{2}$ is likely to prevent the proliferation of catalase positive microbes due to alternating cycles of growth and decay in the bacterial population. They suggest that the result of incremental addition is reduced $\mathrm{H}_{2} \mathrm{O}_{2}$ disproportionation and slower microbial acclimation. According to Pardieck et al. (1992) incremental addition results in a longer residence time for $\mathrm{H}_{2} \mathrm{O}_{2}$ in solution and a constant oxygen supply. However, based on this information, the addition of $\mathrm{H}_{2} \mathrm{O}_{2}$ all at once may have caused a rapid increase in microbial population as a result 
of rapid microbial acclimation and $\mathrm{H}_{2} \mathrm{O}_{2}$ disproportionation. Although a large portion of the $\mathrm{H}_{2} \mathrm{O}_{2}$ may have been lost in this process, it is reasonable that the large microbial population could have been supported by the remaining $\mathrm{H}_{2} \mathrm{O}_{2}$ in solution and the oxygen supplied by agitation. The rapid increase in population may have been all the system needed to produce the more favorable results over the short duration study.

The results of the dissolved oxygen monitoring (Section 4.3) and microbial enumeration (Section 4.4) do support the explanation based on the work of Pardeick et al. (1992). Dissolved oxygen levels rise after Day 6 in the $\mathrm{H}_{2} \mathrm{O}_{2} /$ Stir reactor of Experimental Series \#1. The rise in DO occurs despite the fact that only one $\mathrm{H}_{2} \mathrm{O}_{2}$ addition was provided at the beginning of the study. This rise in DO supports the supposition that stirring alone is sufficient to increase DO levels and possibly support the microbial population.

The microbial enumeration sampling was only performed at the beginning (prior to $\mathrm{H}_{2} \mathrm{O}_{2}$ addition), middle and end of each experimental series. Therefore discussion on the validity of rapid microbial growth due to the addition of $\mathrm{H}_{2} \mathrm{O}_{2}$ all at once is not possible. However the midpoint microbial sampling of the $\mathrm{H}_{2} \mathrm{O}_{2}$ /Stir reactor of Experimental Series \#1 yielded a greater population than in the Sparge/Stir and Stir reactors. This trend did not exist in Experimental Series \#2 or \#3. This higher population in the $\mathrm{H}_{2} \mathrm{O}_{2}$ /Stir reactor could be the result of rapid microbial acclimation due to the plug addition of $\mathrm{H}_{2} \mathrm{O}_{2}$. 


\subsection{Dissolved Oxygen}

The data detailing the dissolved oxygen concentrations over the course of the three experimental series is given in Tables 4.5 through 4.7 and Figures 4.7 through 4.9. In each experimental series, the dissolved oxygen was initially greater than $7.0 \mathrm{mg} / \mathrm{L}$. Over the course of the experiment, the dissolved oxygen level in each experimental condition fell significantly. Toward the latter part of the experiment, the dissolved oxygen level rose and in some cases reached initial levels. In all cases the dissolved oxygen level was less than saturation, which at $25^{\circ} \mathrm{C}$ is $8.4 \mathrm{mg} / \mathrm{L}$.

Table 4.5. Dissolved Oxygen Data, Experiment \#1.

\begin{tabular}{|r|r|r|r|}
\hline \multicolumn{4}{|c|}{ Dissolved Oxygen Concentration, mg/4 } \\
\hline Time, days & Sparge/Stir & $\mathrm{H}_{2} \mathrm{O}_{2} /$ Stir & \multicolumn{1}{c|}{ Stir } \\
\hline 0 & 7.40 & 7.50 & 7.35 \\
\hline 1 & 8.05 & 8.15 & 7.05 \\
\hline 2 & 5.35 & 6.80 & 7.45 \\
\hline 3 & 1.95 & 4.00 & 1.25 \\
\hline 4 & 3.60 & 4.20 & 1.40 \\
\hline 6 & 6.80 & 0.90 & 0.05 \\
\hline 8 & 7.70 & 4.70 & 4.75 \\
\hline
\end{tabular}

Table 4.6. Dissolved Oxygen Data, Experiment \#2.

\begin{tabular}{|r|r|r|r|}
\hline \multicolumn{4}{|c|}{ Dissolved Oxygen Concentration, mg/4 } \\
\hline Time, days & Sparge/Stir & $\mathrm{H}_{2} \mathrm{O}_{2}$ /Stir & \multicolumn{1}{c|}{ Stir } \\
\hline 0 & 7.95 & 7.45 & 7.15 \\
\hline 1 & 7.60 & 7.70 & 5.75 \\
\hline 2 & 6.00 & 6.35 & 5.90 \\
\hline 3 & 3.56 & 3.65 & 0.05 \\
\hline 4 & 4.10 & 0.95 & 0.08 \\
\hline 5 & 5.80 & 0.05 & 0.20 \\
\hline 6 & 6.75 & 0.55 & 2.75 \\
\hline 7 & 7.20 & 2.53 & 2.50 \\
\hline 8 & 7.25 & 3.70 & 2.70 \\
\hline
\end{tabular}


Table 4.7. Dissolved Oxygen Data, Experiment \#3.

\begin{tabular}{|r|r|r|r|}
\hline \multicolumn{4}{|c|}{ Dissolved Oxygen Concentration, $\mathrm{mg} /$} \\
\hline Time, days & Sparge/Stir & $\mathrm{H}_{2} \mathrm{O}_{2}$ /Stir & \multicolumn{1}{c|}{ Stir } \\
\hline 0 & 8.10 & 7.58 & 7.45 \\
\hline 1 & 6.85 & 7.30 & 4.35 \\
\hline 2 & 3.40 & 4.08 & 4.40 \\
\hline 3 & 3.45 & 2.45 & 0.05 \\
\hline 4 & 2.25 & 0.03 & 0.03 \\
\hline 5 & 5.05 & 0.05 & 0.08 \\
\hline 6 & 6.75 & 0.04 & 0.05 \\
\hline 7 & 7.10 & 2.65 & 0.05 \\
\hline 8 & 7.10 & 5.90 & 3.75 \\
\hline
\end{tabular}

The decline in dissolved oxygen levels was the most pronounced in the Stir reactor. As early as Day 3 of the 8-day study, the DO level was nearly zero in the Stir reactor, down from $>7.0 \mathrm{mg} / \mathrm{L}$ initially. The $\mathrm{DO}$ level remained at near zero levels for as many as $\mathbf{5}$ days in the study. In each of the experimental series, the DO concentration within the Stir reactor rose by the eighth and final day. The final DO levels for the Stir condition ranged from $2.70 \mathrm{mg} / \mathrm{L}$ to $4.75 \mathrm{mg} / \mathrm{L}$ or between 38 percent and 65 percent of the initial levels.

These results were partially expected for the Stir only reactor. Since the oxygen level in the Stir reactor was not enhanced other than by agitation alone, the dissolved oxygen levels were expected to fall from initial levels. These results suggest that the microorganisms were consuming the dissolved oxygen faster than it was supplied by agitation. This is reasonable considering the initial level of diesel fuel contamination and the large oxygen requirement for complete mineralization. According to a balanced stoichiometric equation for hexadecane degradation put forth by McCarty (1988), every mole of hydrocarbon oxidized requires 5 moles of oxygen. This amounts to a 70 percent excess based on mass. Based on an average initial diesel concentration of $3,400 \mathrm{mg} / \mathrm{L}$, 
the mass of diesel fuel present in each system would be $1,700 \mathrm{mg}$ which requires 2,900 mg of oxygen for complete oxidation.

The rise in dissolved oxygen levels toward the end of the experiment was not expected. The results show that agitation alone can effectively increase dissolved oxygen levels in the slurry. As the microbial degradation slows due to reduced diesel concentrations in solution, the utilization of oxygen decreases allowing oxygen levels to again build up.

The DO level within the $\mathrm{H}_{2} \mathrm{O}_{2} / \mathrm{Stir}$ reactor also declined to nearly zero in each of the experimental series and remained near zero for one to three days during the experiments. In each case, the DO levels rose the latter part of the study until the final levels achieved were between 50 percent and 78 percent of the initial levels.

A decline in DO levels was expected for Experimental Series \#1, because the $\mathrm{O}_{2}$ source was added all at once, initially, in the form of one $\mathrm{H}_{2} \mathrm{O}_{2}$ dose. However the regular addition of $\mathrm{H}_{2} \mathrm{O}_{2}$ in Experimental Series \#2 and \#3 was expected to produce a constant DO level. The same explanation offered for the Stir reactor regarding the fall and rise in DO levels can be made for the $\mathrm{H}_{2} \mathrm{O}_{2} /$ Stir reactor. The DO levels fell because the oxygen was being consumed faster than it was supplied from the $\mathrm{H}_{2} \mathrm{O}_{2}$ disproportionation. The $\mathrm{DO}$ level subsequently rose due to a decline in microbial $\mathrm{O}_{2}$ consumption accompanied by $\mathrm{O}_{2}$ uptake as a result of stirring in Experimental Series \#1 and $\mathrm{O}_{2}$ uptake as a result of stirring and later $\mathrm{H}_{2} \mathrm{O}_{2}$ additions in Experimental Series \#2 and \#3.

To avoid fluctuating DO levels in the $\mathrm{H}_{2} \mathrm{O}_{2}$ /Stir condition, the $\mathrm{H}_{2} \mathrm{O}_{2}$ additions could either be increased in concentration, volume or frequency of addition. However, there will be a certain concentration level that inhibits or even kills the microorganisms. 
In Experimental Series \#1, the $\mathrm{H}_{2} \mathrm{O}_{2}$ /Stir reactor outperforms the Stir reactor by a narrow margin, based upon higher $\mathrm{k}$ and lower $\mathrm{t}_{1 / 2}$ values. However, in Experimental Series \#2, the results from the Stir reactor are better than the $\mathrm{H}_{2} \mathrm{O}_{2} /$ Stir reactor. The differences between the $\mathrm{H}_{2} \mathrm{O}_{2} / \mathrm{Stir}$ and $\mathrm{Stir}$ are not significant in comparison to the error involve in this experimentation. The $\mathrm{H}_{2} \mathrm{O}_{2}$ additions are at most providing minimal oxygen enhancement over stirring alone or the additions are hindering the degradation. Optimization of the aspects of $\mathrm{H}_{2} \mathrm{O}_{2}$ addition for oxygen enhancement in slurry-phase biodegradation of diesel fuel contaminated soil should be an area of future work.

The Sparge/Stir reactor also experienced a decline in DO. The DO level fell as low as $1.95 \mathrm{mg} / \mathrm{L}$ and lasted for one day. The final levels of DO within the Sparge/Stir reactors were between 88 percent and 104 percent of the initial levels.

Although the decline in DO for the Sparge/Stir reactor was small and short lived relative to the other treatment conditions, the results were still unexpected. The constant flow of air was expected to result in a constant dissolved oxygen level. The reduction in DO levels probably indicates a higher rate of $\mathrm{O}_{2}$ consumption than $\mathrm{O}_{2}$ application.

An interesting area of future research might involve investigation into an air sparging rate that maintains a constant dissolved oxygen level. In this experimentation, the air flow rate was limited by the reactor design. The rubber stopper seal and the volatile hydrocarbon trap created two constraints on the sealed system that limited the air flow to one liter per hour. Investigation into increased air sparging rates would require the development of a more rigorous experimental apparatus.

A comparison of the dissolved oxygen levels within the reactor conditions of the experimental series is given in Figures 4.6, 4.7 and 4.8. In each case the trend of falling then rising dissolved oxygen concentrations is apparent. 


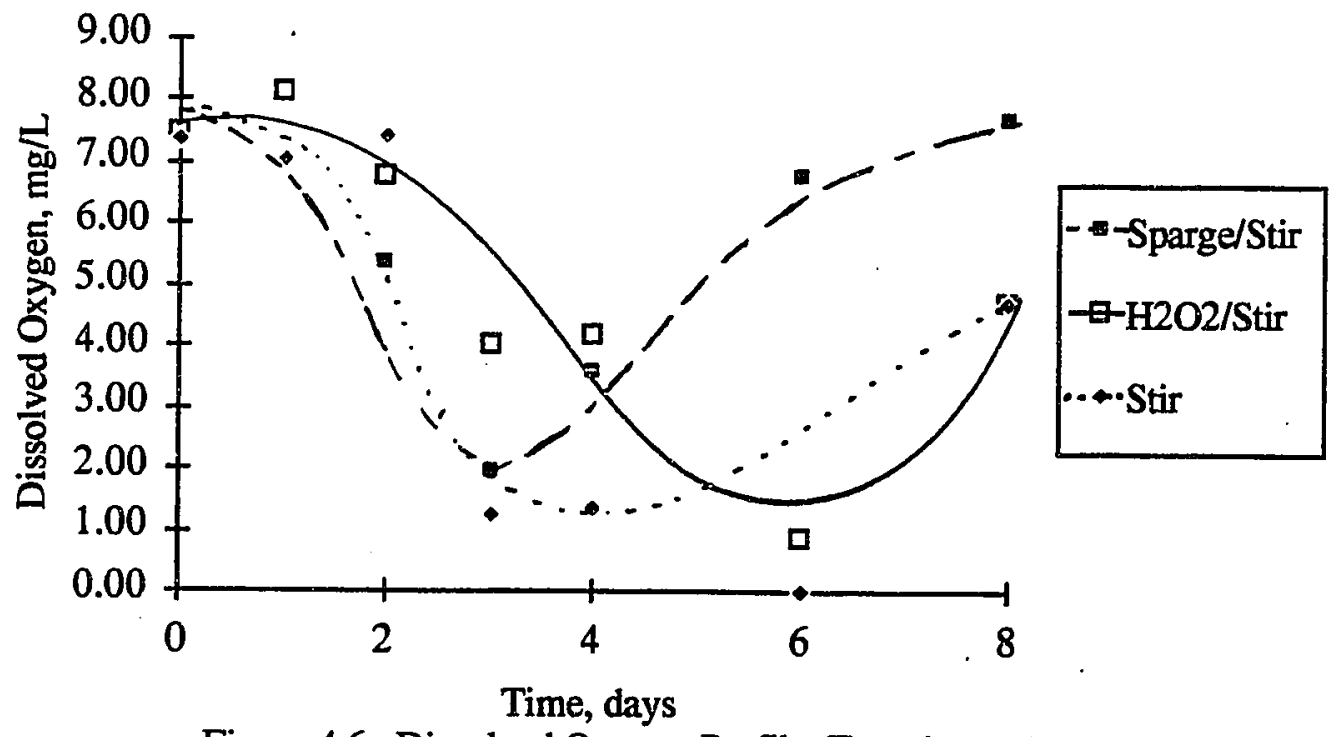

Figure 4.6. Dissolved Oxygen Profile, Experiment \#1.

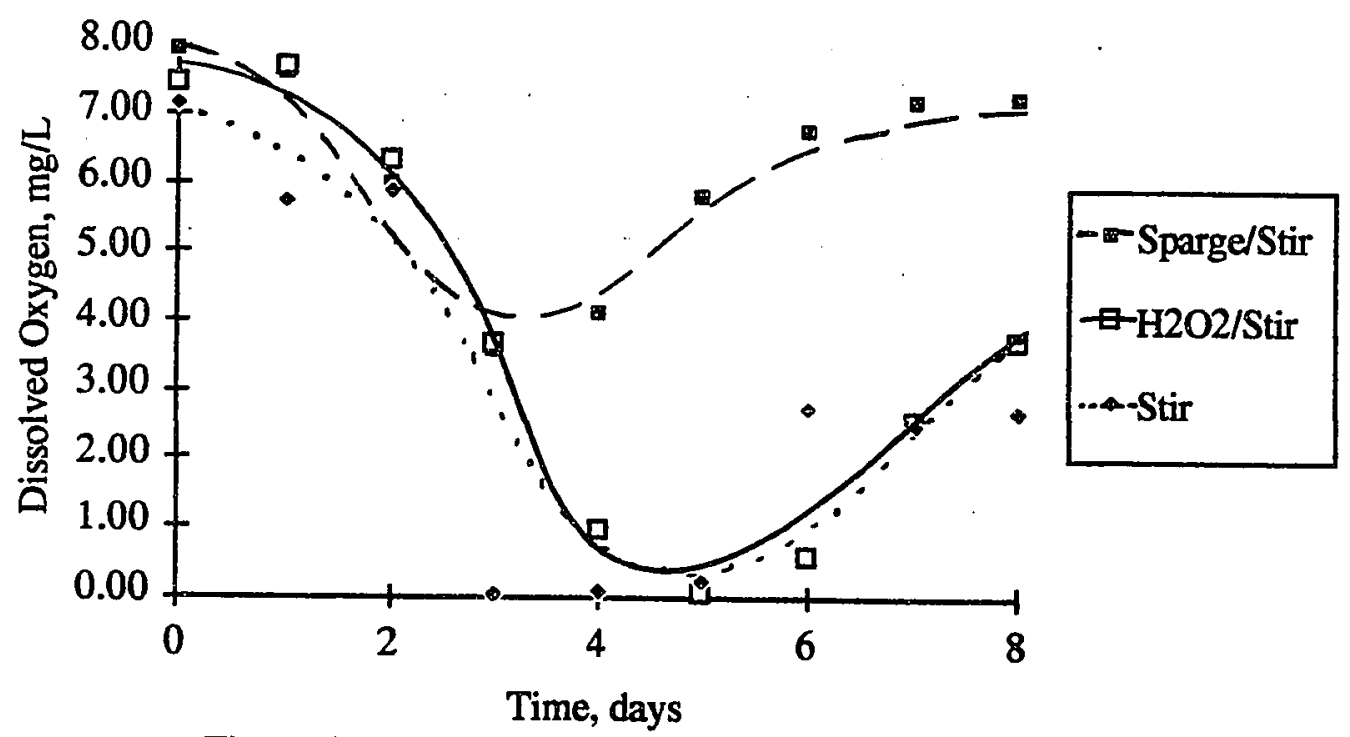

Figure 4.7. Dissolved Oxygen Profile, Experiment \#2. 


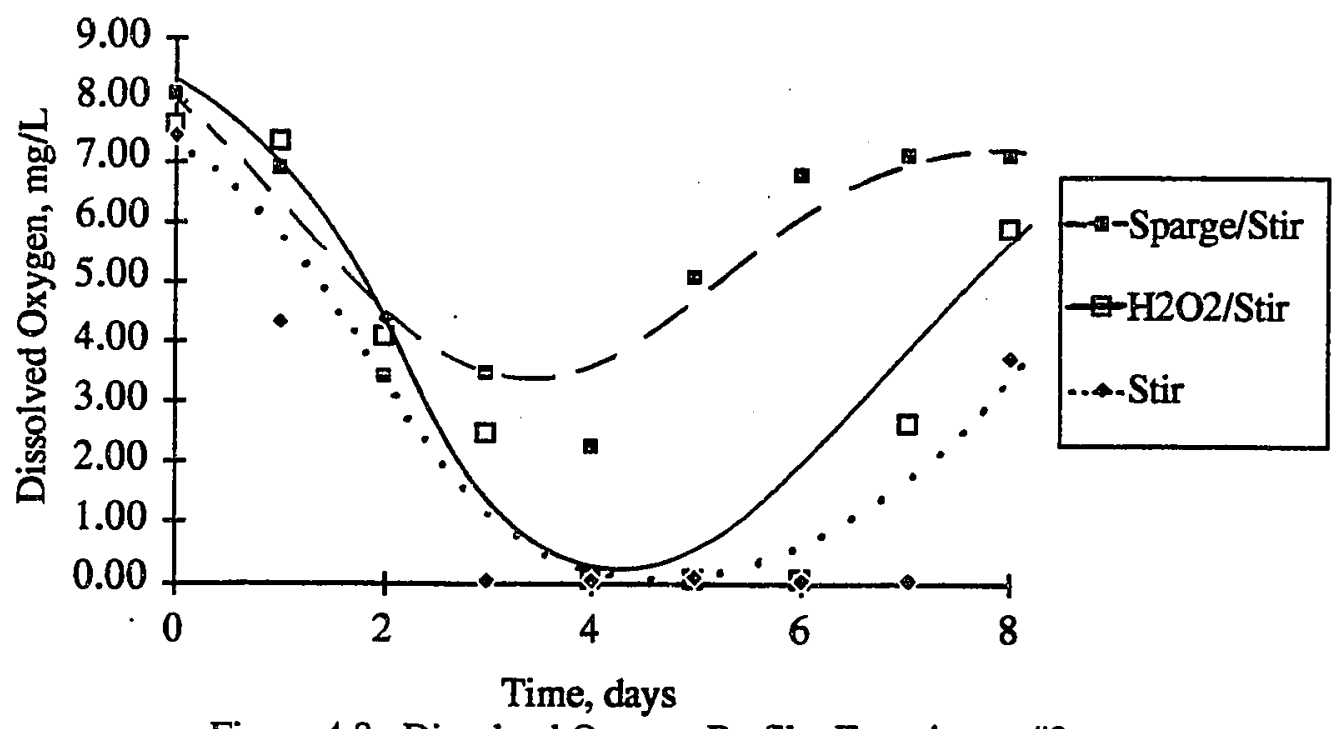

Figure 4.8. Dissolved Oxygen Profile, Experiment \#3.

\subsection{Microorganisms}

The microbial population data for the three experimental series are given in Table 4.8. The average initial population in the reactors was $78,000 \mathrm{CFU} / \mathrm{mL}$. The average final population was $95,000,000 \mathrm{CFU} / \mathrm{mL}$, indicating microorganism growth under the conditions studied. The microbial populations showed the largest increase between Day 0 and Day $3 / 4$ (the designation Day 3/4 is used here because in Experimental Series \#1 the second microbial population sample was taken on Day 4 whereas in Experimental Series \#2 and \#3 the second sample was taken on Day 3). The microbial population increases were in the range of 150 - and 1,200-fold between Day 0 and Day $3 / 4$. The microbial populations increased at a slower rate from Day 3/4 to Day 7, except for the Sparge/Stir reactor in Experimental Series \#2, which showed a slight population decrease. The population increases between Day 3/4 and Day 7 ranged from 0.9 - and 4-fold. 
The reduced microbial population increase between Day 3/4 to Day 7 supports the conclusions made based on the dissolved oxygen monitoring. The DO level increase in the latter part of the study was due to a decline in microbial $\mathrm{O}_{2}$ consumption. This decline in microbial $\mathrm{O}_{2}$ consumption was apparent in the microbial enumerations which showed bacteria populations leveling off between Day 3/4 and Day 7 .

Table 4.8. Microorganism Growth Data.

Experiment \#1

\begin{tabular}{|r|r|r|c|}
\hline & Microbial Population, CFU/mL (x10^6) \\
\hline Time, days & Sparge/Stir & $\mathrm{H}_{2} \mathrm{O}_{2} /$ Stir & \multicolumn{1}{c|}{ Stir } \\
\hline 0 & $0.105^{*}$ & $0.115^{*}$ & $0.092^{*}$ \\
\hline 4 & 29.000 & 39.000 & 36.000 \\
\hline 7 & 108.000 & 110.000 & 140.000 \\
\hline
\end{tabular}

Experiment \#2

\begin{tabular}{|r|r|r|c|}
\hline & Microbial Population, CFU/mL (x10^6) \\
\hline Time, days & Sparge/Stir & $\mathrm{H}_{2} \mathrm{O}_{2} /$ Stir & \multicolumn{1}{c|}{ Stir } \\
\hline 0 & 0.069 & 0.070 & 0.082 \\
\hline 3 & 81.000 & 19.400 & 12.200 \\
\hline 7 & 71.000 & 68.000 & 34.000 \\
\hline
\end{tabular}

Experiment \#3

\begin{tabular}{|r|r|r|r|}
\hline & \multicolumn{3}{|c|}{ Microbial Population, CFU/mL (x10^6) } \\
\hline Time, days & Sparge/Stir & $\mathrm{H}_{2} \mathrm{O}_{2}$ /Stir & \multicolumn{1}{c|}{ Stir } \\
\hline 0 & 0.072 & 0.090 & 0.083 \\
\hline 3 & 87.000 & 86.000 & 87.000 \\
\hline 7 & 121.000 & 88.000 & 113.000 \\
\hline
\end{tabular}

* initial populations in Experimental Series \#1 are high due to improper overnight storage of the samples at room temperature prior to plating; all of the other samples were refrigerated prior to plating to prevent continued microbial growth.

The results reported here represent averages of triplicate plates. The average relative standard deviation for the triplicate plate counts was 14 percent, with a high of 34 percent and low of 1.0 percent. The initial background microbial population was 17,000 CFU/mL, despite starting with sterilized soil. The background population was determined by plating from a slurry reactor prepared as described in the procedure section 
of Chapter 3 with the exception that Solmar consortium was not added. The data presented in Table 4.8 have not been corrected for the initial background microbial population. Due to the presence of this background, indigenous bacteria, degradations observed in this study cannot be solely credited to the Solmar formulation.

There is not a significant difference between the microbial populations resulting from the three experimental conditions. The main result obtained from the microorganism data is that the populations are roughly the same concentration in each reactor at the beginning, middle and end of the experiment. The equality of populations at the beginning of the experiment shows that an equal amount of consortium was added to the three experimental conditions. The population equality during and at the end of the experiment suggests that the microorganisms are equally adapted to degradation under each of the experimental conditions investigated. The variation in diesel fuel degradation between the experimental conditions was not due to population differences.

Plate counting of microbial colonies is a crude method of determining populations. This technique is not sensitive enough to detect any difference between the experimental reactors under the conditions studied. Also the degradation of diesel fuel is too rapid. If the contaminant was less easily degraded, the investigation period could be increased and microbial enumeration could be performed more frequently to reveal population differences.

\subsection{Nutrients}

Tables 4.9 through 4.11 and Figures 4.9 through 4.14 provide the results of the nutrient level monitoring during each experimental run of this study. Prior to beginning each experiment, the $\mathrm{NH}_{3}-\mathrm{N}$ and $\mathrm{PO}_{4}{ }^{3-}-\mathrm{P}$ levels in the contaminated slurries were adjusted to a carbon:nitrogen:phosphorus level of 100:10:1. During the experiment these 
nutrients were not supplemented. The nitrogen and phosphorus levels were monitored within the three different reactors.

Table 4.9. Nutrient Concentration Data, Experiment \#1.

\begin{tabular}{|r|r|r|r|r|r|r|}
\hline & \multicolumn{3}{|c|}{ Nitrogen Concentration, $\mathrm{mg} / \mathrm{L}$} & \multicolumn{3}{|c|}{ Phosphorus Concentration, $\mathrm{mg} / \mathrm{L}^{*}$} \\
\hline Time, days & Sparge/Stir & $\mathrm{H}_{2} \mathrm{O}_{2} /$ Stir & Stir & Sparge/Stir & $\mathrm{H}_{2} \mathrm{O}_{2} /$ Stir & \multicolumn{1}{c|}{ Stir } \\
\hline 0 & 325 & 375 & 375 & 147 & 123 & 150 \\
\hline 2 & 350 & 275 & 275 & 113 & 110 & 123 \\
\hline 4 & 350 & 375 & 375 & 57 & 100 & 73 \\
\hline 8 & 225 & 275 & 275 & 60 & 57 & 50 \\
\hline
\end{tabular}

* the absolute values for phosphate-phosphorus are in error in Experimental Series \#1 due to improper use of the Hach Analysis Kit; the values are reported for relative significance in comparison of the three experimental conditions.

Table 4.10. Nutrient Concentration Data, Experiment \#2.

\begin{tabular}{|r|r|r|r|r|r|r|}
\hline & \multicolumn{3}{|c|}{ Nitrogen Concentration, $\mathrm{mg} / \mathrm{L}$} & \multicolumn{3}{|c|}{ Phosphorus Concentration, $\mathrm{mg} / \mathrm{L}$} \\
\hline Time, days & Sparge/Stir & $\mathrm{H}_{2} \mathrm{O}_{2} /$ Stir & Stir & Sparge/Stir & $\mathrm{H}_{2} \mathrm{O}_{2} /$ Stir & \multicolumn{1}{c|}{ Stir } \\
\hline 0 & 375 & 400 & 425 & 19 & 18 & 17 \\
\hline 2 & 450 & 400 & 450 & 12 & 11 & 11 \\
\hline 4 & 550 & 425 & 425 & 9 & 7 & 11 \\
\hline 6 & 450 & 400 & 350 & 13 & 10 & 15 \\
\hline 8 & 300 & 250 & 325 & 11 & 5 & 9 \\
\hline
\end{tabular}

Table 4.11. Nutrient Concentration Data, Experiment \#3.

\begin{tabular}{|r|r|r|r|r|r|r|}
\hline & \multicolumn{3}{|c|}{ Nitrogen Concentration, $\mathrm{mg} / \mathrm{L}$} & \multicolumn{3}{|c|}{ Phosphorus Concentration, $\mathrm{mg} / \mathrm{L}$} \\
\hline Time, days & Sparge/Stir & $\mathrm{H}_{2} \mathrm{O}_{2} /$ Stir & \multicolumn{1}{|c|}{ Stir } & Sparge/Stir & $\mathrm{H}_{2} \mathrm{O}_{2} /$ Stir & \multicolumn{1}{c|}{ Stir } \\
\hline 0 & 350 & 325 & 325 & 21 & 20 & 19 \\
\hline 2 & 350 & 275 & 225 & 9 & 13 & 8 \\
\hline 4 & 250 & 300 & 275 & 5 & 6 & 5 \\
\hline 6 & 200 & 225 & 225 & 3 & 4 & 3 \\
\hline 8 & 175 & 200 & 200 & 4 & 5 & 3 \\
\hline
\end{tabular}




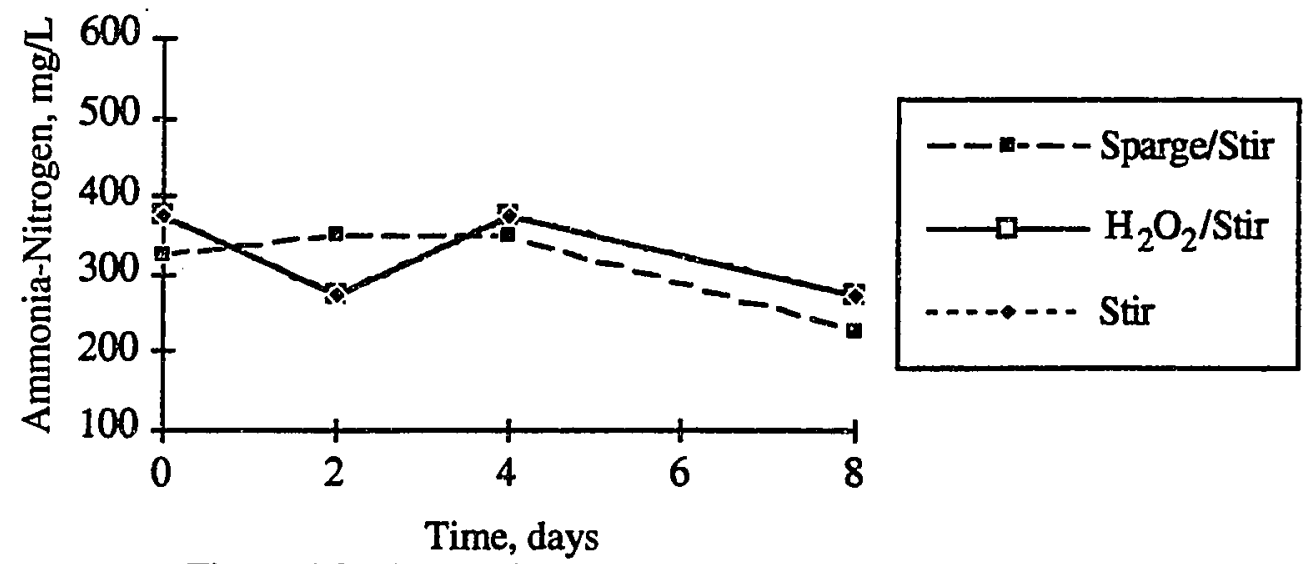

Figure 4.9. Ammonia-Nitrogen Profile, Experiment \#1.

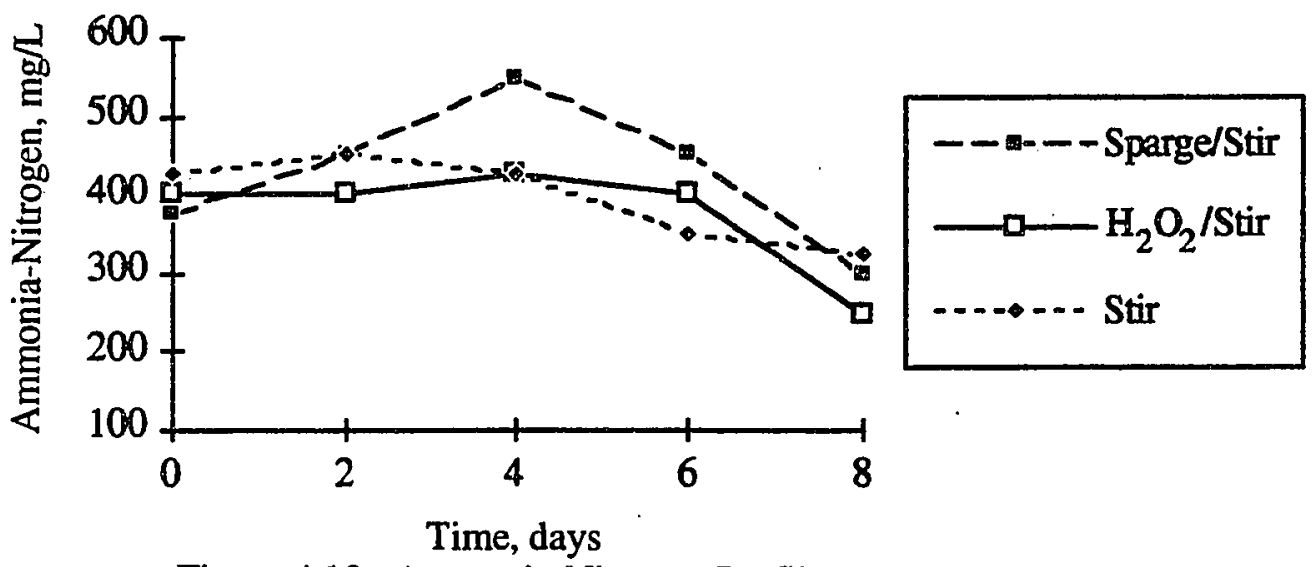

Figure 4.10. Ammonia-Nitrogen Profile, Experiment \#2. 


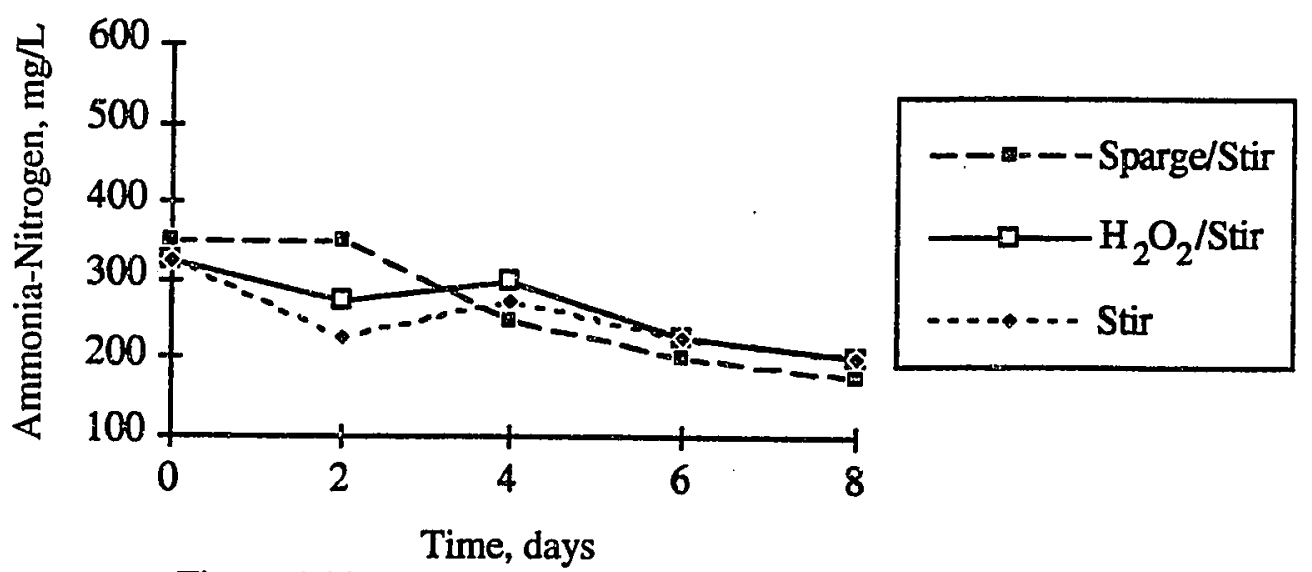

Figure 4.11. Ammonia-Nitrogen Profile, Experiment \#3.

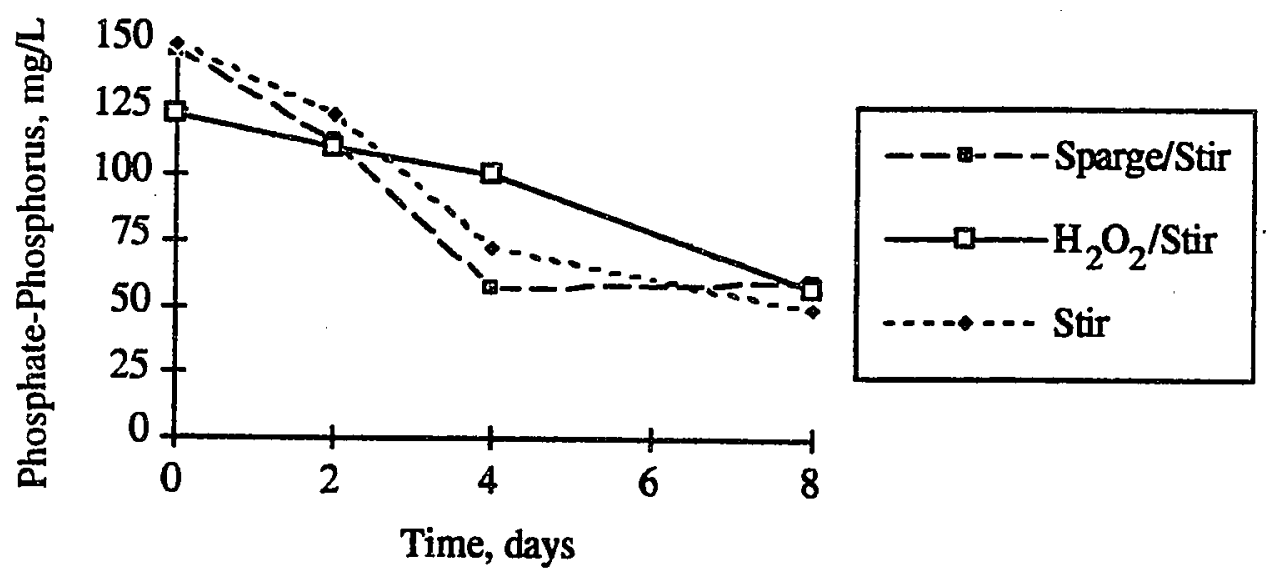

Figure 4.12. Phosphate-Phosphorus Profile, Experiment \#1. 


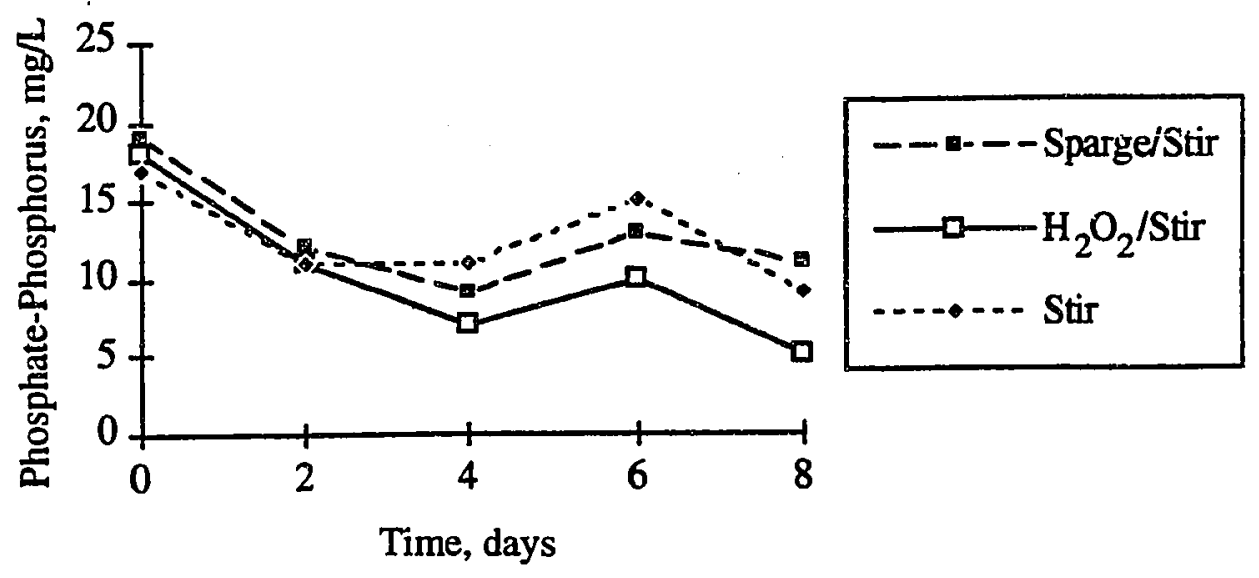

Figure 4.13. Phosphate-Phosphorus Profile, Experiment \#2.

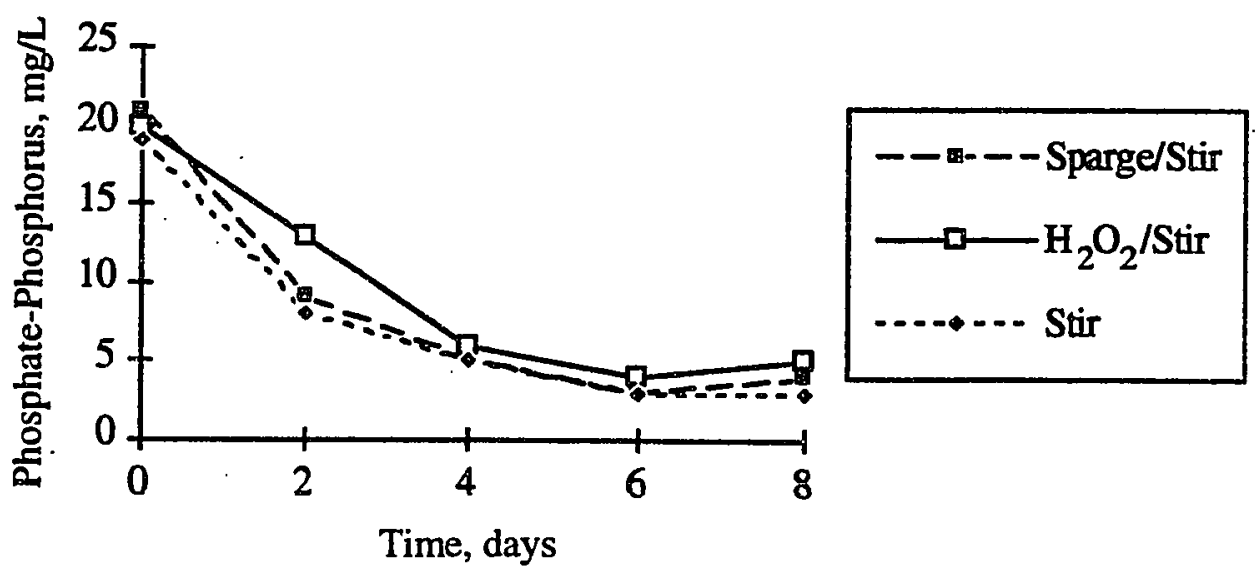

Figure 4.14. Phosphate-Phosphorus Profile, Experiment \#3.

The results show that the levels of $\mathrm{NH}_{3}-\mathrm{N}$ and $\mathrm{PO}_{4}{ }^{3--} \mathrm{P}$ decline over the course of an experimental run. The average nitrogen levels at the beginning and end of the experimental series were $360 \mathrm{mg} / \mathrm{L}$ and $250 \mathrm{mg} / \mathrm{L}$, respectively. This amounts to an 
average nitrogen reduction of 31 percent. The general trend in the $\mathrm{NH}_{3}-\mathrm{N}$ measurements is a decline in concentration over the course of the study, as depicted in Figures 4.9, 4.10 and 4.11. There are a few cases where the ammonia-nitrogen levels fluctuated. The most notable fluctuation occurred with the $\mathrm{NH}_{3}-\mathrm{N}$ measurements of the Sparge/Stir reactor of Experimental Series \#2. At the midpoint of the study, the measured nitrogen level was 47 percent greater than the starting concentration. Much of this variation is due to the low sensitivity of the colorimetric Hach test kit.

The quantity of $\mathrm{NH}_{3}-\mathrm{N}$ utilized in the diesel fuel consumption was between 38 and $88 \mathrm{mg}$. This nitrogen utilization is less than the consumption expected based upon the C:N:P ratio of 100:10:1 suggested by Harder et al. (1991) and Grundman et al. (1991). According to the 100:10:1 ratio and based on an initial diesel fuel concentration of $3,000 \mathrm{mg} / \mathrm{L}$ or $1,500 \mathrm{mg}$ of diesel assuming a slurry volume of $500 \mathrm{~mL}, 150 \mathrm{mg}$ of $\mathrm{NH}_{3}-\mathrm{N}$ would be required for biodegradation. The actual nitrogen utilization results are between 25 percent and 59 percent of those expected.

The general trend in the phosphate-phosphorus data was a decline in concentration over the 8-day period. The nature of the $\mathrm{PO}_{4}{ }^{3-}-\mathrm{P}$ declines varied between the experimental series as shown in Figures $4.12,4.13$ and 4.14. There was some fluctuations in the data, with the most pronounced being the data from Experimental Series \#2.

The phosphate-phosphorus levels within the experimental reactors change more dramatically than the ammonia-nitrogen levels. The $\mathrm{PO}_{4}{ }^{3--} \mathrm{P}$ reductions ranged from 42 percent to 84 percent. The larger reduction in phosphate levels within the slurry reactors may be in part the result of strong attractive forces between the soil particles and $\mathrm{PO}_{4}{ }^{3-}$ anion. Mitchell (1993) reports that negatively charged species like phosphate, which are 
about the same size and possess the same geometry as the silica tetrahedron, are strongly attracted to the surfaces or edges of soil particles. This nature of the phosphate radical is the reason $\mathrm{PO}_{4}{ }^{3-}$ compounds are effective deflocculating agents for soil suspensions.

The absolute values for phosphate-phosphorus reported for Experimental Series \#1 are in error due to improper use of the Hach Analysis Kit. The values are reported for their relative significance in comparison of the three experimental conditions of Series \#1. For this reason, the data from Experimental Series \#1 cannot be used in a discussion of the milligrams of phosphorus utilized in the diesel fuel degradation. The mass of phosphorus utilized in the degradation recorded for Experimental Series \#2 and \#3 ranged from 4 to $9 \mathrm{mg}$. Based on the 100:10:1 C:N:P ratio suggested by Harder et al. (1991) and Grundman et al. (1991) and an initial diesel fuel mass of $1,500 \mathrm{mg}$, the phosphorus requirement should be $15 \mathrm{mg}$. Thus the actual phosphorus utilizations were between 27 percent and 60 percent of the expected values. Despite greater $\mathrm{PO}_{4}{ }^{3-}-\mathrm{P}$ reductions relative to $\mathrm{NH}_{3}$ reductions, the phosphorus utilization as a percentage of that expected based on the 100:10:1 C:N:P ratio was approximately equal to the nitrogen utilization.

\subsection{Monitored Conditions}

The conditions of bath temperature, slurry temperature and slurry $\mathrm{pH}$ were monitored daily through the experimental series. The bath and slurry temperatures remained fairly constant at $25^{\circ} \mathrm{C}$ through the use of the recirculating, immersion heater (Figure 3.2). The daily measurements of bath and slurry pH for the three experimental runs are reported with the Raw Data in Appendix F.

The slurry $\mathrm{pH}$ values did vary during each experimental run and are reported in Table 4.12. Although the $\mathrm{pH}$ values did vary from neutral, they remained within the desired control range of $\mathrm{pH} 6.5$ to 8.5. No $\mathrm{pH}$ adjustments were made during the 
experimentation as the observed variation was within the optimal range for hydrocarbon biodegradation (pH 6 to 8.5) suggested by Dalyan et al. (1990).

Table 4.12. Slurry pH Data.

Experiment \#1

\begin{tabular}{|r|r|r|r|}
\hline & & \multicolumn{1}{|c|}{$\mathrm{pH}$} & \\
\hline Time, days & Sparge/Stir & $\mathrm{H}_{2} \mathrm{O}_{2}$ /Stir & \multicolumn{1}{c|}{ Stir } \\
\hline 0 & 7.20 & 7.20 & 7.10 \\
\hline 1 & 7.50 & 7.50 & 7.40 \\
\hline 2 & 7.40 & 7.50 & 7.50 \\
\hline 3 & 7.10 & 7.30 & 7.00 \\
\hline 4 & 7.20 & 7.30 & 7.00 \\
\hline 6 & 7.50 & 7.20 & 6.90 \\
\hline 6 & 7.60 & 7.20 & 7.00 \\
\hline 8 & 8.00 & 7.50 & 7.30 \\
\hline
\end{tabular}

Experiment \#2

\begin{tabular}{|r|r|r|r|}
\hline & & \multicolumn{1}{|c|}{$\mathrm{pH}$} & \\
\hline Time, days & Sparge/Stir & $\mathrm{H}_{2} \mathrm{O}_{2} /$ Stir & \multicolumn{1}{c|}{ Stir } \\
\hline 0 & 7.20 & 7.20 & 7.20 \\
\hline 1 & 7.55 & 7.45 & 7.25 \\
\hline 2 & 7.45 & 7.25 & 7.25 \\
\hline 3 & 7.25 & 7.15 & 6.85 \\
\hline 4 & 7.20 & 6.90 & 6.80 \\
\hline 5 & 7.35 & 6.80 & 6.75 \\
\hline 6 & 7.55 & 7.05 & 7.00 \\
\hline 7 & 7.70 & 7.05 & 7.00 \\
\hline 8 & 7.80 & 7.05 & 7.00 \\
\hline
\end{tabular}

Experiment \#3

\begin{tabular}{|r|r|r|r|}
\hline & & \multicolumn{1}{|c|}{$\mathrm{pH}$} & \\
\hline Time, days & Sparge/Stir & $\mathrm{H}_{2} \mathrm{O}_{2} /$ Stir & \multicolumn{1}{c|}{ Stir } \\
\hline 0 & 7.15 & 7.15 & 7.15 \\
\hline 1 & 7.35 & 7.35 & 7.55 \\
\hline 2 & 7.35 & 7.25 & 7.55 \\
\hline 3 & 7.40 & 7.70 & 7.45 \\
\hline 4 & 7.35 & 7.75 & 7.15 \\
\hline 5 & 7.65 & 7.80 & 7.15 \\
\hline 6 & 8.00 & 7.55 & 7.00 \\
\hline 7 & 8.15 & 7.50 & 7.10 \\
\hline 8 & 8.35 & 7.65 & 7.30 \\
\hline
\end{tabular}


There was a common trend in $\mathrm{pH}$ measurements for each of the treatment conditions in each of the experimental series. The $\mathrm{pH}$ increased from initial levels in the early stage of the experiment, then decreased around the middle to latter half of the experiment which was finally followed by a rise above initial levels by the end of the experimental run. The initial rise in $\mathrm{pH}$ ranged from 0.05 to 0.40 , the decline in $\mathrm{pH}$ ranged from 0.05 to 0.60 and the final rise in $\mathrm{pH}$ ranged from 0.30 to 1.0 . The $\mathrm{H}_{2} \mathrm{O}_{2} / \mathrm{Stir}$ reactor of Experimental Series \#3 was the only exception to the common $\mathrm{pH}$ trend. The $\mathrm{pH}$ measurements for this reactor fluctuated toward the latter part of the study as opposed to a steadily increasing.

Similar fluctuations in pH were observed by Dalyan et al. (1990) in the study of slurry-phase biodegradation of hexadecane. Over a 12-day study, they experienced an initial decrease in $\mathrm{pH}$ of 0.20 , followed by a rise in $\mathrm{pH}$ of 0.40 and then a decline in $\mathrm{pH}$ of 0.10. The initial and final $\mathrm{pH}$ in the study by Daylan et al. (1990) were 7.5 and 7.7, respectively. After a series of slurry-phase experiments beginning at a range of $\mathrm{pH}$ values from 4.5 to 11.5 , Daylan et al. (1990) concluded that the $\mathrm{pH}$ shifts were driven by a tendency to attain the neutral $\mathrm{pH}$ range. By a comparison of $\mathrm{pH}$ changes in inoculated and sterile systems, they concluded that the $\mathrm{pH}$ shifts were attributable to the microbiological reaction and not abiotic chemical changes occurring at the soil surfaces. Daylan et al. (1990) explained the acidification shifts as a result of carbon dioxide evolution, intermediary occurrence of fatty acids or the occurrence of other acid degradation products. However, they did not offer any explanation for the alkaline shifts.

The slurry $\mathrm{pH}$ does not appear to play a significant role in the bioremediation of diesel fuel. This conclusion is supported by Dalyan et al. (1990). They concluded that the slurry biodegradation of hexadecane has only a limited influence on $\mathrm{pH}$ values. 


\subsection{Volatile Emissions}

The amount of diesel fuel lost by volatile emissions was estimated by extracting organics from soil traps placed on the reactor outlets. In each experiment, the sparged reactor was adapted for volatile emissions trapping. The volatile emissions from the hydrogen peroxide/stir reactor were also trapped, but only during Experiment \#3. The traps were in place for the duration of the experiment. They were only tested once, at the end of the experiment.

In the testing of the hydrocarbon trap soil, a 35 to 40 gram sample of soil was extracted with 50.0 to $60.0 \mathrm{~mL}$ of freon. After agitation for 30 minutes in the reciprocating shaker bath, the freon/soil slurry was filtered using a Buchner funnel and medium grade filter paper. The volatilization of the freon was minimized by cooling the vacuum flask in an ice bath during the filtration. The freon filtrate was concentrated to between 1.0 and $5.0 \mathrm{~mL}$ in a graduated centrifuge tube by heating in a water bath at $55^{\circ} \mathrm{C}$. The freon sample was stored in the refrigerator at $4^{\circ} \mathrm{C}$ for a minimum of 30 minutes prior to injection as a $1.0 \mu \mathrm{L}$ sample on the gas chromatograph. The results of the gas chromatograph analysis were converted from mg diesel per liter of freon as calibrated from the standards to mg diesel trapped by multiplying by the volume of freon used in the extraction.

The volatile emissions data are provided in Tables 4.13 and 4.14. "Soil Weight" is the quantity of soil loaded into the column that comprised the trap. The heading " $\Delta$ Weight" refers to the change in weight of the packed column over the course of an experimental run. Diesel Initial refers to the initial mass of diesel fuel present within the respective reactor. Diesel Trapped is the quantity of diesel extracted from the soil of the 
given trap. Percent Trapped refers to the cumulative diesel fuel trapped over the course of an experiment as a percentage of the initial concentration present.

Table 4.13. Volatile Emission Data for the Sparge/Stir Reactor.

\begin{tabular}{|l|c|c|c|}
\hline Sparge/Stir & Experiment \#1 & Experiment \#2 & Experiment \#3 \\
\hline Soil Weight, $\mathrm{g}$ & 37.22 & 36.43 & 33.77 \\
\hline$\Delta$ Weight, g & 0.6786 & 0.7443 & 0.5268 \\
\hline Diesel Initial, mg & $2,263$. & $1,583$. & $1,494$. \\
\hline Diesel Trapped, mg & 0.7103 & 0.2801 & 0.4143 \\
\hline Percent Trapped & 0.0314 & 0.0177 & 0.0277 \\
\hline
\end{tabular}

Table 4.14. Volatile Emission Data for the $\mathrm{H}_{2} \mathrm{O}_{2}$ /Stir Reactor.

\begin{tabular}{|l|c|}
\hline $\mathrm{H}_{2} \mathrm{O}_{2} /$ Stir & Experiment \#3 \\
\hline Soil Weight, $\mathrm{g}$ & 36.63 \\
\hline$\Delta$ Weight, g & 0.0375 \\
\hline Diesel Initial, mg & $1,311$. \\
\hline Diesel Trapped, mg & 0.2005 \\
\hline Percent Trapped & 0.0153 \\
\hline
\end{tabular}

Very little diesel was extracted from the soil of any of the four emission traps used in this experimentation. The greatest mass of diesel fuel trapped, $0.7103 \mathrm{mg}$, occurred in the Sparge/Stir reactor of Experimental Series \#1. The least amount of diesel trapped, $0.2005 \mathrm{mg}$, occurred in the non-sparged reactor tested, the $\mathrm{H}_{2} \mathrm{O}_{2} /$ Stir reactor of Experimental Series \#3.

The cumulative diesel fuel trapped over the course of an experiment as a percentage of the initial concentration present results for the Sparge/Stir reactor of Experiment \#1, \#2 and \#3 were $0.03,0.02$ and 0.03 percent, respectively. The volatile emissions from the $\mathrm{H}_{2} \mathrm{O}_{2} /$ Stir reactor trapped during Experiment \#3 were 0.02 percent of 
the initial fuel concentration present in the reactor. These results indicate, under the conditions tested and at the concentrations investigated, that diesel fuel is relatively nonvolatile. These results are consistent with the low volatility characteristics reported for Grade \#2 diesel fuel. The initial boiling point at atmospheric pressure is $185^{\circ} \mathrm{C}$ (ASTM, 1990a). The minimum flash point is $52^{\circ} \mathrm{C}$, which means that below $52^{\circ} \mathrm{C}$, Grade \#2 diesel fuel is not volatile enough to support combustion (ASTM, 1990b).

The difference in diesel fuel trapped in the Sparge/Stir reactors and the $\mathrm{H}_{2} \mathrm{O}_{2} / \mathrm{Stir}$ reactor was not as large as expected. An average of $0.4682 \mathrm{mg}$ diesel or 0.0256 percent was trapped from the Sparge/Stir reactor compared to 0.2005 and 0.0153 percent for the $\mathrm{H}_{2} \mathrm{O}_{2}$ /Stir reactor. The air sparging amounted to a 40 percent increase in diesel volatilized. The air sparging was anticipated to cause a larger quantity of diesel fuel to be volatilized.

Despite minimal quantities of diesel fuel extracted, large changes in total weight were observed in the soil traps. There was a before and after weight difference of between 500 and $800 \mathrm{mg}$ for the Sparge/Stir reactors and $38 \mathrm{mg}$ for the $\mathrm{H}_{2} \mathrm{O}_{2} / \mathrm{Stir}$ reactor. These data indicate that the traps most likely collected water over the course of the experiment. The fact that the sparged reactors picked up more water than the $\mathrm{H}_{2} \mathrm{O}_{2}$ reactor can be explained by the constant flow of air through the sparged reactor.

A poison control experimental condition was not incorporated in this study. An adequately poisoned system would have allowed for the determination of abiotic losses in the experimentation. However, maintaining a poisoned system that is exposed to air can be difficult. 


\section{CHAPTER 5. CONCLUSIONS}

The microorganisms appear to have been successful in reducing diesel fuel contamination under the environmental conditions studied. All three experimental systems, Sparge/Stir, $\mathrm{H}_{2} \mathrm{O}_{2} /$ Stir and Stir, result in greater than 90 percent reduction in diesel fuel concentration in just 8 days. Initial diesel fivel levels ranged from $4,526 \mathrm{mg} / \mathrm{L}$ to $2,621 \mathrm{mg} / \mathrm{L}$ and final levels ranged from $225 \mathrm{mg} / \mathrm{L}$ to $0 \mathrm{mg} / \mathrm{L}$. In most cases, half of the initial diesel fuel concentration present was degraded in less than 2 days. The average diesel reduction percentages at 2, 4, 6 and 8 days for all three conditions and the three experimental series were $65,82,88$ and 97 , respectively.

The data from Experimental Series \#1 and \#2 were fit by a first order kinetics model. The correlation coefficients range from 0.929 to 0.985 . Experimental Series \#3 was not adequately fit by first order kinetics. The trends in the data suggest that the Sparge/Stir reactor was more effective than the $\mathrm{H}_{2} \mathrm{O}_{2} /$ Stir and Stir reactors. The Sparge/Stir condition results in the lowest diesel fuel half-life and the largest first order rate constant.

Error analysis showed that the kinetic parameters determined for the three conditions of Experimental Series \#1 were not significantly different. However, error analysis of Experimental Series \#2 showed that the kinetics of the Sparge/Stir condition were significantly different than the kinetics of the $\mathrm{H}_{2} \mathrm{O}_{2} /$ Stir and Stir conditions. The $\mathrm{H}_{2} \mathrm{O}_{2}$ /Stir and Stir conditions of Experimental Series \#2 were not significantly different from one another.

Three specific errors were measured and analyzed in this experimental investigation: same sample/repeated injection error, day-to-day/same standard error and 
slurry reactor sampling error. The average same sample/repeated injection error was 7.2 percent. The average day-to-day/same standard errors were: 8.9 percent, 5.8 percent and 4.6 percent for Experimental Series \#1, \#2 and \#3, respectively. The average sampling/extraction error measured was 5.3 percent. Greater than 50 percent of the degradation data collected was more significant than the average 7.2 percent error associated with the sample injection.

The dissolved oxygen monitoring in the three experimental conditions revealed the common trend of falling then rising levels over the 8 day studies. The aeration methods investigated were not sufficient to maintain constant DO levels. The DO levels fell because the oxygen was being consumed faster than it was supplied. The rise in DO during the latter part of the study was possibly due to a decline in microbial $\mathrm{O}_{2}$ consumption accompanied by $\mathrm{O}_{2}$ uptake as a result of stirring for the Stir and $\mathrm{H}_{2} \mathrm{O}_{2} / \mathrm{Stir}$ reactors and stirring plus sparging for the Sparge/Stir reactor.

The microorganisms in this study, Solmar L-104 formulation and the indigenous population, were capable of growth under the conditions studied. The average initial population increased from $78,000 \mathrm{CFU} / \mathrm{mL}$ to an average final population of $95,000,000$ CFU/mL.

The $\mathrm{NH}_{3}-\mathrm{N}$ and $\mathrm{PO}_{4}{ }^{3-}-\mathrm{P}$ levels within each experimental condition declined over the course of the study. The average nitrogen levels at the beginning and end of the experimental series were $360 \mathrm{mg} / \mathrm{L}$ and $250 \mathrm{mg} / \mathrm{L}$, respectively. This amounts to an average nitrogen reduction of 31 percent. The quantity of $\mathrm{NH}_{3}-\mathrm{N}$ utilized in the diesel reduction was between 38 to $88 \mathrm{mg}$.

The phosphate-phosphorus levels within the experimental reactors changed more dramatically than the ammonia-nitrogen levels. The $\mathrm{PO}_{4}{ }^{3-}-\mathrm{P}$ reductions ranged from 42 
to 84 percent. The quantity of phosphorus utilized in the degradation measured in Experimental Series \#2 and \#3 ranged from 4 to $9 \mathrm{mg}$.

The bath and slurry temperatures remained relatively constant at $25^{\circ} \mathrm{C}$ throughout the study. The slurry $\mathrm{pH}$ did vary during each experimental run. The common trend was an initial increase, then a decrease around the middle to latter part of the experiment, followed by a rise above initial levels by the end of the experimental run. Although the $\mathrm{pH}$ values did vary, they remained within the desired control range and no adjustments were necessary.

Very little emissive losses of diesel fuel were measured. The mass of diesel fuel trapped ranged from 0.2005 to $0.7103 \mathrm{mg}$. This represents a range of 0.02 to 0.03 percent of the initial diesel fuel concentrations within the respective reactors. Air sparging amounted to a 40 percent increase in diesel volatilized, although the actual quantity was negligible compared to the total mass of fuel present. The large change in mass observed in the Sparge/Stir reactor traps was likely due to water entrained in the constant air flow.

The hypothesis that (1) oxygen enhancement by air sparging and hydrogen peroxide addition in connection with stirring in slurry-phase treatment of diesel fuel contaminated soils will result in higher biodegradation rates than oxygen enhancement by stirring alone and (2) oxygen addition using hydrogen peroxide with agitation is predicted to result in the highest biodegradation rate has not been proven.

The biodegradation results for the three experimental conditions investigated, air sparging/agitation, $\mathrm{H}_{2} \mathrm{O}_{2}$ addition/agitation and agitation, do not show any large differences between the conditions. Error analysis of the data from Experimental Series \#1 showed that the three conditions investigated were not significantly different. Error analysis of the data from Experimental Series \#2 showed that the Sparge/Stir condition 
was significantly different from the $\mathrm{H}_{2} \mathrm{O}_{2} / \mathrm{Stir}$ and the Stir experimental conditions. The data from Experimental Series \#3 were not adequately fit by the first order kinetics model. The error analysis and the application of the first order kinetics model to the data of this study suggest that further experimentation is necessary to make a comparison of the effectiveness of the oxygen addition methods investigated.

Future investigations should seek repeatability and reproducibility in the experiments performed in this study so that the oxygen addition methods analyzed can be compared. Future investigations should attempt to optimization the oxygen addition methods. $\mathrm{H}_{2} \mathrm{O}_{2}$ addition requires optimization with respect to delivery concentration and frequency of addition. Optimization of the $\mathrm{H}_{2} \mathrm{O}_{2}$ addition could involve toxicity measurements and slurry half life determinations. The air sparging delivery and flow rate could also be optimized. The air sparging used in this study was constrained by the experimental apparatus. Future investigations should also attempt to thoroughly evaluate the errors associated with the analytical procedures and attempt to minimize them. 


\section{REFERENCES}

American Public Health Association (APHA) and American Water Works Association (AWWA), 1985, Standard Methods for the Examination of Water and Wastewater, 16th Ed., Washington D.C.

American Society for Testing and Materials (ASTM), 1990a, Annual Book of ASTM Standards, Standard Method for Distillation of Petroleum Products, 05.01 (D8682), 7-20.

ASTM, 1990b, Annual Book of ASTM Standards, Standard Specification for Diesel Fuel Oils, 05.01 (D975-89a), 336-346.

Arthur, M. F., Zwick, T. C., O'Brien, G. K. and Marsh. S. S., 1990, Evaluation of Aeration Methods to Bioremediate Fuel-Contaminated Soils, Biological Processes, Innovative Hazardous Waste Treatment Technology Series, Volume 3, H.M. Freeman and P.R. Sferra-Eds, Lancaster, PA: Technomic Publishing Co., 185-196.

Autry, A. R. and Shearon, M., 1991, Micrcorganisms Aid Soil Remediation, Environmental Protection. 8, 21.

Bauman, B. J., 1989, Soils Contaminated by Motor Fuels: Research Activities and Perspectives of the American Petroleum Institute, Petroleum Contaminated Soils, Vol. I, P. T. Kostecki and E. J. Calabrese-Eds., Chelsea, MI: Lewis Publishers, 319.

Bell, C. E., Kostecki, P. T. and Calabrese, E. J., 1989, Review of State Cleanup Levels for Hydrocarbon Contaminated Soils, Petroleum Contaminated Soils, Vol. I, P. T. Kostecki and E. J. Calabrese-Eds., Chelsea, MI: Lewis Publishers, 77-90.

Bradford, M. L. and Krishnamoorthy, R., 1991, Consider Bioremediation for Waste Site Cleanup, Chemical Engineering Progress, 80-85.

Brox, G. H. and Hanify, D. E., 1991, Bioremediation of Hazardous Wastes in a Slurry Reactor - The EIMCO Biolift Reactor, Presented at ASME Winter Annual Meeting, 5th Annual Bioprocess Engineering Program Symposium. Atlanta, GA, December 2-4.

Castaldi, F.J. and Ford, D. L., 1992, Slurry Bioremediation of Petrochemical Waste Sludges, Water Science and Technology, 25(3), 207-212.

Compeau, G. C., Mahaffey, W. D. and Patras, L., 1991, Full-Scale Bioremediation of Contaminated Soil and Water, Environmental Biotechnology for Waste Treatment, G. S. Sayler et al. -Eds., New York: Plenum Press, 91-109. 
Dalyan, U., Harder, H. and Hopner, T., 1990, Hydrocarbon Biodegradation in Sediments and Soils, A Systematic Examination of Physical and Chemical Conditions - Part II. pH Values, Erdol \& Kohle, Erdgas, Petrochemie. 43(9), 337-342.

Dosani, M., Hessling, J., Smith, M. L., Jones, A. and Mahaffey, W. R., 1993, Project Summary - On-Site Engineering Report of the Slurry-Phase Biological Reactor for Pilot-Scale Testing on Contaminated Soil, EPA/600/SR-93/066, Risk Reduction Engineering Laboratory, Cincinnati, $\mathrm{OH}$.

Emcon Associates, promotional literature (no date).

Friedman, G. M. and Sanders, J. E., 1978, Principles of Sedimentology, New York: John Wiley \& Sons, 66-69.

Galaska, E. G., Skladany, G. J. and Nyer, E. K., 1990, Biological Treatment of Groundwater, Soils and Soil Vapors Contaminated with Petroleum Hydrocarbons, 44th Purdue Industrial Waste Conference Proceedings, Chelsea, Michigan: Lewis Publishers, 11-21.

Grubbs, R. B., 1986, Enhanced Biodegradation of Aliphatic and Aromatic Hydrocarbons through Bioaugmentation, presented to the 4th Annual Hazardous Materials Management Conference/Exhibit, Atlantic City, NJ, June 2-4.

Grundmann, R. and Rehm, H. J., 1991, Biodegradation of Diesel-Fuel, Erdol \& Kohle, Erdgas, Petrochemie, 44(4), 149-150.

Harder, H., Kurzel-Seidel, B. and Hopner, T., 1991, Hydrocarbon Biodegradation in Sediments and Soils, Erdol \& Kohle, Erdgas, Petrochemie, 44(2), 59-62.

Hills, J. J., 1989, A State's Perspective of the Problems Associated with Petroleum Contaminated Soils, Petroleum Contaminated Soils, Vol. I, P. T. Kostecki and E. J. Calabrese-Eds, Chelsea, MI: Lewis Publishers, 21-26.

Hinchee, R. E. and Arthur, M., 1991, Bench Scale Studies of the Soil Aeration Process for Bioremediation of Petroleum Hydrocarbons, Applied Biochemistry and Biotechnology, 28/29, 901-906.

Kopp, J. F. and McKee, G. D., 1983, Methods for Chemical Analysis of Water and Wastes, EPA-600/4-79-020, Environmental Monitoring and Support Laboratory, Cincinnati, $\mathrm{OH}$.

McCarty, P. L., 1988, Bioengineering Issues Related to In Situ Remediation of Contaminated Soils and Groundwater, Environmental Biotechnology, G. S. Omenn - Ed., New York: Plenum Press, 143-162.

McFarland, M. J., Sims, R. C. and Blackburn, J. W., 1991, Uses of Treatability Studies in Developing Remediation Strategies for Contaminated Soils, Environmental Biotechnology for Waste Treatment, G. S. Sayler et al.-Eds., New York: Plenum Press, 163-174. 
Methods of Soil Analysis, Part 2: Chemical and Microbiological Properties, 1982, 2nd Ed., A. L. Page et al.-Eds., Madison, WI: American Society of Agronomy, 788790.

Mitchell, J. K., 1993, Fundamentals of Soil Behavior 2 2nd Ed., New York: John Wiley \& Sons, 124.

Molnaa, B. A. and Grubbs, R. B., (no date), Bioremediation of Petroleum Contaminated Soils using a Microbial Consortia as Inoculum, Solmar Corporation Marketing Literature.

Morgan, D. J., Battaglia, A., Smith, J. R., Middleton, A. C., Nakles, D. V. and Linz, D. G., 1991, Evaluation of a Biodegradation Screening Protocol for Contaminated Soil from Manufactured Gas Plant Sites, Gas, Oil, Coal, and Environmental Biotechnology III, C. Akin and J. Smith-Eds., Chicago: Institute of Gas Technology, 55-74.

Namkoong, W., Loehr, R. C. and Malina, J. F., 1988, Kinetics of Phenolic Compounds Removal in Soil, Hazardous Waste \& Hazardous Materials, 5(4), 321-328.

Pardieck, D. L., Bouwer, E. J. and Stone, A. T., 1992, Hydrogen Peroxide Use to Increase Oxidant Capacity for In Situ Bioremediation of Contaminated Soils and Aquifers: A Review, Journal of Contaminant Hydrology, 9, 221-242.

Peters, R. W., Shem, L., Montemagno, C. D. and Lewis, B., 1991, Surfactant Screening of Diesel-Contaminated Soil, Gas, Oil, Coal, and Environmental Biotechnology III, C. Akin and J. Smith-Eds., Chicago: Institute of Gas Technology, 121-147.

Raymond, R. L., Jamison, V. W. and Hudson, J. O., 1976, Beneficial Stimulation of Bacterial Activity in Groundwaters Containing Petroleum Products, American Institute of Chemical Engineers Symposium Series, 74, 390-404.

Ryan, J. R., Loehr, R. C. and Rucker, E., 1991, Bioremediation of Organic Contaminated Soils, Journal of Hazardous Materials, 28, 159-169.

Staps, S. J. J. M., 1990, International Evaluation of In-situ Biorestoration of Contaminated Soil and Groundwater, EPA/540/2-90/012, Washington, D.C.

State of California, 1989, Leaking Underground Fuel Tank Field Manual: Guidelines for Site Assessment, Cleanup and Underground Storage Tank Closure, Leaking Underground Fuel Tank Task Force.

Truitt, M. M., 1983, Soil Mechanics Technology, New Jersey: Prentice-Hall, 50-52.

USEPA, 1982, Chemical Fate Test Guidelines, EPA-560/6-82-003, Washington, D.C.

USEPA, 1986, Test Methods for Evaluating Solid Wastes (SW-846), 3rd Ed., Office of Solid Waste and Emergency Response, Washington, D.C.

USEPA, 1989, Innovative Technology: Slurry-Phase Biodegradation, Fact Sheet 9200.5252FS, Solid Waste and Emergency Response (OS-220), Washington, D.C. 
USEPA, 1990, Slurry Biodegradation, Engineering Bulletin EPA/540/2-90/016, Office of Emergency and Remedial Response, Washington, D.C.

USEPA, 1991, Understanding Bioremediation - A Guidebook for Citizens, EPA/540/291/002, Research and Development, Washington, D.C.

Wang, X. and Bartha, R., 1990, Effects of Bioremediation on Residues, Activity and Toxicity in Soil Contaminated by Fuel Spills, Soil Biology and Biochemistry, 22(4), 501-505.

Westat, Inc., 1986, Underground Motor Fuel Storage Tanks: A National Survey, Vol. I: Technical Report, Vol. II: Appendices, USEPA, Washington, D.C., PB86-216512, National Technical Information Service. 


\section{APPENDICES}

Page

1. Appendix A: Sample Calculations $\quad 88$

2. Appendix B: EPA Method 8015

3. Appendix C: Media Preparation and Spread Plate Technique 91

4. Appendix D: Gas Chromatograph Data 97

5. Appendix E: Calibration Data 104

6. Appendix F: Raw Data 93

7. Appendix G: Gas Chromatograph and Integrator Settings 109 


\section{Appendix A: Sample Calculations}

\section{Diesel Fuel Contamination in Prepared Soil}

The average initial diesel fuel contamination in the prepared soil was determined from the integrated total area results of the gas chromatograph analyses. The data from the first extraction of the prepared soil will be used as an example. The result of the GC analysis for this sample are provided in Appendix D (Table D.1) under Run \# 297. The calibration data for this particular run are provided in the "Comments" section of the table.

Total Area

Calibration Equation

Calibration Slope

Calibration intercept

Sample Size

Extraction Volume

Soil Concentration
$1,242,500$

Total Area $=($ slope $)($ Diesel $)+$ intercept

360.68

28,642

1 gram

$10 \mathrm{~mL}$ (freon)

$\left(\frac{\text { Total Area - Intercept }}{\text { Slope }}\right)\left(\frac{\text { Extraction Volume }}{\text { Sample Volume }}\right)=\left(\frac{1,242,500-28,642}{360.68}\right)\left(\frac{10 \mathrm{~mL}}{1 \mathrm{~g}}\right)=\frac{33,654 \mathrm{mg}}{\mathrm{kg}}$ 


\section{Initial Slurry Concentration}

Soil Contamination

Soil Loading

Soil Bulk Density

Aqueous Phase

Mixture Ratio

Slurry Volume
$30,000 \mathrm{mg} / \mathrm{kg}$ (average)

$50 \mathrm{~g}$

\section{$1.1 \mathrm{~g} / \mathrm{mL}$}

$450 \mathrm{~mL}$

10 percent solids by weight

$450 \mathrm{mLH}_{2} \mathrm{O}+50 \mathrm{gsoil}\left(\frac{\mathrm{mL}}{1.1 \mathrm{~g}}\right)=500 \mathrm{~mL}$

\section{Slurry Concentration}

(50 g soil $)\left(\frac{1 \mathrm{~kg}}{1000 \mathrm{~g}}\right)\left(\frac{30,000 \mathrm{mgDiesel}}{\mathrm{kgsoil}}\right)\left(\frac{1}{500 \mathrm{mLSlurry}}\right)\left(\frac{1,000 \mathrm{~mL}}{\mathrm{~L}}\right)=\left(\frac{3,000 \mathrm{mgDiesel}}{\text { LSlurry }}\right)$ 


\section{Intermediate Slurry Concentration}

As with the diesel fuel contamination in the prepared soil, the intermediate slurry concentrations were determined from the integrated total area results of the GC analyses.

The data from the Day 4 analysis in Experimental Series \#1 of the Sparge/Stir reactor will be used as an example. The result of the GC analysis for this sample are provided in Appendix D (Table D.1) under Sample S/S 3 and the calibration equation and data are given in Appendix E.

Total Area

Calibration Equation

Calibration SIope

Calibration intercept

Sample Volume

Extraction Volume

Slurry Concentration
15,604

Total Area $=($ intercept $)\left[(\text { Diesel })^{(\text {slope })}\right]$

\subsection{5}

80.711

$5 \mathrm{~mL}$

$10 \mathrm{~mL}$ (freon)

$\left(\frac{\text { Total Area }}{\text { Intercept }}\right)\left(\frac{1}{\text { Slope }}\right)\left(\frac{\text { Extraction Volume }}{\text { Sample Volume }}\right)=\left(\frac{15,604}{80.711}\right)\left(\frac{1}{1.1515}\right)\left(\frac{10 \mathrm{~mL}}{5 \mathrm{~mL}}\right)=\frac{193 \mathrm{mg}}{\mathrm{L}}$ 


\section{Error Analysis}

Error analysis was applied to the exponential model representing the first order kinetics.

The Exponential Model (Cricket Graph version 1.3) was of the form:

$$
\mathrm{D}=\mathrm{D}_{\mathrm{o}} 10^{-\mathrm{kt}}
$$

where $\mathrm{D}$ is Diesel Concentration in $\mathrm{mg} / \mathrm{L}$

$D_{0}$ is the initial Diesel Concentration in $\mathrm{mg} / \mathrm{L}$

$t$ is Time in days

$\mathrm{k}$ is the first order rate constant in time $\mathrm{e}^{-1}$.

The derivation and error analysis are as follows:

$$
\begin{aligned}
& \frac{D}{D_{0}}=10^{-k t} \\
& \log _{10}\left(\frac{D}{D_{0}}\right)=-k t \\
& k=\frac{1}{t} \log _{10}\left(\frac{D_{0}}{D}\right) \\
& \lambda^{2}(k)=\left(\frac{\partial k}{\partial t}\right)^{2} \lambda^{2}(t)+\left(\frac{\partial k}{\partial D}\right)^{2} \lambda^{2}(D) \\
& \frac{\partial k}{\partial t}=-\frac{1}{t^{2}} \log _{10}\left(\frac{D_{0}}{D}\right) \\
& \frac{\partial k}{\partial D}=-\frac{1}{k D} \\
& \lambda(k)=\sqrt{\left(-\frac{1}{t^{2}} \log _{10}\left(\frac{D_{0}}{D}\right)\right)^{2} \lambda^{2}(t)+\left(-\frac{1}{k D}\right)^{2} \lambda^{2}(D)}
\end{aligned}
$$


The data from the Day 4 analysis in Experimental Series \#1 of the Sparge/Stir reactor will be used as an example. The first order rate constant determined from the Exponential Model for the Sparge/Stir reactor of Experimental Series \#1 was 0.23570 days $^{-1}$.

$$
\begin{gathered}
\mathrm{t}=4 \text { days } \\
\lambda(\mathrm{t})=0.170 \text { days } \\
\mathrm{Do}=4,526 \mathrm{mg} / \mathrm{L} \\
\mathrm{D}=193 \mathrm{mg} / \mathrm{L} \\
\lambda(\mathrm{D})=(193 \mathrm{mg} / \mathrm{L})(0.072)=13.9 \mathrm{mg} / \mathrm{L} \\
\lambda(\mathrm{k})=\sqrt{\left(\frac{-1}{(4 \text { days })^{2}} \log _{10}\left(\frac{4,526 \frac{\mathrm{mg}}{\mathrm{L}}}{193 \frac{\mathrm{mg}}{\mathrm{L}}}\right)\right)^{2}(0.17 \text { days })^{2}+\left(\frac{-1}{(4 \text { days })\left(193 \frac{\mathrm{mg}}{\mathrm{L}}\right)}\right)^{2}\left(13.9 \frac{\mathrm{mg}}{\mathrm{L}}\right)^{2}} \\
\lambda(\mathrm{k})=0.02315 \text { days }^{-1} \\
\text { Percent Error }=\frac{\lambda(\mathrm{k})}{\mathrm{k}} \times 100 \%=\frac{0.02315 \text { days }^{-1}}{0.23570 \text { days }^{-1}} \times 100 \%=9.8 \text { percent }
\end{gathered}
$$

This error analysis was applied at each of the time points (excluding the initial time points) of each experimental condition within Experimental Series \#1 and \#2. Within each experimental series, for each experimental condition, these errors were averaged. The average error was used in evaluating the significance of the differences in the first order rate constants between the experimental conditions. 
Appendix B: EPA Method 8015 
METHOD 8015

NONHALOGENATED VOLATILE ORGANICS

\subsection{SCOPE AND APPLICATION}

1.1 Method 8015 is used to determine the concentration of various nonhalogenated volatile organic compounds. Table 1 indicates the compounds that may be investigated by this method.

\subsection{SUMMARY OF METHOD}

2.1 Method 8015 provides gas chromatographic conditions for the detection of certain nonhalogenated volatile organic compounds. Samples may be analyzed using direct injection or purge-and-trap (Method 5030). Ground water samples must be analyzed by Method 5030. A temperature program is used in the gas chromatograph to separate the organic compounds. Detection is achieved by a flame ionization detector (FID).

2.2 If interferences are encountered, the method provides an optional gas chromatographic column that may be helpful in resolving the analytes from interferences that may occur and for analyte confirmation.

\subsection{INTERFERENCES}

3.1 Refer to Method 5030 and 8000 .

3.2 Samples can be contaminated by diffusion of volatile organics (particularly chlorofluorocarbons and methylene chloride) through the sample container septum during shipment and storage. A field sample blank prepared from reagent water and carried through sampling and subsequent storage and handling can serve as a check on such contamination.

\subsection{APPARATUS AND MATERIALS}

\subsection{Gas chromatograph:}

4.1.1 Gas Chromatograph: Analytical system complete with gas chromatograph suitable for on-column injections or purge-and-trap sample introduction and all required accessories, including detectors, column supplies, recorder, gases, and syringes. A data system for measuring peak heights and/or peak areas is recommended.

\subsubsection{Columns:}

4.1.2.1 Column 1: 8 - $\mathrm{ft} \times 0.1$-in I.D. stainless steel or glass column packed with $1 \% \mathrm{SP}-1000$ on Carbopack-B $60 / 80$ mesh or equivalent.

$$
8015-1
$$

Revision 0 Date September 1986 
Acrylamide

Diethyl ether

Ethanol

Methyl ethyl ketone (MEK)

Methyl isobutyl ketone (MIBK)

Paraldehyde (trimer of acetaldehyde) 
4.1.2.2 Column 2: 6-ft $\times 0.1-$ in I.D. stainless steel or glass column packed with n-octane on Porasil-C 100/120 mesh (Durapak) or equivalent.

\subsubsection{Detector: Flame ionization (FID).}

4.2 Sample introduction apparatus: Refer to Method 5030 for the appropriate equipment for sample introduction purposes.

4.3 Syringes: A 5-mL Luerlok glass hypodermic and a 5-mL, gas-tight with shutoff valve.

4.4 Volumetric flask: $10-, 50-, 100-, 500-$, and $1,000-\mathrm{mL}$ with a groundglass stopper.

4.5 Microsyringe: 10 - and 25-uL with a 0.006-in I.D. needle (Hamilton $702 \mathrm{~N}$ or equivalent) and a 100-uL.

\subsection{REAGENTS}

5.1 Reagent water: Reagent water is defined as a water in which an interferent is not observed at the method detection limit (MDL) of the analytes of interest.

5.2 Stock standards: Stock solutions may be prepared from pure standard materials or purchased as certified solutions. Prepare stock standards in methanol using assayed liquids.

5.2.1 Place about $9.8 \mathrm{~mL}$ of methanol in a $10-\mathrm{mL}$ tared ground-glassstoppered volumetric flask. Allow the flask to stand, unstoppered, for about 10 min or until all alcohol-wetted surfaces have dried. Weigh the flask to the nearest $0.1 \mathrm{mg}$.

5.2.2 Using a 100-uL syringe, immediately add two or more drops of assayed reference material to the flaski then reweigh. The liquid must fall directly into the alcohol without contacting the neck of the flask.

5.2.3 Reweigh, dilute to volume, stopper, and then mix by inverting the flask several times. Calculate the concentration in micrograms per microliter (ug/uL) from the net gain in weight. When compound purity is assayed to be $96 \%$ or greater, the weight may be used without correction to calculate the concentration of the stock standard. Commercially prepared stock standards may be used at any concentration if they are certified by the manufacturer or by an independent source.

5.2.4 Transfer the stock standard solution into a Tefion-sealed screw-cap bottle. Store, with minimal headspace, at $-10^{\circ} \mathrm{C}$ to $-20^{\circ} \mathrm{C}$ and protect from light.

5.2.5 Standards must be replaced after 6 months, or sooner if comparison with check standards indicates a problem.

$$
8015-3
$$

Revision $\frac{0}{\text { September } 1986}$
Date


5.3 Secondary dilution standards: Using stock standard solutions, prepare in methanol secondary dilution standards, as needed, that contain the compounds of interest, either singly or mixed together. The secondary dilution standards should be prepared at concentrations such that the aqueous calibration standards prepared in Section 5.4 will bracket the working range of the analytical system. Secondary dilution standards should be stored with minimal headspace for volatiles and should be checked frequently for signs of degradation or evaporation, especially just prior to preparing calibration standards from them.

5.4 Calibration standards: Calibration standards at a minimum of five concentration levels are prepared in reagent water from the secondary dilution of the stock standards. One of the concentration levels should be at a concentration near, but above, the method detection limit. The remaining concentration levels should correspond to the expected range of concentrations found in real samples or should define the working range of the GC. Each standard should contain each analyte for detection by this method (e.g.., some or all of the compounds listed in Table 1 may be included). In order to prepare accurate aqueous standard solutions, the following precautions must be observed.

5.4.1 Do not inject more than $20 \mathrm{uL}$ of alcoholic standards into $100 \mathrm{~mL}$ of reagent water.

5.4.2 Use a 25-UL Hamilton $702 \mathrm{~N}$ microsyringe or equivalent (variations in needle geometry will adversely affect the ability to deliver reproducible volumes of methanolic.standards into water).

5.4.3 Rapidly inject the alcoholic standard into the filled volumetric flask. Remove the needle as fast as possible after injection. only.

5.4.4 Mix aqueous standards by inverting the flask three times

5.4.5 Fill the sample syringe from the standard solution contained in the expanded area of the flask (do not use any solution contained in the neck of the flask).

5.4.6 Never use pipets to dilute or transfer samples or aqueous standards.

5.4.7 Aqueous standards are not stable and should be discarded after $1 \mathrm{hr}$, unless properly sealed and stored. The aqueous standards can be stored up to $24 \mathrm{hr}$, if held in sealed vials with zero headspace.

5.5 Internal standards (if internal standard calibration is used): To use this approach, the analyst must select one or more inter\$1 standards that are similar in analytical behavior to the compounds of interest. The analyst must further demonstrate that the measurement of the internal standard is not affected by method or matrix interferences. Because of these limitations, no internal standard can be suggested that is applicable to all samples.

$$
8015-4
$$

Revision $\frac{0}{\text { Sate }}$ September 1986 
5.5.1 Prepare calibration standards at a minimum of five concentration levels for each parameter of interest as described in Section 5.4 .

5.5.2 Prepare a spiking solution containing each of the internal standards using the procedures described in Sections 5.2 and 5.3 . It is recommended that the secondary dilution standard be prepared at a concentration of $15 \mathrm{ug} / \mathrm{mL}$ of each internal standard compound. The addition of $10 \mathrm{uL}$ of this standard to $5.0 \mathrm{~mL}$ of sample or calibration standard would be equivalent to $30 \mathrm{ug} / \mathrm{L}$.

5.5.3 Analyze each calibration standard according to Section 7.0, adding $10 \mathrm{uL}$ of internal standard spiking solution directly to the syringe.

5.6 Surrogate standards: The analyst should monitor both the performance of the analytical system and the effectiveness of the method in dealing with each sample matrix by spiking each sample, standard, and reagent water blank with one or two surrogate compounds recommended to encompass the range of temperature program used in this method. From stock standard solutions prepared as in Section 5.2, add a volume to give $750 \mathrm{ug}$ of each surrogate to $45 \mathrm{~mL}$ of reagent water contained in a 50-mL volumetric flask, mix, and dilute to volume for a concentration of $15 \mathrm{ng} / \mathrm{uL}$. Add $10 \mathrm{uL}$ of this surrogate spiking solution directly into the $5-\mathrm{mL}$ syringe with every sample and reference standard analyzed. If the internal standard calibration procedure is used, the surrogate compounds may be added directiy to the internal standard spiking solution (Paragraph 5.5.2). solvents.

5.7 Methanol: pesticide quality or equivalent. Store away from other

\subsection{SAMPLE COLLECTION, PRESERVATION, AND HANDLING} Section 4.1 .

6.1 See the introductory material to this chapter, Organic Analytes,

\subsection{PROCEDURE}

7.1 Volatile compounds are introduced into the gas chromatograph either by direct injection or purge-and-trap (Method 5030). Method 5030 may be used directly on ground water samples or low-level contaminated soils and sediments. For medium-level soils or sediments, methanolic extraction, as described in Method 5030, may be necessary prior to purge-and-trap analysis.

\subsection{Gas chromatography conditions (Recommended):}

7.2.1 Column 1: Set helium gas flow at $40 \mathrm{~mL} / \mathrm{min}$ flow rate. Set column temperature at $45^{\circ} \mathrm{C}$ for $3 \mathrm{~min}$; then program an $8^{\circ} \mathrm{C} / \mathrm{min}$ temperature rise to $220^{\circ} \mathrm{C}$ and hold for $15 \mathrm{~min}$.

$$
8015-5
$$

Revision 0 Date September 1986 
7.2.2 Column 2: Set helium gas flow at $40 \mathrm{~mL} / \mathrm{min}$ flow rate. Set column temperature at $50^{\circ} \mathrm{C}$ for 3 min; then program a $6^{\circ} \mathrm{C} / \mathrm{min}$ temperature rise to $170^{\circ} \mathrm{C}$ and hold for $4 \mathrm{~min}$. techniques.

7.3 Calibration: Refer to Method 8000 for proper calibration

7.3.1 Calibration must take place using the same sample introduction method that will be used to analyze actual samples (see Section 7.4.1).

7.3.2 The procedure for internal or external calibration may be used. Refer to Method 8000 for a description of each of these procedures.

\subsection{Gas chromatographic analysis:}

7.4.1 Introduce volatile compounds into the gas chromatograph using either Method 5030 (purge-and-trap method) or the direct injection method. If the internal standard calibration technique is used, add $10 \mathrm{UL}$ of internal standard to the sample prior to purging.

7.4.1.1 Direct injection: In very limited applications (e.g., aqueous process wastes), direct injection of the sample into the GC system with a 10 uL syringe may be appropriate. One such application is for verification of the alcohol content of an aqueous sample prior to determining if the sample is ignitable (Methods 1010 or 1020). In this case, it is suggested that direct injection be used. The detection limit is very high (approximately 10,000 ug/L): therefore, it is only permitted when concentrations in excess of $10,000 \mathrm{ug} / \mathrm{L}$ are expected or for water-soluble compounds that do not purge. The system must be calibrated by direct injection (bypassing the purge-and-trap device).

7.4.2 Follow Section 7.6 in Method 8000 for instructions on the analysis sequence, appropriate dilutions, establishing daily retention time windows, and identification criteria. Include a mid-level standard after each group of 10 samples in the analysis sequence.

7.4.3 Record the sample volume purged or injected and the resulting peak sizes (in area units or peak heights). Method 8000 .

7.4.4 Calculation of concentration is covered in Section 7.8 of

7.4.5 If analytical interferences are suspected, or for the purpose of confirmation, analysis using the second GC column is recommended.

7.4.6 If the response for a peak is off-scale, prepare a dilution of the sample with reagent water. The dilution must be performed on a second aliquot of the sample which has been properly sealed and stored prior to use.

$$
8015-6
$$

Revision 0 Date September 1986 


\subsection{QUALITY CONTROL}

8.1 Refer to Chapter One for specific quality control procedures and Method 8000 for gas chromatographic procedures. Quality control to ensure the proper operation of the purge-and-trap device is covered in Method 5030.

8.2 Mandatory quality control to validate the GC system operation is found in Method 8000, Section 8.6.

8.3 Calculate surrogate standard recovery on all samples, blanks, and spikes. Determine if recovery is within limits (limits established by performing QC procedure outlined in Method 8000, Section 8.10).

8.3.1 If recovery is not within limits, the following is required.

- Check to be sure there are no errors in calculations, surrogate solutions and internal standards. Also, check instrument performance.

- Recalculate the data and/or reanalyze the extract if any of the above checks reveal a problem.

- Reextract and reanalyze the sample if none of the above are a problem or flag the data as "estimated concentration."

\subsection{METHOD PERFORMANCE}

9.1 The accuracy and precision obtained will be determined by the sample matrix, sample introduction technique, and calibration procedures used.

9.2 Specific method performance information will be provided as it becomes available.

\subsection{REFERENCES}

1. Bellar, T.A., and J.J. Lichtenberg, J. Amer. Water Works Assoc., 66(12), pp. 739-744, 1974.

2. Bellar, T.A., and J.J. Lichtenberg, Semi-Automated Headspace Analysis of Drinking. Waters and Industrial Waters for Purgeable Volatile Organic Compounds, in Van Hall, ed., Measurement of Organic Pollutants in Water and Wastewater, ASTM STP 686, pp. 108-129, 1979.

3. Development and Application of Test Procedures for Specific Organic Toxic Substances in Wastewaters: Category 11 - Purgeables and Category 12 Acrolein, Acrylonitrile, and Dichlorodifluoromethane, Report for EPA Contract 68-03-2635 (in preparation).

$8015-7$

Revision $\frac{0}{\text { September } 1986}$
Date 
METHOD OS15

NaNHALOEENATEE VOLATILE OAGANEES
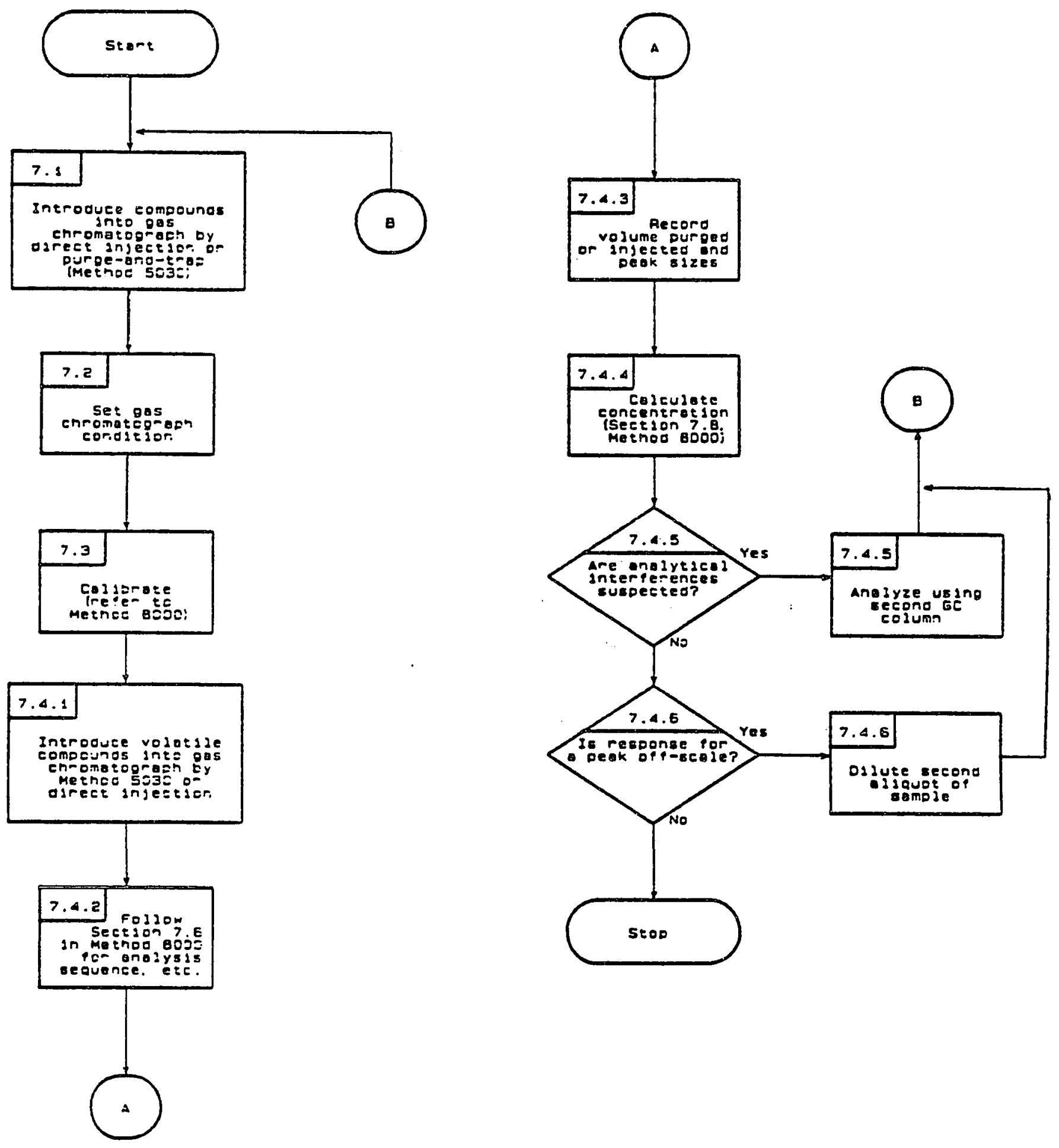

$8015-8$

Revision 0

Date September 1986 


\section{Appendix C: Media Preparation and Spread Plate Technique}

The microbial enumerations were performed in triplicate on a yeast extract/dextrose/calcium carbonate (YDC) agar medium using a spread plate technique (APHA and AWWA, 1985, and Methods of Soil Analysis, 1982). The YDC media was prepared according to the following recipe: 0.5 percent yeast extract, 1.5 percent agar, 2.0 percent glucose and 2.0 percent calcium carbonate $\left(\mathrm{CaCO}_{3}\right)$. The media was sterilized in an autoclave at $121^{\circ} \mathrm{C}$ and $15 \mathrm{psig}$ for 20 minutes. The media was cooled to $50^{\circ} \mathrm{C}$ and distributed in roughly $15 \mathrm{~mL}$ portions into glass petri dishes. The media was gently swirled during the transfer to keep the $\mathrm{CaCO}_{3}$ in solution yet not produce bubbles in the media. The mouth of the media container was passed through a Bunsen burner flame occasionally during the transferring to prevent any outside contamination. The plates were cured overnight then inspected for contamination before either immediate use or refrigerated storage at $4^{\circ} \mathrm{C}$.

Slurry samples, $1.0 \mathrm{~mL}$, were taken from each reactor with separate, sterile pipettes. The samples were serially diluted to $10^{-6}$ in $9.0 \mathrm{~mL}$ sterile, buffered dilution blanks. The dilution blanks contained 0.3 millimolar potassium dihydrogen phosphate. Three $0.1 \mathrm{~mL}$ aliquots of each dilution were transferred to prepared petri plates. The $0.1 \mathrm{~mL}$ aliquot on each plate was spread over the agar surface using a sterile glass spreader. The spreading was started on the plates of the highest dilution continuing down to the lowest dilution. Every six to nine plates, a fresh, sterile glass spreader was used to prevent any cross contamination. The glass spreaders were not sterilized in an alcohol flame due to cross contamination observed in initial platings.

After spreading all the dilution samples on the plates in triplicate, the plates were inverted. The plates were incubated at $28^{\circ} \mathrm{C}$ for 3 days. Only plates with colony forming 
units between 30 and 300 were counted. The average of the triplicate counts was reported in this study. 


\section{Appendix D: Gas Chromatograph Data}

Table D.1. Gas Chromatograph Data, Experiment \#1.

\begin{tabular}{|c|c|c|c|c|c|}
\hline Run & Date & Sample & [Diesel], mg/L & Total Area & Comments \\
\hline 297 & $3 / 2$ & SOIL 1 & & $1,242,500$ & $m=360.68, y=28,642$, corr $=0.99291$ \\
\hline 389 & $4 / 12$ & $\mathrm{C}$ & 1,007 & 295,290 & stegasarus tail(ST)-air in needle/septum \\
\hline 390 & $4 / 12$ & $\mathrm{C}$ & 1,007 & 283,040 & ST-large \\
\hline 393 & $4 / 13$ & $\mathrm{C}$ & 1,007 & 264,780 & ST-small \\
\hline 394 & $4 / 13$ & $\mathrm{C}$ & 1,007 & 249,230 & ST-large \\
\hline 395 & $4 / 13$ & $\bar{C}$ & 1,007 & 259,250 & ST-large \\
\hline 396 & $4 / 13$ & $\mathrm{D}$ & 705 & 200,370 & ST-small \\
\hline 397 & $4 / 13$ & $\mathrm{E}$ & 403 & 88,522 & ST-small \\
\hline 398 & $4 / 13$ & $\bar{F}$ & 101 & 17,306 & ST-large \\
\hline 404 & $4 / 15$ & $\mathrm{~A}$ & 3,021 & 724,630 & ST-small \\
\hline 405 & $4 / 15$ & $\mathbf{B}$ & 2,014 & 522,730 & "1" \\
\hline 406 & $4 / 15$ & $\bar{C}$ & 1,007 & 236,470 & $"$ \\
\hline 407 & $4 / 15$ & $\mathrm{D}$ & 705 & 175,060 & $"$ \\
\hline 408 & $4 / 15$ & $\bar{E}$ & 403 & 71,187 & " \\
\hline 409 & $4 / 15$ & $\mathbf{F}$ & 101 & 12,609 & ST-large, difficult injection \\
\hline 416 & $4 / 20$ & $\mathrm{C}$ & 1,007 & 258,910 & air spikes \\
\hline 417 & $4 / 20$ & $\bar{B}$ & 2,014 & 511,090 & air spikes \\
\hline 418 & $4 / 20$ & $\bar{A}$ & 3,021 & 990,300 & \\
\hline 419 & $4 / 21$ & $\mathrm{C}$ & 1,007 & 266,470 & \\
\hline 420 & $4 / 21$ & S/S 1* & & 588,840 & \\
\hline 421 & $4 / 21$ & $\mathrm{H} / \mathrm{S} \mathrm{I}$ & & 594,300 & \\
\hline 422 & $4 / 21$ & S 1 & & 537,820 & \\
\hline 423 & $4 / 22$ & $\mathrm{C}$ & 1,007 & 294,650 & \\
\hline 424 & $4 / 22$ & $\mathrm{D}$ & 705 & 192,090 & \\
\hline 425 & $4 / 22$ & $\mathrm{E}$ & 403 & 81,350 & \\
\hline 426 & $4 / 22$ & $F$ & 101 & 15,276 & \\
\hline 427 & $4 / 22$ & S/S 2 & & 78,633 & \\
\hline 428 & $4 / 23$ & $\mathrm{C}$ & 1.007 & 222,000 & \\
\hline 429 & $4 / 23$ & $\mathrm{H} / \mathrm{S} 2$ & & 132,690 & \\
\hline 430 & $4 / 23$ & 52 & & 101,200 & \\
\hline 431 & $4 / 23$ & SOIL 2a & & $2,352,500$ & out of calibration \\
\hline 432 & $4 / 24$ & $\mathrm{C}$ & 1,007 & 207,670 & \\
\hline 433 & $4 / 24$ & $\bar{C}$ & 1,007 & 228,920 & \\
\hline 434 & $4 / 26$ & $\mathrm{C}$ & 1,007 & 244,260 & \\
\hline 435 & $4 / 26$ & S/S 3 & & 15,604 & \\
\hline 436 & $4 / 26$ & $\mathrm{H} / \mathrm{S} 3$ & & 36,090 & \\
\hline 437 & $4 / 26$ & S3 & & 44,124 & \\
\hline 438 & $4 / 26$ & SOIL 2b & & 274,160 & \\
\hline
\end{tabular}


Table D.1. Gas Chromatograph Data, Experiment \#1 (cont.'d).

\begin{tabular}{|c|c|c|c|c|c|}
\hline Run & Date & Sample & [Diesel], mg/L & Total Area & Comments \\
\hline 439 & $4 / 26$ & $\mathrm{G}$ & 51 & 7,674 & \\
\hline 440 & $4 / 27$ & FREON & & 7,675 & \\
\hline 441 & $4 / 27$ & FREON.b & & 0 & \\
\hline 442 & $4 / 27$ & $\mathrm{G}$ & 51 & 0 & \\
\hline 443 & $4 / 27$ & S/S 4 & & 11,976 & \\
\hline 444 & $4 / 27$ & $\mathrm{H} / \mathrm{S} 4$ & & 5,519 & \\
\hline 445 & $4 / 27$ & $\mathrm{S4}$ & & 21,066 & \\
\hline 446 & $4 / 28$ & $\mathrm{C}$ & 1,007 & 193,060 & ATT -3 , peaks off-scale \\
\hline 447 & $4 / 28$ & $\mathrm{C}$ & 1,007 & 231,180 & \\
\hline 448 & $4 / 28$ & $\mathrm{~S} / \mathrm{S} 4$ & & 6,276 & \\
\hline 450 & $4 / 28$ & SOIL 3 & & 410,490 & \\
\hline 451 & $4 / 28$ & $\mathrm{G}$ & 51 & 4,474 & THRSH - 2 \\
\hline 452 & $4 / 28$ & $\mathbf{F}$ & 101 & 21,371 & THRSH -2 \\
\hline 453 & $4 / 28$ & $\overline{\mathrm{H}}$ & 10 & 1,825 & THRSH -2 \\
\hline 454 & $4 / 29$ & $\bar{F}$ & 101 & 30,070 & THRSH -2 \\
\hline 455 & $4 / 29$ & $\mathrm{G}$ & 51 & 4,653 & THRSH -2 \\
\hline 456 & $4 / 29$ & $\mathrm{H}$ & 10 & 1,439 & THRSH - 2 \\
\hline 457 & $4 / 29$ & $\overline{\mathrm{H}}$ & 10 & 2,802 & THRSH -2 \\
\hline 458 & $4 / 29$ & S/S 5 & & 8,185 & THRSH -2 \\
\hline 459 & $4 / 29$ & $\mathrm{H} / \mathrm{S} 5$ & & 11,672 & THRSH -2 \\
\hline 460 & $4 / 30$ & $\mathrm{G}$ & 51 & 12,244 & THRSH -2 \\
\hline 461 & $4 / 30$ & S 5 & & 23,711 & THRSH -2 \\
\hline 462 & $4 / 30$ & S 5 & & 4,143 & \\
\hline 463 & $5 / 2$ & $\mathrm{C}$ & 1,007 & 222,220 & \\
\hline 464 & $5 / 2$ & $\mathrm{H} / \mathrm{S} 5$ & & 6,861 & \\
\hline 465 & $5 / 3$ & $\mathrm{C}$ & 1,007 & 227,840 & \\
\hline 466 & $5 / 3$ & S/S 5 & & 2,926 & \\
\hline
\end{tabular}

* S/S refers to Sparge/Stir reactor, $\mathrm{H} / \mathrm{S}$ refers to $\mathrm{H}_{2} \mathrm{O}_{2} /$ Stir reactor and $\mathrm{S}$ refers to the Stir reactor; the number following the abbreviation refers to the sample number within the experimental series. 
Table D.2. Gas Chromatograph Data, Experiment \#2.

\begin{tabular}{|c|c|c|c|c|c|c|}
\hline Run & Date & Sample & [Diesel], mg/L & Signal & Total Area & Comments \\
\hline 467 & $5 / 3$ & FREON & & & 0 & clean \\
\hline 468 & $5 / 4$ & $\mathrm{E}$ & 403 & & 103,750 & ATT-2,THRSH-2 \\
\hline 469 & $5 / 4$ & D & 705 & & 208,470 & ATT-1,THRSH-2 \\
\hline 470 & $5 / 4$ & $\mathrm{C}$ & 1,007 & & 254,380 & \\
\hline 471 & $5 / 4$ & $\bar{B}$ & 2,014 & & 490,750 & freon peak frontal glitch (FG) \\
\hline 472 & $5 / 4$ & $\bar{A}$ & 3,021 & & 647,000 & " "low area? \\
\hline 473 & $5 / 4$ & $\mathrm{~A}$ & 3,021 & & 681,610 & "1" \\
\hline \multicolumn{7}{|c|}{ changed septa } \\
\hline 478 & $5 / 5$ & $\mathrm{C}$ & 1,007 & & 218,770 & miss inj, nut too tight \\
\hline 479 & $5 / 5$ & $\mathrm{C}$ & 1,007 & & 269,000 & frontal glitch \\
\hline 480 & $5 / 5$ & HC TRAP & & & 24,300 & air peaks \\
\hline 481 & $5 / 6$ & $\mathrm{C}$ & 1,007 & & 239,600 & diff inj \\
\hline 482 & $5 / 6$ & B & 2,014 & & 509,920 & trying out needle fit peak \\
\hline 483 & $5 / 6$ & $\mathrm{~A}$ & 3,021 & & 622,590 & FG \\
\hline 484 & $5 / 6$ & $\mathrm{~A}$ & 3,021 & & 732,830 & low area, inj time too short \\
\hline 485 & $5 / 6$ & $\bar{A}$ & 3,021 & & 769,950 & FG \\
\hline 486 & $5 / 6$ & $\mathrm{~A}$ & 3,021 & & 741,930 & $\mathrm{FG}$ \\
\hline 487 & $5 / 6$ & $\mathrm{~B}$ & 2,014 & & 496,570 & $\mathrm{FG}$ \\
\hline 488 & $5 / 7$ & $\overline{\mathrm{B}}$ & 2,014 & & $.504,870$ & $\mathrm{FG}$ \\
\hline 489 & $5 / 7$ & $\mathrm{C}$ & 1,007 & & 272,070 & \\
\hline 490 & $5 / 7$ & $\bar{D}$ & 705 & & 228,790 & air peaks \\
\hline 491 & $5 / 7$ & $\bar{E}$ & 403 & & 114,010 & air peaks \\
\hline 492 & $5 / 7$ & $\mathrm{~F}$ & 101 & & 22,651 & baseline rise, air peaks \\
\hline 493 & $5 / 8$ & $\mathrm{C}$ & 1,007 & & 268,680 & \\
\hline 494 & $5 / 8$ & $\mathrm{~S} / \mathrm{S} \mathrm{O}^{*}$ & & & 409,020 & \\
\hline 495 & $5 / 8$ & $\mathrm{H} / \mathrm{S} \mathrm{O}$ & & & 430,360 & \\
\hline 496 & $5 / 8$ & So & & & 349,160 & \\
\hline 497 & $5 / 9$ & $\mathrm{C}$ & 1,007 & & 328,830 & inc $\mathrm{H} 2 / \mathrm{N} 2$, signal up 8 to 11 \\
\hline 498 & $5 / 9$ & $\mathrm{C}$ & 1,007 & & 249,860 & H2 decr prior, signal 7.6 \\
\hline 499 & $5 / 9$ & NS 0 & & & 4,447 & \\
\hline 500 & $5 / 9$ & $\mathrm{SO}$ & & & 320,320 & \\
\hline 501 & $5 / 10$ & $\mathrm{C}$ & 1,007 & & 259,890 & \\
\hline 502 & $5 / 10$ & $\mathrm{H} / \mathrm{S} 0$ & & & 460,510 & \\
\hline 503 & $5 / 10$ & $\mathrm{~S} / \mathrm{SO}$ & & 7.1 & 389,890 & \\
\hline 504 & $5 / 10$ & $\mathrm{~S} / \mathrm{S} 1$ & & 7.1 & 135,550 & \\
\hline 505 & $5 / 10$ & $\mathrm{H} / \mathrm{S} 1$ & & & 271,000 & \\
\hline 506 & $5 / 10$ & S 1 & & 7.1 & 366,350 & \\
\hline 507 & $5 / 11$ & NS 1 & & 7.1 & 1,597 & \\
\hline
\end{tabular}


Table D.2. Gas Chromatograph Data, Experiment \#2 (cont.'d).

\begin{tabular}{|c|c|c|c|c|c|c|}
\hline Run & Date & Sample & [Diesel], mg/L & Signal & Total Area & Comments \\
\hline 508 & $5 / 11$ & $\mathrm{~S} / \mathrm{S} 2$ & & & 152,700 & \\
\hline 509 & $5 / 11$ & $\mathrm{H} / \mathrm{S} 2$ & & & 152,270 & \\
\hline 510 & $5 / 11$ & S2 & & 7.3 & 199,990 & \\
\hline 511 & $5 / 11$ & NS 2 & & & 3,986 & out of paper \\
\hline 512 & $5 / 11$ & S/S 3 & & 7.1 & 38,038 & drop on tip \\
\hline 513 & $5 / 11$ & $\mathrm{H} / \mathrm{S} 3$ & & 7.1 & 95,364 & \\
\hline 514 & $5 / 11$ & S3 & & 7.2 & 94,534 & \\
\hline 515 & $5 / 11$ & NS 3 & & 7.1 & 1,506 & \\
\hline 516 & $5 / 11$ & S/S 1 & & 7.1 & 121,770 & \\
\hline 517 & $5 / 11$ & S/S 2 & & 7.1 & 138,020 & \\
\hline 518 & $5 / 11$ & $\mathrm{C}$ & 1,007 & 7.1 & 241,460 & drop on tip \\
\hline 519 & $5 / 11$ & S/S 4 & & 7.2 & 38,287 & \\
\hline 520 & $5 / 12$ & $\mathrm{C}$ & 1,007 & 7.2 & 259,120 & \\
\hline 521 & $5 / 12$ & $\mathrm{H} / \mathrm{S} 4$ & & 7.2 & 94,544 & \\
\hline 522 & $5 / 12$ & S 4 & & 7.2 & 82,978 & \\
\hline 523 & $5 / 12$ & NS 4 & & 7.2 & 1,495 & \\
\hline 524 & $5 / 12$ & S/S 3 & & 7.1 & 40,755 & \\
\hline 525 & $5 / 12$ & S/S 5 & & 7.1 & 18,833 & \\
\hline 526 & $5 / 13$ & $\mathrm{C}$ & 1,007 & 7.2 & 267,880 & \\
\hline 527 & $5 / 13$ & $\mathrm{H} / \mathrm{S} 5$ & & 7.2 & 49,584 & inj before equilib time \\
\hline 528 & $5 / 13$ & S 5 & & 7.1 & 35,146 & \\
\hline 529 & $5 / 13$ & NS 5 & & 7.1 & 2,038 & \\
\hline 530 & $5 / 14$ & S/S 6 & & 7.1 & 14,536 & unusual large peak at 32.82 \\
\hline 531 & $5 / 14$ & $\mathrm{H} / \mathrm{S} 6$ & & 7.0 & 34,270 & \\
\hline 532 & $5 / 14$ & 56 & & 7.0 & 30,887 & \\
\hline 533 & $5 / 14$ & NS 6 & & 7.0 & 1,653 & \\
\hline 534 & $5 / 15$ & $\mathrm{C}$ & 1,007 & 7.2 & 248,820 & \\
\hline 535 & $5 / 15$ & S/S 7 & & 6.8 & 7,543 & \\
\hline 536 & $5 / 15$ & $\mathrm{H} / \mathrm{S} 7$ & & 6.9 & 26,981 & \\
\hline 537 & $5 / 15$ & S7 & & 6.9 & 17,995 & \\
\hline 538 & $5 / 17$ & $\mathrm{C}$ & 1,007 & 7.2 & 270,410 & ATT-3, peaks off-scale \\
\hline 539 & $5 / 17$ & NS 7 & & 7.0 & 2,030 & \\
\hline 540 & $5 / 17$ & S/S 8 & & 7.0 & 5,642 & \\
\hline 541 & $5 / 17$ & $\mathrm{H} / \mathrm{S} 8$ & & 7.0 & 22,352 & \\
\hline 542 & $5 / 17$ & 58 & & 7.1 & 15,414 & \\
\hline 543 & $5 / 18$ & $\mathrm{C}$ & 1,007 & 7.0 & 252,720 & \\
\hline 544 & $5 / 18$ & NS 8 & & 7.0 & 2,544 & \\
\hline 545 & $5 / 18$ & HC TRAP & & & 54,606 & $50 \mathrm{~mL}$ evap to $1.4 \mathrm{~mL}$ \\
\hline 546 & $5 / 18$ & HC TRAP & & 7.0 & 59,198 & both runs have odd shape \\
\hline
\end{tabular}

* S/S, H/S, S and NS refer to the Sparge/Stir, $\mathrm{H}_{2} \mathrm{O}_{2} /$ Stir, Stir Nonstirred reactors; the subsequent number refers to the sample number within the experimental series. HC TRAP refers to the hydrocarbon trap volatile emissions sample. 
Table D.3. Gas Chromatograph Data, Experiment \#3.

\begin{tabular}{|l|l|c|r|r|r|l|}
\hline Run & Date & Sample & Conc, $\mathrm{mg} /$ L & Signal & Total Area & Comments \\
\hline 547 & $5 / 19$ & blank & 0 & 60.0 & & reset flowrates, signal high \\
\hline 549 & $5 / 20$ & blank & 0 & & 2,578 & \\
\hline 550 & $5 / 20$ & blank & 0 & & 3,154 & \\
\hline 551 & $5 / 20$ & C & 1,007 & 8.5 & 223,040 & difficult injection \\
\hline 552 & $5 / 20$ & C & 1,007 & 7.8 & 228,480 & diff inj \\
\hline 553 & $5 / 20$ & C & 1,007 & 7.8 & 218,240 & \\
\hline 554 & $5 / 20$ & C & 1,007 & 8.9 & 217,460 & \\
\hline 555 & $5 / 20$ & FREN & 0 & 8.6 & 2,035 & baseline rise \\
\hline 556 & $5 / 21$ & C & 1,007 & 7.7 & 217,260 & \\
\hline 557 & $5 / 21$ & B & 2,014 & 7.4 & 417,540 & \\
\hline 558 & $5 / 21$ & A & 3,021 & 7.1 & 519,020 & \\
\hline 559 & $5 / 21$ & C & 1,007 & 13.8 & 308,950 & \\
\hline 560 & $5 / 22$ & C & 1,007 & 11.5 & 302,420 & \\
\hline 561 & $5 / 22$ & C & 1,007 & 11.6 & 306,230 & \\
\hline 562 & $5 / 22$ & C & 1,007 & 11.5 & 339,250 & \\
\hline 563 & $5 / 22$ & C & 1,007 & 11.0 & 293,350 & \\
\hline 564 & $5 / 23$ & C & 1,007 & 10.9 & 304,700 & \\
\hline 565 & $5 / 23$ & B & 2,014 & 11.0 & 564,730 & \\
\hline 566 & $5 / 23$ & A & 3,021 & 11.3 & 781,050 & \\
\hline 567 & $5 / 24$ & C & 1,007 & 11.1 & 301,550 & \\
\hline 568 & $5 / 24$ & D & 705 & 11.1 & 236,020 & \\
\hline 569 & $5 / 24$ & E & 403 & 11.4 & 125,260 & \\
\hline 570 & $5 / 24$ & F & 101 & 10.4 & 32,473 & baseline rise \\
\hline 571 & $5 / 24$ & G & 51 & 10.4 & 7,280 & \\
\hline 572 & $5 / 24$ & H & 10 & 10.3 & 3,459 & baseline rise \\
\hline 573 & $5 / 24$ & H & 10 & 11.8 & 7,390 & baseline rise \\
\hline 574 & $5 / 25$ & C & 1,007 & 11.1 & 332,710 & \\
\hline 575 & $5 / 25$ & C & 1,007 & 11.1 & 317,090 & \\
\hline 576 & $5 / 25$ & S/S 0* & & 11.1 & 447,960 & \\
\hline 577 & $5 / 25$ & H/S 0 & & 11.4 & 373,410 & \\
\hline 578 & $5 / 25$ & S 0 & & 11.4 & 387,490 & \\
\hline 579 & $5 / 25$ & S/S & & 11.2 & 259,820 & \\
\hline 580 & $5 / 25$ & H/S & & 11.0 & 289,170 & H2 increased prior to run \\
\hline 581 & $5 / 25$ & S & & 11.2 & 234,890 & \\
\hline 582 & $5 / 26$ & C & 1,007 & 11.6 & 319,070 & \\
\hline 583 & $5 / 26$ & S/S & & 11.7 & 221,280 & \\
\hline 584 & $5 / 26$ & H/S & & 11.3 & 148,600 & \\
\hline 585 & $5 / 26$ & S & & 11.0 & 166,540 & drop on tip \\
\hline
\end{tabular}


Table D.3. Gas Chromatograph Data, Experiment \#3 (cont.'d).

\begin{tabular}{|l|c|c|r|r|l|l|}
\hline Run & Date & Sample & Conc, mg/L & Signal & Total Area & Comments \\
\hline 586 & $5 / 26$ & S/S 3 & & 11.1 & 115,410 & \\
\hline 587 & $5 / 26$ & H/S 3 & & 11.0 & 143,530 & \\
\hline 588 & $5 / 26$ & S 3 & & 10.7 & 126,260 & \\
\hline 589 & $5 / 27$ & C & 1,007 & 10.7 & 333,130 & H2 increased prior \\
\hline 590 & $5 / 27$ & C & 1,007 & 11.2 & 335,280 & \\
\hline 591 & $5 / 27$ & S/S 4 & & 10.9 & 54,678 & \\
\hline 592 & $5 / 27$ & H/S 4 & & 10.9 & 131,290 & \\
\hline 593 & $5 / 27$ & S 4 & & 10.9 & 207,270 & \\
\hline 594 & $5 / 27$ & S/S 5 & & 10.9 & 28,383 & \\
\hline 595 & $5 / 27$ & H/S 5 & & 10.8 & 309,140 & \\
\hline 596 & $5 / 28$ & C & 1,007 & 11.1 & 344,810 & \\
\hline 597 & $5 / 28$ & S 5 & & 10.8 & 196,170 & \\
\hline 598 & $5 / 28$ & C & 1,007 & 10.6 & 341,940 & \\
\hline 599 & $5 / 28$ & B & 2,014 & 10.7 & 643,410 & \\
\hline 600 & $5 / 28$ & A & 3,021 & 10.6 & 961,380 & \\
\hline 601 & $5 / 29$ & C & 1,007 & 10.7 & 340,420 & H2 increased prior, diff inj \\
\hline 602 & $5 / 29$ & D & 705 & 10.7 & 264,310 & \\
\hline 603 & $5 / 29$ & E & 403 & 10.8 & 146,450 & \\
\hline 604 & $5 / 30$ & F & 101 & 10.7 & 38,897 & baseline rise \\
\hline 605 & $5 / 30$ & C & 1,007 & 10.9 & 365,500 & \\
\hline 606 & $5 / 30$ & S/S 6 & & 10.6 & 35,621 & \\
\hline 607 & $5 / 31$ & H/S 6 & & 10.8 & 119,940 & \\
\hline 608 & $6 / 1$ & C & 1,007 & 11.0 & 374,940 & \\
\hline 609 & $6 / 1$ & C & 1,007 & 10.7 & 370,100 & \\
\hline 610 & $6 / 1$ & S 6 & & 10.2 & 220,420 & \\
\hline 611 & $6 / 1$ & S/S 7 & & 10.2 & 14,859 & \\
\hline 612 & $6 / 1$ & H/S 7 & & 10.1 & 36,410 & \\
\hline 613 & $6 / 1$ & S 7 & & 10.3 & 98,303 & \\
\hline 614 & $6 / 2$ & C & 1,007 & 10.1 & 348,850 & \\
\hline 615 & $6 / 2$ & S/S 8 & & 10.7 & 31,255 & H2 increased prior to run \\
\hline 616 & $6 / 2$ & H/S 8 & & 10.6 & 32,697 & \\
\hline 617 & $6 / 2$ & S 8 & & 10.6 & 49,167 & \\
\hline 618 & $6 / 2$ & S/S TRAP & & 10.7 & 125,300 & 376.6 mg \\
\hline 619 & $6 / 3$ & C & 1,007 & 11.0 & 352,930 & air peaks \\
\hline 620 & $6 / 3$ & H/S TRAP & & 10.8 & 68,186 & 182.3 mg \\
\hline 621 & $6 / 3$ & S/S 0 & & 10.7 & 448,990 & \\
\hline 622 & $6 / 3$ & H/S 0 & & 10.6 & 417,790 & \\
\hline 623 & $6 / 3$ & S 0 & & 10.6 & 443,940 & \\
\hline 624 & $6 / 3$ & H/S 5 & & 11.0 & 319,240 & \\
\hline & & & & & \\
\hline
\end{tabular}


Table D.3. Gas Chromatograph Data, Experiment \#3 (cont.'d).

\begin{tabular}{|r|c|c|r|r|r|l|}
\hline Run & Date & Sample & Conc, mg/L & Signal & Total Area & Comments \\
\hline 625 & $6 / 4$ & S/S 8 & & 11.1 & 31,569 & \\
\hline 626 & $6 / 4$ & C & 1,007 & 11.4 & 375,810 & \\
\hline 627 & $6 / 4$ & S & & 11.1 & 208,080 & \\
\hline 628 & $6 / 4$ & S/S 1 & & 11.1 & 290,540 & \\
\hline 629 & $6 / 4$ & S 6 & & 10.9 & 211,820 & \\
\hline 630 & $6 / 4$ & F & 101 & 11.0 & 36,915 & air peaks \\
\hline 631 & $6 / 4$ & G & 51 & 10.8 & 10,735 & air spikes \\
\hline 632 & $6 / 6$ & C & 1,007 & 10.5 & 338,770 & \\
\hline 633 & $6 / 6$ & H & 10 & 10.5 & 6,240 & \\
\hline 634 & $6 / 6$ & A & 3,021 & 10.5 & 926,540 & \\
\hline
\end{tabular}

* S/S, $\mathrm{H} / \mathrm{S}$ and $\mathrm{S}$ refer to the Sparge/Stir, $\mathrm{H}_{2} \mathrm{O}_{2} / \mathrm{Stir}$ and Stir reactors; the subsequent number refers to the sample number within the experimental series.

S/S TRAP and H/S TRAP refer to the hydrocarbon trap volatile emissions samples from the Sparge/Stir and $\mathrm{H}_{2} \mathrm{O}_{2} /$ Stir reactors. 


\section{Appendix E: Calibration Data}

In this section the data used for calibration of the gas chromatograph is presented. Calibration curves of total integrated area versus diesel fuel concentration were prepared based on this data. Each calibration curve is based on average total areas for multiple runs of the 6 to 8 standard samples of known diesel fuel concentration. A new calibration curve was prepared prior to each experimental series.

Table E. 1 is a presentation of the calibration data for Experimental Series \#1. The total areas presented represent averages of 2 gas chromatograph runs for standard samples $A$ and $B, 3$ runs for standard samples D, E and F and 15 runs for standard sample $C$. The standard deviation and relative standard deviation are based on the average of the runs

listed. The data here for each sample should not be confused with that given in Table 3.7, Injection Error. The averages. listed in Table E.1 are based on samples that were not necessarily run on the same day and not necessarily back-to-back.

Table E.1. Experiment \#1 Calibration Data.

\begin{tabular}{|c|c|r|r|r|r|}
\hline Sample & Run \# & [Diesel], mg/L & Total Area (ave) & S.D. & R.S.D., \% \\
\hline A & $404 / 418$ & 3,021 & 857,465 & 187,857 & 21.9 \\
\hline B & $405 / 417$ & 2,014 & 516,910 & 8,231 & 1.6 \\
\hline C & $389-465$ & 1,007 & 249,511 & 26,635 & 10.7 \\
\hline D & $396 / 407 / 424$ & 705 & 189,173 & 12,905 & 6.8 \\
\hline E & $397 / 408 / 425$ & 403 & 80,353 & 8,710 & 10.8 \\
\hline F & $398 / 409 / 426$ & 101 & 15,064 & 2,356 & 15.6 \\
\hline
\end{tabular}

S.D. refers to standard deviation.

R.S.D. refers to relative standard deviation. 
The data in Table E.1 was fit to a Total Area versus Diesel Concentration plot using a Power Law Model on a Hewlett Packard 42S calculator. The best fit function on the calculator yielded the Power Law Model as a better fit than the Linear Model, although the difference in the correlation was not that great. The Power Law Model used has the following form:

$$
\text { Area }=b *(\text { Diesel })^{M}
$$

where Area is the average Total Area, Diesel is the fuel concentration in $\mathrm{mg} / \mathrm{L}, \mathrm{M}$ is the slope and $b$ is the $y$-intercept of the linearized plot. The transformed linear regression is shown in Figure E.1.

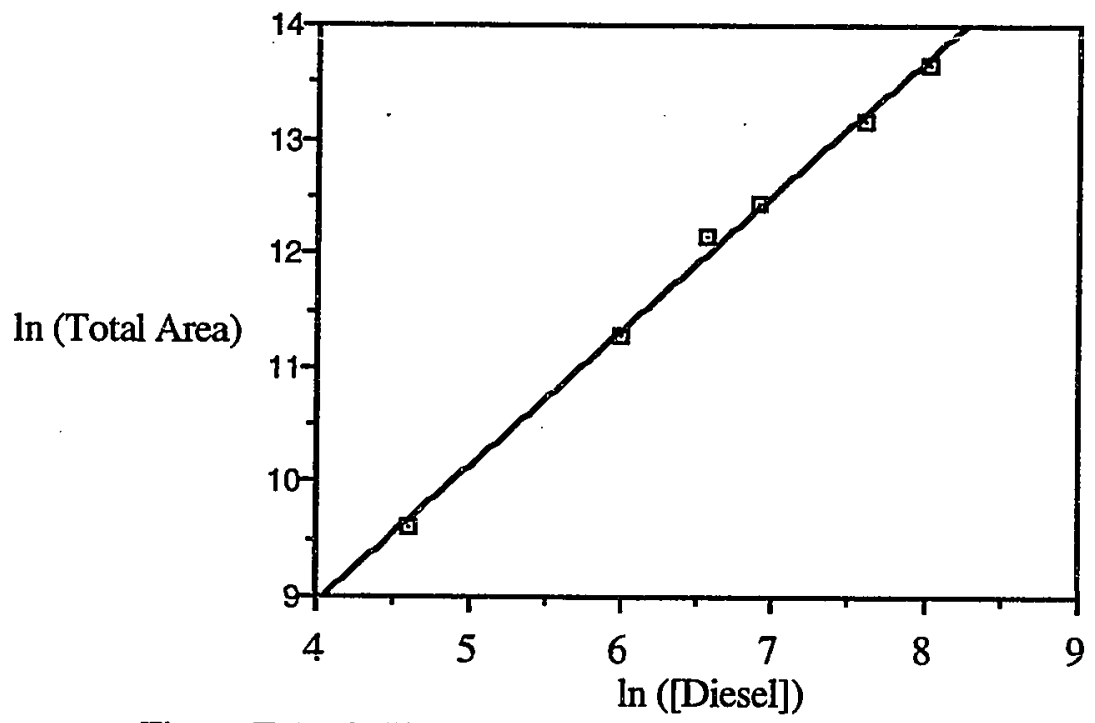

Figure E.1. Calibration Curve, Experiment \#1.

The following numbers were obtained from the linear regression:

$$
\begin{aligned}
M & =1.1515 \\
b & =80.7109 \\
\text { correlation } & =0.99425
\end{aligned}
$$


Table E.2 is a presentation of the calibration data for Experimental Series \#2. The total areas presented represent averages of 2 gas chromatograph runs for standard samples D, E and G, 3 runs for standard samples A, B, F and $H$ and 4 runs for standard sample C.

Table E.2. Experiment \#2 Calibration Data.

\begin{tabular}{|c|c|r|r|r|r|}
\hline Sample & Run \# & [Diesel], mg/L & Total Area (ave) & S.D. & R.S.D., \% \\
\hline A & $484 / 485 / 486$ & 3,021 & 748,227 & 19,359 & 2.6 \\
\hline B & $482 / 487 / 488$ & 2,014 & 503,787 & 6,741 & 1.3 \\
\hline C & $470 / 479 / 481 / 489$ & 1,007 & 258,763 & 14,925 & 5.8 \\
\hline D & $469 / 490$ & 705 & 218,630 & 14,368 & 6.6 \\
\hline E & $468 / 491$ & 403 & 108,880 & 7,255 & 6.7 \\
\hline F & $452 / 454 / 492$ & 101 & 24,697 & 4,697 & 19.0 \\
\hline G & $451 / 455$ & 51 & 4,564 & 127 & 2.8 \\
\hline H & $453 / 456 / 457$ & 10 & 2,022 & 703 & 34.8 \\
\hline
\end{tabular}

A standard linear regression function on the HP42S was used to generate the Total Area versus Diesel Concentration calibration plot. The linear model used has the form:

$$
\text { Area }=M *[\text { Diesel }]+b
$$

where Area is the average Total Area, [Diesel] is Diesel Concentration in $\mathrm{mg} / \mathrm{L}, \mathrm{M}$ is the slope and $b$ is the $y$-intercept. The linear regression is shown in Figure E.2. 


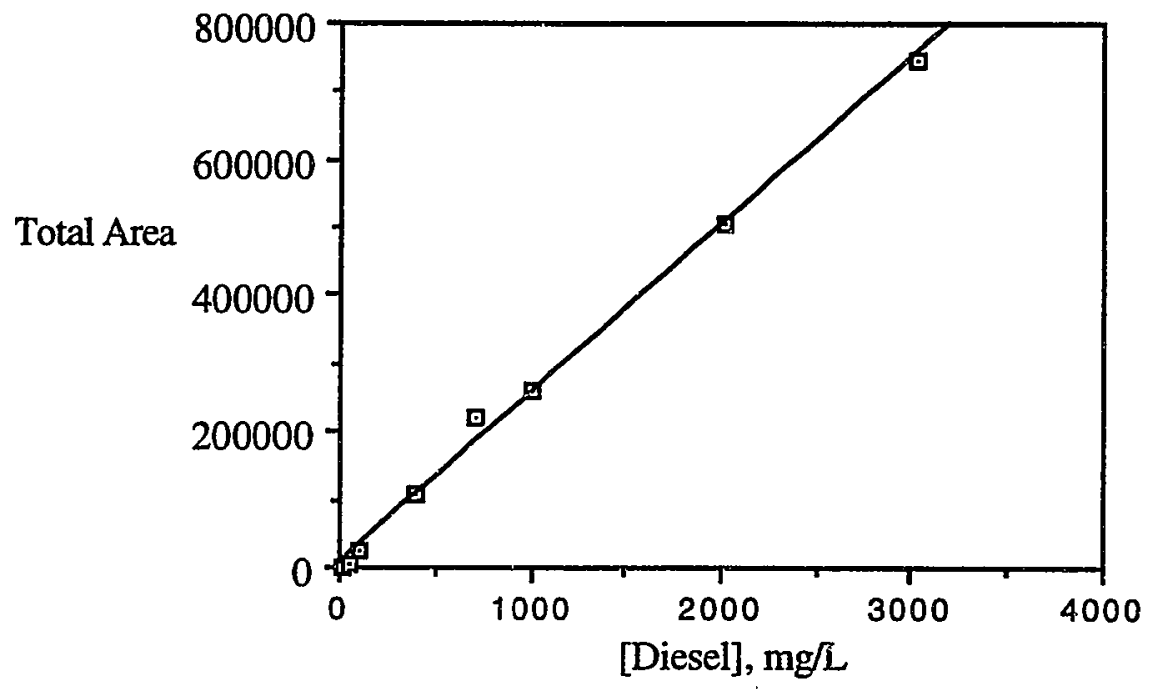

Figure E.2. Calibration Curve, Experiment \#2.

The following numbers were obtained from the linear regression:

$$
\begin{aligned}
M & =247.68 \\
b & =7345.8 \\
\text { correlation } & =0.99825
\end{aligned}
$$


Table E. 3 outlines the calibration data for Experimental Series \#3. The total areas shown represent averages of 2 gas chromatograph runs for standard samples A, B, D, E, $\mathrm{G}$ and $\mathrm{H}, 3$ runs for standard samples $\mathrm{F}$ and 21 runs for standard sample $\mathrm{C}$.

Table E.3. Experiment \#3 Calibration Data.

\begin{tabular}{|c|c|r|r|r|r|}
\hline Sample & Run \# & [Diesel], mg/L & Total Area (ave) & S.D. & R.S.D., \% \\
\hline A & $566 / 600$ & 3,021 & 871,215 & 127,513 & 14.6 \\
\hline B & $565 / 599$ & 2,014 & 604,070 & 55,635 & 9.2 \\
\hline C & $560-632$ & 1,007 & 335,184 & 24,886 & 7.4 \\
\hline D & $568 / 602$ & 705 & 250,165 & 20,004 & 8.0 \\
\hline E & $569 / 603$ & 403 & 135,855 & 14,984 & 11.0 \\
\hline F & $570 / 604 / 630$ & 101 & 36,095 & 3,290 & 9.1 \\
\hline G & $571 / 631$ & 51 & 9,008 & 2,443 & 27.1 \\
\hline H & $572 / 573$ & 10 & 5,425 & 2,780 & 51.2 \\
\hline
\end{tabular}

The standard linear regression model mentioned previously was used to generate the Area versus Diesel calibration plot and is shown in Figure E.3.

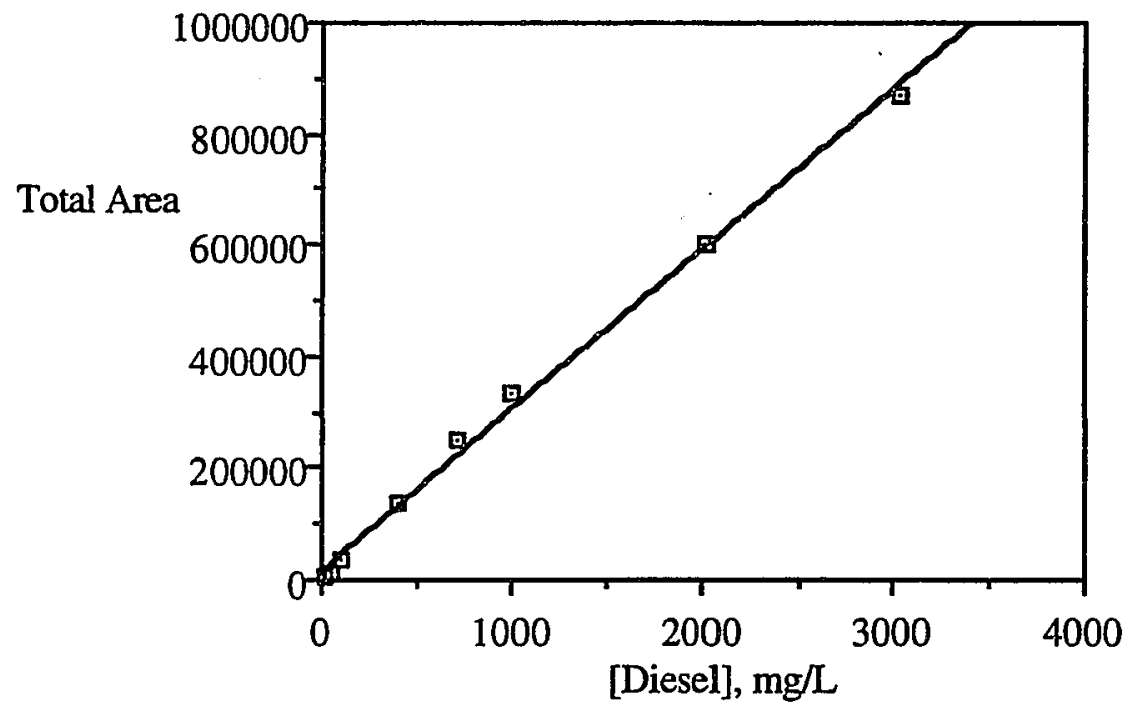

Figure E.3. Calibration Curve, Experiment \#3.

The following numbers were obtained from the linear regression:

$$
\begin{aligned}
\mathrm{M} & =289.21 \\
\mathrm{~b} & =16571 \\
\text { correlation } & =0.99795
\end{aligned}
$$




\section{Appendix F: Raw Data}

Table F.1. Raw Data, Experiment \#1.

\begin{tabular}{|c|c|c|c|c|c|c|c|c|c|}
\hline \multicolumn{4}{|c|}{ Reactor S/S - Sparge/Stir } & & & & & & \\
\hline Date & Time & Day & {$\left[\begin{array}{c}\text { Diesel] } \\
\mathrm{mg} / \mathrm{L}\end{array}\right.$} & $\begin{array}{l}\text { [DO], } \\
\mathrm{mg} / \mathrm{L}\end{array}$ & $\begin{array}{l}\text { Microbes, } \\
\text { CFU } / \mathrm{mL}\end{array}$ & $\mathrm{T},{ }^{\circ} \mathrm{C}$ & $\mathrm{pH}$ & $\begin{array}{l}{[\mathrm{N}],} \\
\mathrm{mg} / \mathrm{L}\end{array}$ & $\begin{array}{l}{[\mathrm{P}]^{*},} \\
\mathrm{mg} / \mathrm{L}\end{array}$ \\
\hline $4 / 20$ & $18: 00$ & 0 & 4,526 & 7.40 & 105,000 & 24.0 & 7.20 & 325 & 147 \\
\hline $4 / 21$ & $17: 00$ & 1 & & 8.05 & & 24.5 & 7.50 & & \\
\hline $4 / 22$ & $16: 00$ & 2 & 788 & 5.35 & & 25.0 & 7.40 & 350 & 113 \\
\hline $4 / 23$ & $15: 00$ & 3 & & 1.95 & & 25.0 & 7.10 & & \\
\hline $4 / 24$ & $14: 00$ & 4 & 193 & 3.60 & $29,000,000$ & 25.0 & 7.20 & 350 & 57 \\
\hline $4 / 26$ & $9: 00$ & 6 & & 6.80 & & 24.5 & 7.50 & & \\
\hline $4 / 26$ & 23:00 & 6 & 154 & & & 25.0 & 7.60 & & \\
\hline $4 / 28$ & $1: 00$ & 7 & & & $108,000,000$ & & & & \\
\hline $4 / 28$ & $23: 00$ & 8 & 45 & 7.70 & & 25.0 & 8.00 & 225 & 60 \\
\hline \multicolumn{10}{|c|}{ Reactor H/S - H2O2/Stir } \\
\hline Date & Time & Day & $\begin{array}{c}\text { [Diesel], } \\
\mathrm{mg} / \mathrm{L}\end{array}$ & $\begin{array}{c}\mathrm{DO}], \\
\mathrm{mg} / \mathrm{L}\end{array}$ & $\begin{array}{c}\text { Microbes, } \\
\text { CFU } / \mathrm{mL}\end{array}$ & $\mathrm{T},{ }^{\circ} \mathrm{C}$ & $\mathrm{pH}$ & $\begin{array}{c}{[\mathrm{N}],} \\
\mathrm{mg} / \mathrm{L}\end{array}$ & $\begin{array}{l}{[\mathrm{P}]^{*},} \\
\mathrm{mg} / \mathrm{L}\end{array}$ \\
\hline $4 / 20$ & $18: 00$ & 0 & 4,563 & 7.50 & 115,000 & 24.0 & 7.15 & 375 & 123 \\
\hline $4 / 21$ & $17: 00$ & 1 & & 8.15 & & 25.0 & 7.50 & & \\
\hline $4 / 22$ & 16:00 & 2 & 1,241 & 6.80 & & 25.0 & 7.50 & 275 & 110 \\
\hline $4 / 23$ & $15: 00$ & 3 & & 4.00 & & 25.0 & 7.30 & & \\
\hline $4 / 24$ & $14: 00$ & 4 & 401 & 4.20 & $39,000,000$ & 25.0 & 7.30 & 375 & 100 \\
\hline $4 / 26$ & $9: 00$ & 6 & & 0.90 & & 25.0 & 7.20 & & \\
\hline $4 / 26$ & 23:00 & 6 & 78 & & & 25.0 & 7.20 & & \\
\hline $4 / 28$ & $1: 00$ & 7 & & & $110,000,000$ & & & & \\
\hline $4 / 28$ & 23:00 & 8 & 95 & 4.70 & & 25.0 & 7.50 & 275 & 57 \\
\hline & & & & & & & & & \\
\hline \multicolumn{10}{|c|}{ Reactor S - Stir } \\
\hline Date & Time & Day & $\begin{array}{c}\text { [Diesel] } \\
\mathrm{mg} / \mathrm{L}\end{array}$ & $\begin{array}{l}{[\mathrm{DO}]} \\
\mathrm{mg} / \mathrm{L}\end{array}$ & $\begin{array}{l}\text { Microbes, } \\
\text { CFU } / \mathrm{mL}\end{array}$ & $\mathrm{T},{ }^{\circ} \mathrm{C}$ & $\mathrm{pH}$ & $\begin{array}{l}{[\mathrm{N}]} \\
\mathrm{mg} / \mathrm{L}\end{array}$ & $\begin{array}{l}{[\mathrm{P}]^{*},} \\
\mathrm{mg} / \mathrm{L}\end{array}$ \\
\hline $4 / 20$ & $18: 00$ & 0 & 4,184 & 7.35 & 92,000 & 24.0 & 7.10 & 375 & 150 \\
\hline $4 / 21$ & $17: 00$ & 1 & & 7.05 & & 25.0 & 7.40 & & \\
\hline $4 / 22$ & $16: 00$ & 2 & 981 & 7.45 & & 25.0 & 7.50 & 275 & 123 \\
\hline $4 / 23$ & $15: 00$ & 3 & & 1.25 & & 25.0 & 7.00 & & \\
\hline $4 / 24$ & $14: 00$ & 4 & 477 & 1.40 & $36,000,000$ & 24.5 & 7.00 & 375 & 73 \\
\hline $4 / 26$ & $9: 00$ & 6 & & 0.05 & & 25.0 & 6.90 & & \\
\hline $4 / 26$ & $23: 00$ & 6 & 251 & & & 24.5 & 7.00 & & \\
\hline $4 / 28$ & $1: 00$ & 7 & & & $140,000,000$ & & & & \\
\hline $4 / 28$ & 23:00 & 8 & 61 & 4.75 & & 25.0 & 7.30 & 275 & 50 \\
\hline
\end{tabular}

* The absolute phosphorus concentrations listed for this experimental run are in error; the concentrations are valid in relative comparison within this experimental series. 
Table F.2. Raw Data, Experiment \#2.

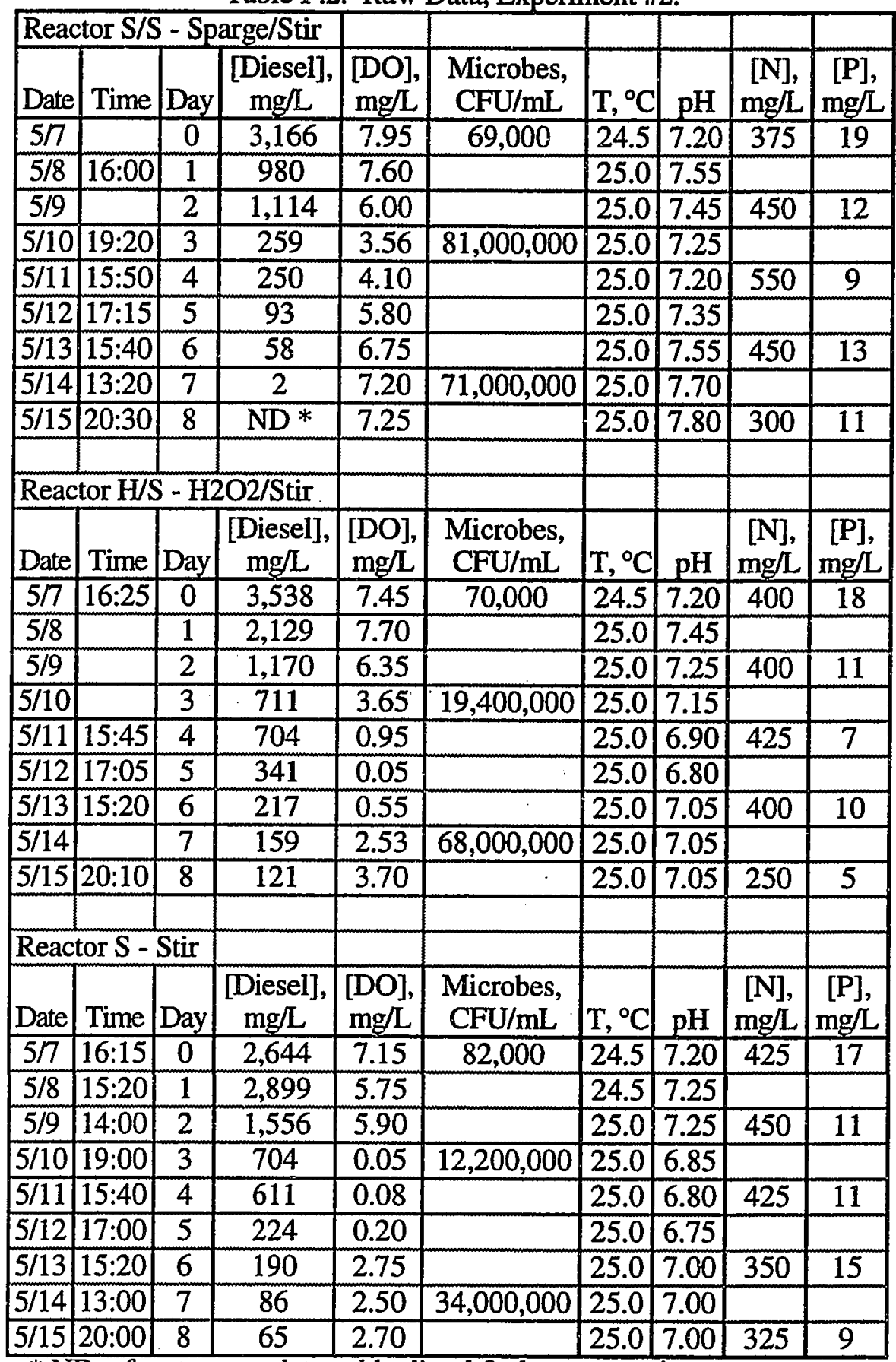

$*$ ND refers to a nondetectable diesel fuel concentration. 
Table F.2. Raw Data, Experiment \#2 (cont.'d).

\begin{tabular}{|c|c|c|c|c|c|c|c|c|c|}
\hline \multicolumn{3}{|l|}{ Reactor NS - No Stir } & & & & & & \\
\hline Date & Time & Day & $\begin{array}{c}\text { [Diesel], } \\
\mathrm{mg} / \mathrm{L}\end{array}$ & $\begin{array}{c}\text { [DO], } \\
\mathrm{mg} / \mathrm{L}\end{array}$ & $\begin{array}{c}\text { Microbes, } \\
\text { CFU/mL }\end{array}$ & $\mathrm{T},{ }^{\circ} \mathrm{C}$ & $\mathrm{pH}$ & $\begin{array}{r}{[\mathrm{N}],} \\
\mathrm{mg} / \mathrm{L}\end{array}$ & $\begin{array}{c}{[\mathrm{P}]} \\
\mathrm{mg} / \mathrm{L}\end{array}$ \\
\hline $5 / 7$ & $16: 45$ & 0 & ND & 4.20 & 19,000 & 24.5 & 7.50 & 225 & 18 \\
\hline $5 / 8$ & $16: 00$ & 1 & ND & 0.75 & & 24.5 & 7.00 & & \\
\hline $5 / 9$ & $14: 30$ & 2 & ND & 0.10 & & 24.5 & 7.00 & 400 & 27 \\
\hline $5 / 10$ & $19: 20$ & 3 & ND & 0.05 & $5,500,000$ & 24.5 & 7.05 & & \\
\hline $5 / 11$ & $15: 50$ & 4 & ND & 0.03 & & 24.5 & 7.05 & 475 & 20 \\
\hline $5 / 12$ & $17: 15$ & 5 & ND & 0.85 & & 25.0 & 7.05 & & \\
\hline $5 / 13$ & $15: 40$ & 6 & ND & 0.60 & & 25.0 & 7.05 & 25 & 22 \\
\hline $5 / 14$ & & 7 & ND & 2.40 & $6,700,000$ & 25.0 & 7.20 & & \\
\hline $5 / 15$ & $20: 30$ & 8 & ND & 2.78 & & 25.0 & 7.20 & 300 & 13 \\
\hline
\end{tabular}

* ND refers to a nondetectable diesel fuel concentration. 
Table F.3. Raw Data, Experiment \#3.

\begin{tabular}{|c|c|c|c|c|c|c|c|c|c|}
\hline \multicolumn{10}{|c|}{ Reactor S/S - Sparge/Stir } \\
\hline Date & Time & Day & $\begin{array}{c}\text { [Diesel], } \\
\text { mg/L }\end{array}$ & $\begin{array}{l}\text { [DO], } \\
\mathrm{mg} / \mathrm{L}\end{array}$ & $\begin{array}{l}\text { Microbes, } \\
\text { CFU/mL }\end{array}$ & $\mathrm{T},{ }^{\circ} \mathrm{C}$ & $\mathrm{pH}$ & $\begin{array}{c}{[\mathrm{N}]} \\
\mathrm{mg} / \mathrm{L}\end{array}$ & $\begin{array}{l}{[\mathrm{P}]} \\
\mathrm{mg} / \mathrm{L}\end{array}$ \\
\hline $5 / 22$ & $20: 30$ & 0 & 2,987 & 8.10 & 72,000 & 25.0 & 7.15 & 350 & 21 \\
\hline $5 / 23$ & & 1 & 1,788 & 6.85 & & 25.0 & 7.35 & & \\
\hline $5 / 24$ & $14: 30$ & 2 & 1,416 & 3.40 & & 25.0 & 7.35 & 350 & 8.5 \\
\hline $5 / 25$ & & 3 & 684 & 3.45 & $87,000,000$ & 25.0 & 7.40 & & \\
\hline $5 / 26$ & & 4 & 264 & 2.25 & & 25.0 & 7.35 & 250 & 5 \\
\hline $5 / 27$ & $15: 40$ & 5 & 82 & 5.05 & & 25.0 & 7.65 & & \\
\hline $5 / 28$ & $13: 45$ & 6 & 132 & 6.75 & & 25.0 & 8.00 & 200 & 3 \\
\hline $5 / 29$ & & 7 & ND & 7.10 & $121,000,000$ & 25.0 & 8.15 & & \\
\hline $5 / 30$ & $23: 30$ & 8 & 103 & 7.10 & & 25.0 & 8.35 & 175 & 4 \\
\hline & & & & & & & & & \\
\hline \multicolumn{10}{|c|}{ Reactor H/S - H2O2/Stir } \\
\hline Date & Time & Day & $\begin{array}{c}\text { [Diesel] } \\
\mathrm{mg} / \mathrm{L}\end{array}$ & $\begin{array}{c}{[\mathrm{DO}],} \\
\mathrm{mg} / \mathrm{L}\end{array}$ & $\begin{array}{c}\text { Microbes, } \\
\text { CFU } / \mathrm{mL}\end{array}$ & $\mathrm{T},{ }^{\circ} \mathrm{C}$ & $\mathrm{pH}$ & $\begin{array}{c}{[\mathrm{N}]} \\
\mathrm{mg} / \mathrm{L}\end{array}$ & $\begin{array}{c}{[\mathrm{P}],} \\
\mathrm{mg} / \mathrm{L}\end{array}$ \\
\hline $5 / 22$ & $20: 30$ & 0 & 2,621 & 7.58 & 90,000 & 25.0 & 7.15 & 325 & 20 \\
\hline $5 / 23$ & $16: 00$ & 1 & 1,885 & 7.30 & & 25.0 & 7.35 & & \\
\hline $5 / 24$ & $14: 15$ & 2 & 913 & 4.08 & & 25.0 & 7.25 & 275 & 13 \\
\hline $5 / 25$ & $16: 20$ & 3 & 878 & 2.45 & $86,000,000$ & 25.0 & 7.70 & & \\
\hline $5 / 26$ & $19: 05$ & 4 & 793 & 0.03 & & 25.0 & 7.75 & 300 & 6 \\
\hline $5 / 27$ & & 5 & 2,058 & 0.05 & & 25.0 & 7.80 & & \\
\hline $5 / 28$ & & 6 & 715 & 0.04 & & 25.0 & 7.55 & 225 & 4 \\
\hline $5 / 29$ & $17: 00$ & 7 & 137 & 2.65 & $88,000,000$ & 25.0 & 7.50 & & \\
\hline $5 / 30$ & & 8 & 112 & 5.90 & & 25.0 & 7.65 & 200 & 5 \\
\hline & & & & & & & & & \\
\hline \multicolumn{10}{|c|}{ Reactor S - Stir } \\
\hline Date & Time & Day & $\begin{array}{c}\text { [Diesel], } \\
\mathrm{mg} / \mathrm{L}\end{array}$ & $\begin{array}{c}{[\mathrm{DO}]} \\
\mathrm{mg} / \mathrm{L}\end{array}$ & $\begin{array}{c}\text { Microbes, } \\
\text { CFU/mL }\end{array}$ & $\mathrm{T},{ }^{\circ} \mathrm{C}$ & $\mathrm{pH}$ & $\begin{array}{l}{[\mathrm{N}]} \\
\mathrm{mg} / \mathrm{L} \\
\end{array}$ & $\begin{array}{l}{[\mathrm{P}],} \\
\mathrm{mg} / \mathrm{L}\end{array}$ \\
\hline $5 / 22$ & & 0 & 2.760 & 7.45 & 83,000 & 25.0 & 7.15 & 325 & 19 \\
\hline $5 / 23$ & $16: 00$ & 1 & 1.510 & 4.35 & & 25.0 & 7.55 & & \\
\hline $5 / 24$ & $14: 15$ & 2 & 1,181 & 4.40 & & 25.0 & 7.55 & 225 & 8 \\
\hline $5 / 25$ & $16: 20$ & 3 & 759 & 0.05 & $87,000,000$ & 25.0 & 7.45 & & \\
\hline $5 / 26$ & $18: 50$ & 4 & 1,319 & 0.03 & & 25.0 & 7.15 & 275 & 5 \\
\hline $5 / 27$ & $15: 20$ & 5 & 1,242 & 0.08 & & 25.0 & 7.15 & & \\
\hline $5 / 28$ & $13: 30$ & 6 & 1,380 & 0.05 & & 25.0 & 7.00 & 225 & 3 \\
\hline $5 / 29$ & $16: 55$ & 7 & 565 & 0.05 & $113,000,000$ & 25.0 & 7.10 & & \\
\hline $5 / 30$ & $23: 30$ & 8 & 225 & 3.75 & & 25.0 & 7.30 & 200 & 3 \\
\hline
\end{tabular}

$*$ ND refers to a nondetectable diesel fuel concentration. 


\section{Appendix G: Gas Chromatograph and Integrator Settings}

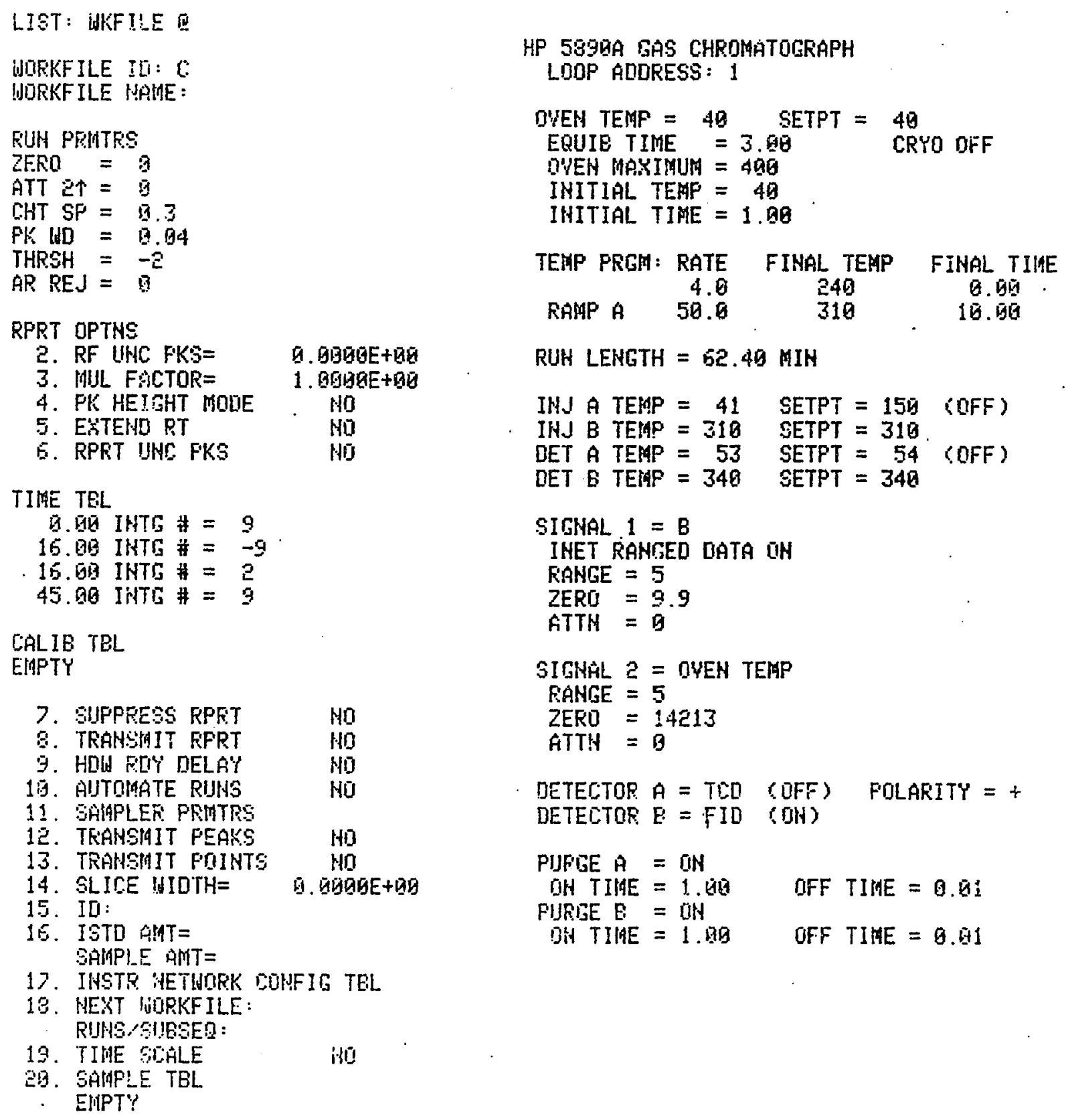

Figure G.1. Gas Chromatograph and Integrator Settings. 